A Dissertation
Presented to
the Faculty of the Graduate School
at the University of Missouri-Columbia
In Partial Fulfillment
of the Requirements for the Degree
Doctor of Education
Cr. Barbara N. Martin, Dissertation Supervisor
by

May, 2015 
(C) Copyright Cynthia S. Grant, 2015

All Rights Reserved 
The undersigned, appointed by the dean of the Graduate School, have examined the dissertation entitled

\section{A CASE STUDY OF TRANSFORMATIONAL LEADERSHIP CHARACTERISITICS OF A PRINCIPAL IN A HIGH POVERTY HIGH ACHIEVING SCHOOL}

presented by Cynthia S. Grant, a candidate for the degree of doctor of education, and hereby certify that, in their opinion, it is worthy of acceptance.

Dr. Barbara N. Martin, Dissertation Advisor

Dr. Sandy Hutchinson

Dr. Carolyn P. McKnight

Dr. Doug Thomas 


\section{ACKNOWLEDGEMENTS}

First and foremost I would like to thank Almighty God for granting me the opportunity and capability to complete such an immense undertaking. One must remember that all things are possible through our Lord and Savior Jesus Christ.

I must also thank Dr. Barbara Martin for her undying belief in me that I could complete this doctoral program. Her endless words of encouragement, feedback, and friendship have meant the world to me and have allowed me to reach my goal. Not only has she been a role model for my professional studies but also a role model for life, always emphasizing the importance of family.

I would also like to thank my dissertation committee: Dr. Sandy Hutchinson, Dr. Carolyn P. McKnight, and Dr. Doug Thomas. Their time and effort provided much needed support and assistance. Such feedback throughout this process was irreplaceable and has made this accomplishment possible.

Thank you to my family. To my parents Al and Dottye, thank you for instilling in me the competitive drive and determination that it took to complete this doctoral program. By your example I have learned what it takes to complete such an undertaking, to always put forth my very best effort, and to never give up. I am truly blessed to have an understanding and supportive husband who has allowed me to chase my dreams and continue my education. He has spent many hours taking care of our children so my attention could by on my studies, attend

class, and spend summers away on campus. To my children Mady and Dylan, while I am sorry to have spent so much time away from you, I hope that you will see this as an example as to what you can accomplish with support, determination, and hard work. Thank you for allowing me the time to finish my papers, helping with dinners, and learning how to do your own laundry. I am looking forward to making up for the time we have lost. To my brothers Jim and Bob, thank you 
for continuing to push me and encourage me to complete my dissertation. The love and support I receive from my family is irreplaceable and has allowed me to reach this milestone.

To my friends in Cohort Seven, thank you for your ongoing support. Without you I don't believe I could have made such a journey. Mike, Jim, Jenny, and Linda, thank you for the opportunity to learn and grow with each of you. I value your perspectives and experiences you shared with me, which have allowed me to become the educator I am today. Thank you to Hayet, Audrey, Carolyn, Cheryl, Asyia, and Kris for becoming my second family. Our time spent together has allowed me to reflect on, learn from, and enjoy the multitude of experienced and viewpoints we shared. Hayet, thank you for thinking of me as you began your journey. The time we have spent together laughing, complaining, and crying has a special place in my heart. I can't wait to see what adventures await for you and me.

Finally, thank you to the participants, for without their time and effort this project would not have been possible. They allowed a stranger into their learning community in order to better understand the amazing impact they have on children every day. 


\section{TABLE OF CONTENTS}

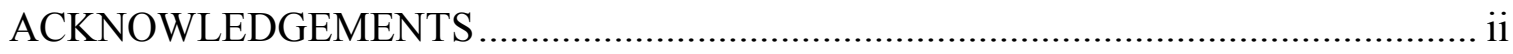

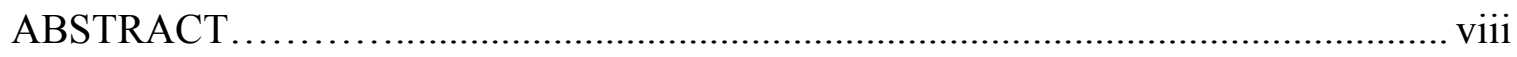

Chapter

1. INTRODUCTION TO STUDY

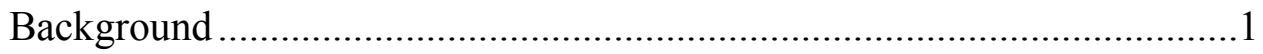

Conceptual Framework ................................................................ 3

Statement of the Problem............................................................. 6

Purpose of the Study ....................................................................

Research Questions ....................................................................

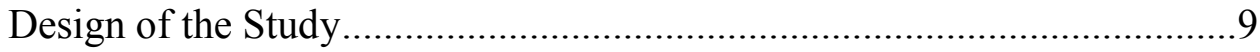

Limitations and Assumptions of the Study .......................................10

Design Controls ............................................................................... 12

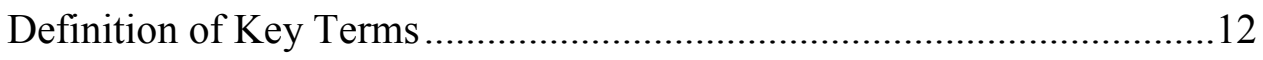

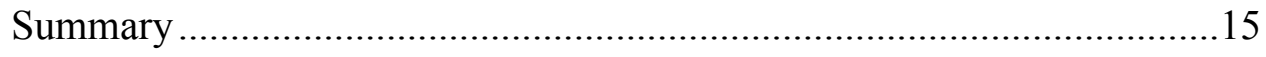

2. REVIEW OF RELATED LITERATURE

Introduction .................................................................................. 17

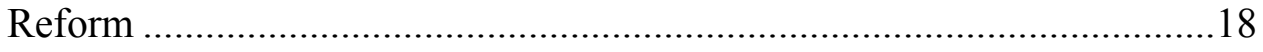

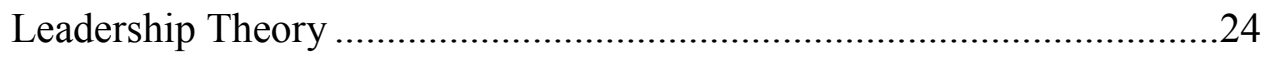

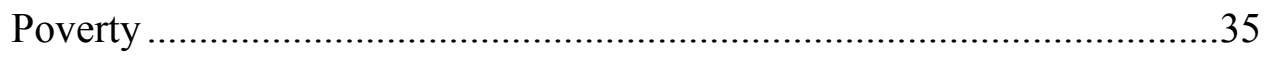

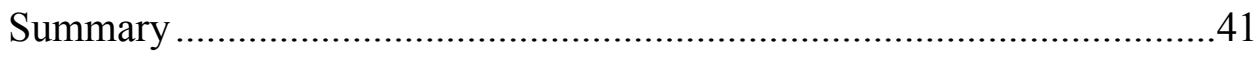

\section{RESEARCH DESIGN AND METHODOLOGY}

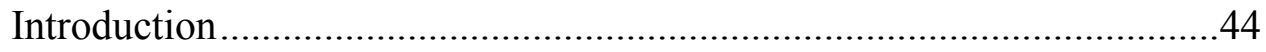

Research Questions ...................................................................45 
Rationale for Use of a Narrative Case Study ........................................46

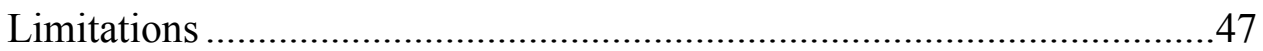

Participants ................................................................................. 47

Data Collection and Instrumentation ...................................................50

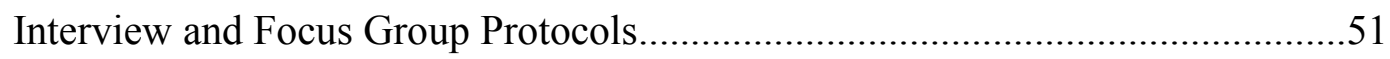

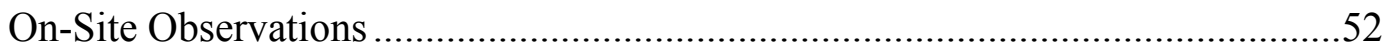

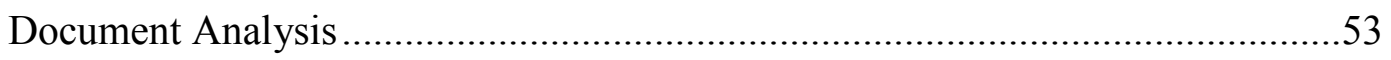

Data Analysis Procedures ...........................................................54

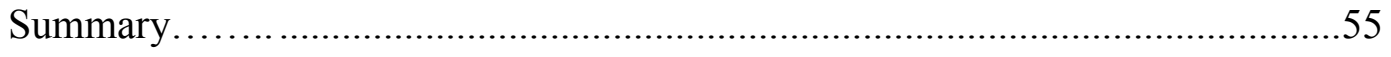

\section{PRESENTATION AND ANALYSIS OF THE DATA}

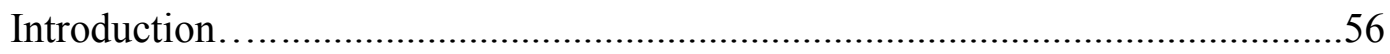

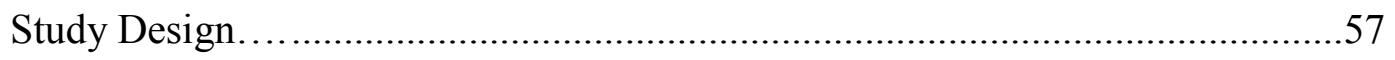

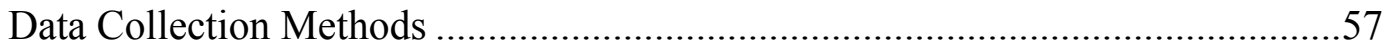

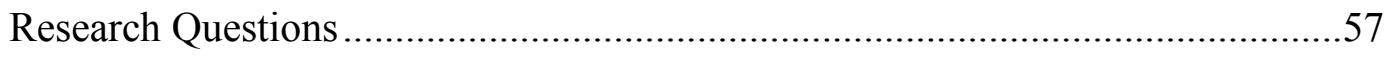

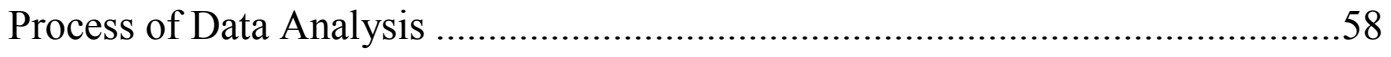

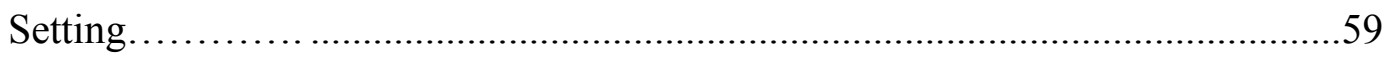

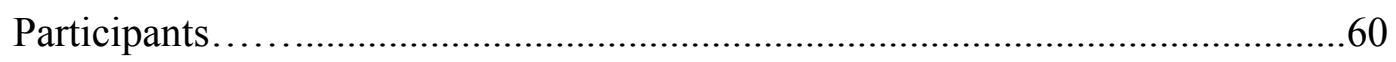

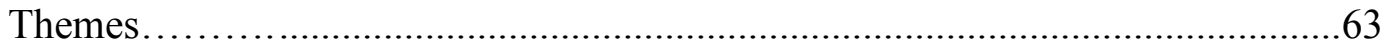

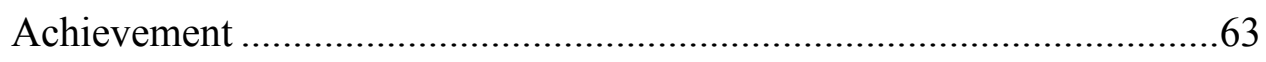

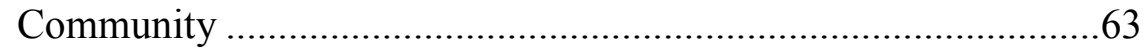

Data Driven Decisions ......................................................64

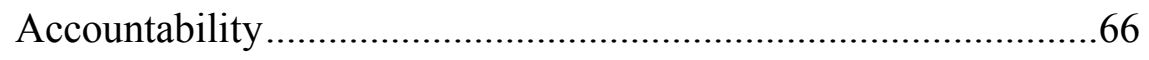

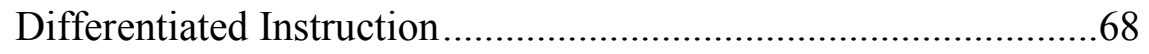

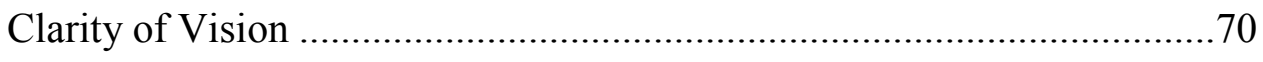




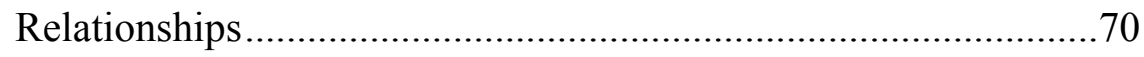

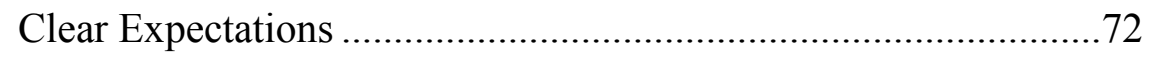

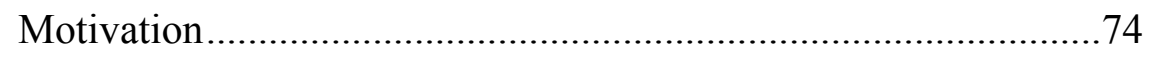

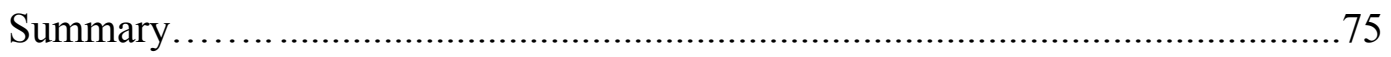

5. SUMMARY, RECOMMENDATIONS, AND CONCLUSIONS

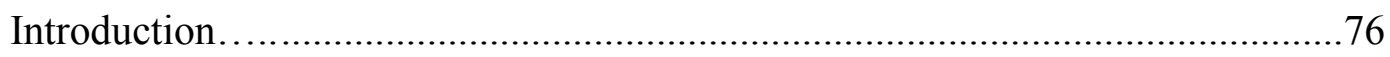

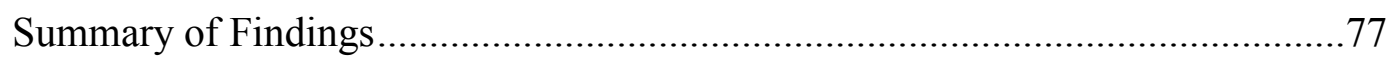

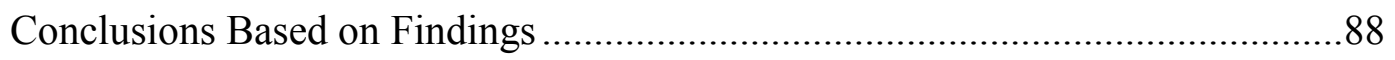

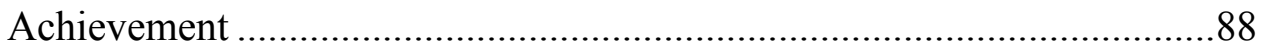

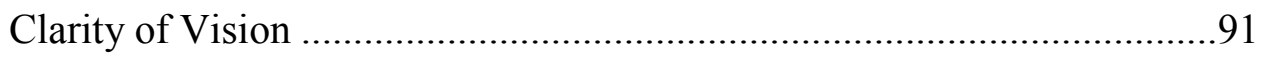

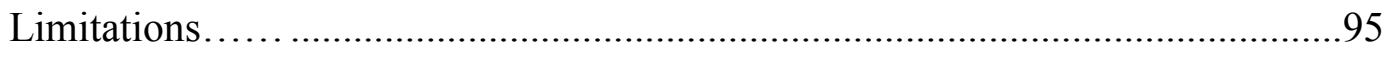

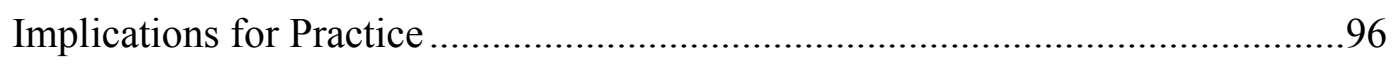

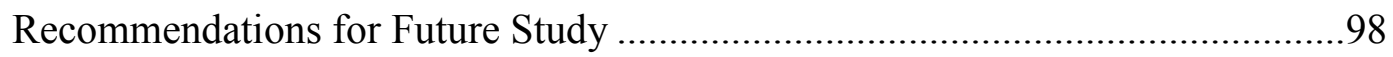

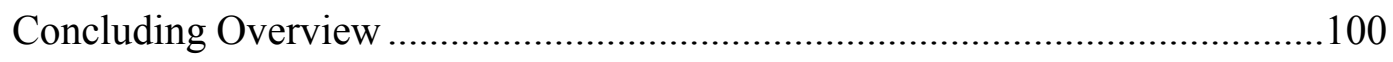

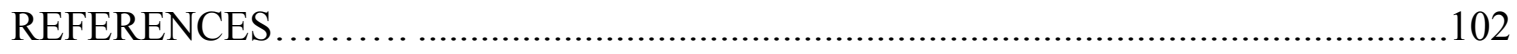

\section{APPENDICES}

Appendix A

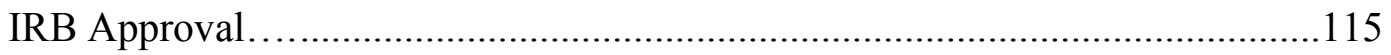

Appendix B

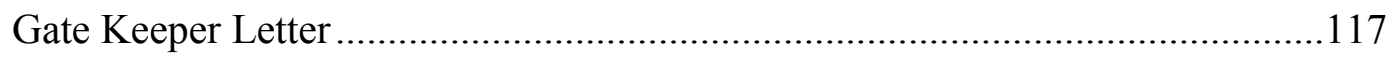

Letter of Informed Consent Principal .............................................................120

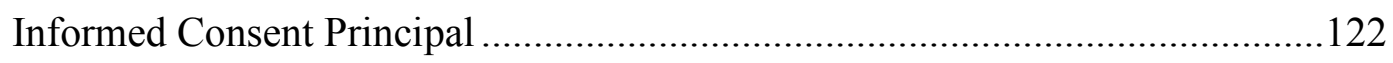

Letter of Informed Consent Central Office Administrator ...................................124

Informed Consent Central Office Administrator .................................................126 


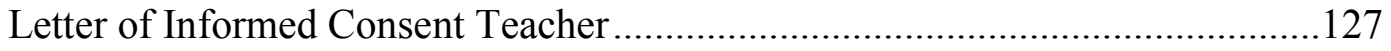

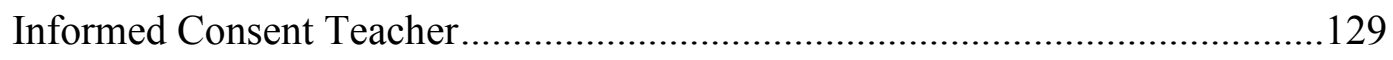

Letter of Informed Consent Parent ............................................................ 130

Informed Consent Parent ........................................................................ 132

Appendix C

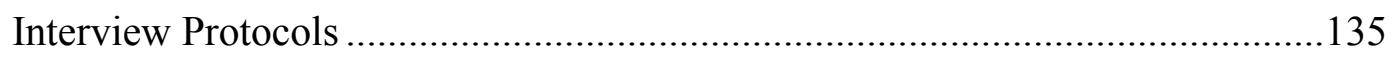

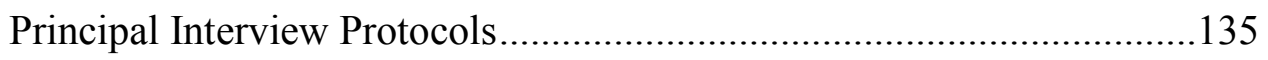

Central Office Administrator Interview Protocols...............................137

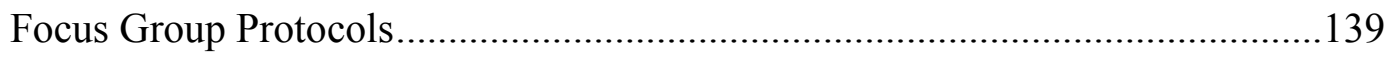

Parent Focus Group Protocols ........................................................139

Teacher Focus Group Protocols ........................................................141

Appendix D

On-site Observation Form........................................................................ 143

Appendix E

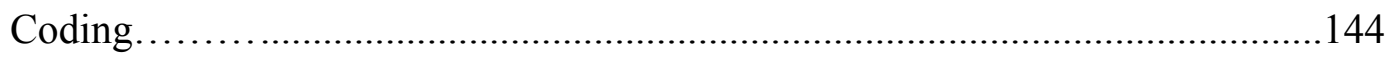

Appendix F

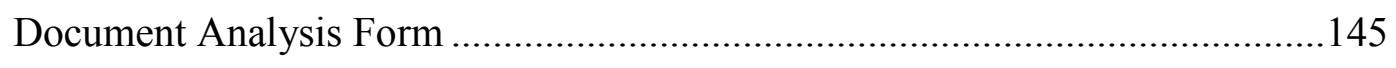

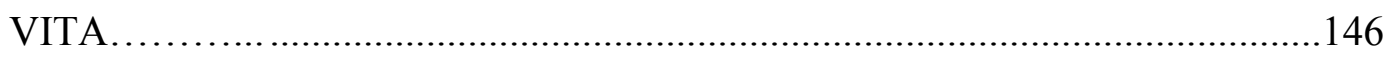




\title{
A CASE STUDY OF TRANSFORMATIONAL LEADERSHIP CHARACTERISITICS OF A PRINCIPAL IN A HIGH POVERTY HIGH ACHIEVING SCHOOL
}

\author{
Cynthia S. Grant
}

Dr. Barbara N. Martin, Dissertation Supervisor

\begin{abstract}
The purpose of this qualitative case study was to identify and examine the characteristics of effective leaders in high-poverty, high-achieving schools in a single school district. Within the context of this inquiry, district and school success was measured through the level of student achievement described by the annual Missouri School Improvement Plan (MSIP) process (Missouri Department of Elementary and Secondary Education [MODESE], 2011). The results of this narrative case study will provide researchers a holistic view of the context in which the school of focus is situated and should enhance the current body of knowledge regarding leadership characteristics present in highly-effective schools located in high-poverty areas. Furthermore, new insights to the professional practices of principals as well as building and sustaining leadership capacity for high-poverty schools within school districts (Lambert, 2006) should be revealed. These findings should result in educational leaders who will be better prepared to respond to diversity, curriculum standards, program requirements, physical and mental disabilities, and produce high achievement (Leithwood \& Riehl, 2003) in high-poverty school settings.
\end{abstract}

The population included an urban elementary school located in Missouri was the setting for this narrative case study. A case study permitted this researcher to retain a holistic view and obtain meaningful characteristics of day-to-day, realistic events taking place within the research setting through interviews, focus groups, document and artifact analysis, and onsite observation (Creswell, 2007; Yin, 2003). Data collections were comprised of interviews, focus groups, on- 
site observations, and document analysis. The interview and focus group protocols allowed the participants the opportunity to provide explanations and firsthand perspectives regarding their perspectives of the leadership style of the principal (Creswell, 2007; Lincoln \& Guba, 1985). The results related to this research study are applicable for public school leaders who are facing the daunting task of school reform. Fullan, (2001) and Marzano (2003) contended the building principals is second only to the classroom teacher when it comes to positively impacting student achievement as the principal has a direct impact on student achievement. 


\section{CHAPTER ONE \\ INTRODUCTION TO THE STUDY \\ Background}

Every school year, district and building leaders across the state of Missouri are faced with the daunting realization of not meeting Adequate Yearly Progress (AYP). Each August, Misouri public schools receive achievement results for state-mandated testing and achievement of AYP (Department of Elementary and Secondary Education, 2010). If districts are unable to meet the necessary requirements, sanctions are placed upon them and they are forced to offer school choice or provide Supplemental Educational Services (Casbarro, 2005; Farnsworth, 2010; Hickok, 2004). School choice allows provides the option for parents to select another school who has met the necessary mandates, thus requiring districts to expend additional costs to provide transportation as well as additional resources such as tutoring to help regain academic deficits (United States Department of Education [USDOE], 2011).

Historically, similar accountability measures had been placed upon public schools through such national reports as 1983 's A Nation at Risk, which called for increased accountability within schools (Anderson, Fowler, \& Medrich, 2007) and stated students attending schools in the United States should be expected to meet high, measureable standards in order to ensure student success. In addition, the level of accountability was increased with the Elementary and Secondary Education Act Reauthorization of 2001 (ESEA), otherwise known as No Child Left Behind (NCLB) (Farnsworth, 2010; Marzano, 2003). This legislation provided additional accountability challenges along with financial support for struggling students attending high-poverty schools in order to meet additional mandates set forth by federal legislators (Farnsworth; Fowler, 2004; Marzano). 
Increased accountability measures set forth by federal and state government involved the development and implementation of NCLB; conversely, school districts have been held accountable for promoting the highest of standards for improving student achievement (Haycock, 2001; Fowler, 2004). Schmoker (2011) reported leaders are now charged with cutting through the clutter in order to distinguish between what is important and what is imperative to the success of all students. This has resulted in school district personnel focusing on identifying and developing effective principals who demonstrate leadership styles that will enhance the promotion of student achievement or risk losing accreditation (Chenoweth, 2007, 2009; Farnsworth, 2010; Haycock). However, Elmore (2002) stated that many school leaders lack the knowledge, skill, and training to implement the necessary initiatives to attain the mandated NCLB requirements. Furthermore, principal effectiveness is a key component to school success (Elmore; Farnsworth; Marzano, 2003; Schmoker) and effectiveness is an essential key component to school success (Elmore; Farnsworth; Marzano, 2003; Schmoker).

Yet even with the offset of parents and community members across the nation holding educators and elected officials responsible for providing the leadership necessary for educational reform (Litchka, 2007; Leithwood \& Riehl, 2003), educational leaders have yet to see clear evidence that such reforms and legislation has assisted schools within marginalized communities with improving educational programs (Brady, 2003). However, what has resulted is political figures have increasingly implemented positive and negative coercion based on results of statemandated reform efforts (Farnsworth, 2010; Leithwood \& Riehl).

As school district personnel across the United States are faced with the label of needs improvement and are being forced to offer school choice, it is important to identify key leadership characteristics that will lay the foundation for the development of high-performing schools by providing direction and influence (Leithwood \& Riehl, 2003). Thereby, the purpose 
of this research was to explore principal leadership styles that are effective in developing and sustaining high-achieving schools located within high-poverty areas.

\section{Conceptual Framework}

Through the analysis of the theoretical framework of leadership theory, the conceptual framework of transformational leadership emerged allowing for a refined approach to the research study (Mertens, 2005). Over time, leadership theory has been recognized as a critical component of effective and successful organizations (Collins, 2001; Marzano et al., 2005). Comparatively, however, the research regarding effective school leadership as it relates to highachieving, high-poverty schools is lacking (Leithwood, 1999). Therefore, this inquiry should provide additional insights to effective leadership qualities needed in high-poverty school settings. The researcher found within the literature school reform efforts that called for school leadership to recognize the need for change and to respond accordingly verses reacting to change mandates (Farnsworth, 2010; Leithwood, 1999; Marzano, 2003). The literature irrefutably suggested successful leaders are all-inclusive to transcend boundaries between all constituents promoting successful change reform (Reeves, 2008). Transformational leaders are identified by the following characteristics: charisma, motivation, intellectual stimulation, individualized consideration, and promoting a common vision and shared values (Bass, 1985; Firestone \& Heller, 1995; Leithwood, 1994). Additionally, transformational leadership promotes the moral issues of justice and equity (Burns, 1978). During the examination of transformational leadership characteristics necessary for change emerge; subsequently, organizational change can cause uncertainty from multiple perspectives, characteristics such as motivation and inspiration, individualization, and intellectual stimulation are essential (Bolman \& Deal, 2008; Bush, 2003; Leithwood, 1994; Yukl, 2002). Consequently, transformational leaders inspire all stakeholders to rise to the occasion in order to meet the challenges of universal needs and purpose, a 
characteristic essential for an autonomous successful school (Bolman \& Deal; Caldwell \& Spinks, 1992). In addition, transformational leaders evoke feelings of trust, admiration, and loyalty within stakeholders, thus motivating them to accomplish more than expected when meeting challenges they face (Yukl, 2009).

Transformational leadership emphasizes the importance of the leader and key constituents sharing a common vision and overall goals (Firestone \& Heller, 1995). This ideal is supported by the formal model of leadership which emphasizes the importance of developing goals and pursuing specific objectives in order to benefit the organization as a whole (Bush, 2003). Bush recognized educational institutions as goal-oriented and consisting of members working toward the achievement of common goals. The foundational work of Gulick and Urwick (1937) supported Bush in the belief that work should be coordinated to achieve goals of greater production. Consequently, transformational leaders evoke participants to meet their maximum potential and beyond in order to move to a higher level of achievement and success (Bolman \& Deal, 2008). Conversely, transactional leadership focuses on a system of rewards and punishment resulting in a reward given if the goal is accomplished; however, if goals are not met, punishment may occur (Bass, 1990). Positional power is also relevant when implementing transactional leadership and does not support the same moral and ethical issues as transformational leadership, but focuses more on power and influence (Bass; Bolman \& Deal; Yukl, 2009).

Similarly, instructional leadership focuses on a combination of experience, expertise, and charisma (Guban, 1984; Hainger \& Murphy, 1986; Hallinger, 2003). Instructional leadership has become more inclusive of leadership practices (Hallinger); as a result, leaders are able to work with educators to strengthen and build upon teaching practices and student learning. Furthermore, a culture of high expectations for teachers and students is developed (Hainger \& 
Murphy; Mortimore, 1993). Moreover, transformational leadership also supports the philosophy of improving teaching and learning through identifying a common mission and vision for the organization (Bass, 1999; Bush, 2003; Schein, 1992; Yukl, 2009). By implementing, acknowledging, and building upon individual considerations, intellectual stimulation, and motivation, transformational leaders can identify strengths and weaknesses of individuals within an organization (Morgan, 1997; Yukl).

Transformational leaders understand and value that all individuals bring multiple perspectives, experiences, and bias to an organization, which is critical when recognizing the importance of individual goals and considerations prominent within transformational leadership behavior (Burns, 1978; Yukl, 2009). Conversely, distributive leadership stresses the allowance of individual expression and relinquishing of power to multiple participants (Andrews \& Crowtner, 2002; Danielson, 2006; Del Favero, 2003; Moller \& Pankake, 2006). Del Favero contended that distributive leadership is necessary for a balance of interest as well as power to promote learning. However, with the implementation of distributive leadership, a lack of clarity related to multiple responsibilities of leadership roles assumed may result in a lack of common goals, values, and beliefs (Bush, 2003). Effective school reform calls for the promotion of institutional goals rather than individual ones (Bass, 1999; Bush; Yukl, 2009). However, transformational leaders recognize and support intellectual stimulation and individual considerations in order to promote the overall organizational goals (Bass; Bolman \& Deal, 2008; Yukl).

Likewise, educational leaders of today must ensure the success of all students (Farnsworth, 2010; Shields 2002), challenge historical assumptions, and value diversity, compassion, and respect (Gewirtz, 1988; Theoharis, 2007). Social justice leadership theory understands that the situations of marginalized groups cannot be separate from the overall 
practices of educational leadership and school reform efforts (Bogotch, 2002; Gewirtz, 1998), Theoharis, 2007). Leaders utilizing social justice theory deliberately implement steps to change the current failing system to promote student success with an emphasis on justice and equity (Gewirtz, 1998; Marshall, 2004; Theoharis, 2007). Through this leadership theory, staff develops the freedom with a voice in promoting a school community focused on closing the achievement gap (Blackmore, 2002; Bogotch, 2000; Gerwirtz, 2002).

Transformational leaders support the idea of overall school community goals as the defining purpose of an organization (Bass, 1990; Bush, 2003; Yukl, 2009). Yukl also contended that leaders intentionally influence individuals to guide, structure, and facilitate activities within an organization to achieve the organizational goals. Goals exist at many levels within an organization and leaders must ensure personal goals are secondary to the organizational goals of the institution (Bush, 2003). Yukl further maintained leaders assist constituents in achieving their goals and providing them with direction and support to ensure individual goals support and sustain the overall goals of the organization. Transformational leaders should coordinate efforts of constituents toward the achievement of common goals. Thus creating an environment which provides direction and support versus rewards and punishment found within transactional and charismatic leadership (Bass; Bolman \& Deal, 2008; Leithwood \& Riehl, 2003).

\section{Statement of the Problem}

Public school leaders have encountered rigorous measures of accountability mandated by state and federal government (Marzano et al., 2005), therefore effective leadership is a key component to promoting student achievement in such an environment (Collins, 2001; Danielson, 2006; Marzano et al.). Districts across the nation should understand and pay particular attention to the development and retention of effective leadership. Educators are continually engaging new expectations for leadership such as coercive political pressures, increased public accountability, 
and continual educational reform (Casbarro, 2005; Farnsworth, 2010; Marzano, 2003; Murphy, 1998). These changing elements are forcing leaders to acquire a new awareness and expertise in the world of education. Consequently, student achievement measured by high-stakes testing has become the assessment schema to identify successful schools (Farnsworth; Lewis, 2002). In addition to state and federal mandates, complex educational environments create additional stressors for leaders as they respond to diversity, curriculum standards, program requirements, and physical and mental disabilities (Leithwood \& Riehl, 2003).

Furthermore, the issue of subgroups present within district demographics demands attention as districts focus on student achievement (Anderson, Fowler, \& Medrich, 2007; Haycock, 2001; Marzano, 2003). In concurrence with overall achievement, subgroup data are expected to show additional growth within achievement levels from year to year to illustrate how districts are working to close the achievement gap. Included among the specific subgroups are students qualifying for free and reduced lunch assistance.

Yet, while some schools in the state of Missouri located in economically disadvantaged areas have made significant gains toward eliminating the achievement gap as identified by the Missouri Department of Elementary and Secondary Education (2010), little research exists to identify these successful Missouri schools and the effective leadership styles promoting their success. As Grint (2005) shared, the leadership and the context of any situation is important, as well as how the problem is situated, to understand the decision-making process that results in student achievement.

\section{Purpose of the Study}

When successful organizations or companies are examined, a major component to their success is an effective leader (Collins, 2001; Marzano et al., 2005). Within the K- 12 educational setting, districts across the nation are searching for new methods of effective leadership. As 
Leithwood and Riehl (2003) argued, an effective leader will provide the foundation for the development of high-performing schools through direction and influence. This study examined a "problem of practice" (Creswell, 2007, p. 35) that exists in schools across the nation. The purpose of this qualitative case study was to identify and examine the characteristics of effective leaders in high-poverty, high-achieving schools in single school district. Within the context of this inquiry, district and school success was measured through the level of student achievement described by the annual Missouri School Improvement Plan (MSIP) process (Missouri Department of Elementary and Secondary Education [MODESE], 2011). The results of this narrative case study will provide researchers a holistic view of the context in which the school of focus is situated and should enhance the current body of knowledge regarding leadership characteristics present in highly-effective schools located in high-poverty areas. Furthermore, new insights to the professional practices of principals as well as building and sustaining leadership capacity for high-poverty schools within school districts (Lambert, 2006) should be revealed. These findings should result in educational leaders who will be better prepared to respond to diversity, curriculum standards, program requirements, physical and mental disabilities, and produce high achievement (Leithwood \& Riehl, 2003) in high-poverty school settings.

\section{Research Questions}

With recent educational reform initiatives, one overarching question continued to guide the researcher: What transformational leadership traits are present in high-poverty, highachieving schools as perceived by faculty, parents, and administrators? Additional research questions emerged as the literature continued to be reviewed. Utilizing a qualitative approach, the following research questions guided this case study: 
1. What transformational leadership traits of the principal are present in a highpoverty, high-achieving school as perceived by teachers, parents, and the principal's supervisors?

2. How does the contextual environment of high-poverty within a school community influence the transformational leadership style of the principal?

3. How do the transformational leadership traits of the principal change behaviors of the teachers and parents?

\section{Design of the Study}

A narrative case study was selected as the design of this research study. For this study, A Missouri school with a high incidence of poverty that has consistently demonstrated the ability to show continual improvement or meet federal and state mandates for accountability provided the setting. The participants for the inquiry consisted of a central office administrator, building administrator, teachers, and parents.

Cresswell (2007) noted:

Qualitative researchers try to develop a complex picture of the problem or issue under study. This involves reporting multiple perspectives, identifying the many factors involved in the situation, and generally sketching the larger picture that emerges. Researchers are bound not by tight cause-and-effect relationships among factors, but rather by identifying the complex interactions of factors in any situation (p. 39).

Stake (2000) postulated a case study is a unique form of research allowing readers an opportunity to learn about a distinctive and complex situation. In this inquiry is a high-poverty, high-performing school. Since this case study will focus on a problem of practice (Creswell, 2007; Yin, 2003) relevant to schools across the nation, a case study will provide a holistic view 
through an observation of a bounded system over time (Creswell, 2007). As Creswell (2007) espoused, qualitative researchers strive for understanding; the participants included in the sample population will have spent extensive time within the context being studied. In addition, the accessibility of participants should also be considered (Mertens, 2005). Therefore, a purposeful sample was selected for this case study in order to collect information to identify the transformational leadership style present in a high-achieving, high-poverty, school, the context of the educational setting related to leadership styles, and teacher/student perceptions of the leader (Creswell, 2007). The sample provided a multitude of perspectives to be explored in order to gain a clearer understanding of the study (Creswell, 2007; Yin, 2003).

In order to provide a comprehensive description and analysis of the case study, multiple data sources were utilized. Stakeholder interviews and focus groups provided a clear picture of individual and group perspectives, along with the analysis of historical documents to build background and to develop an understanding of the historical context of the case. Any additional documents suggested by the participants were also analyzed to provide a distinct understanding of the current leadership perspective. Observations were conducted to provide supplementary information to support the study (Creswell, 2007).

Triangulation of the data was utilized to discover emergent issues (Fowler, 2004) and member-checking was implemented and each participant was given the opportunity to examine his or her response to support the reliability of the data collected (Stake, 2000). Once all data was collected, the researcher utilized coding methods to identify common themes presented (Creswell, 2007; Mertens, 2005).

\section{Limitations and Assumptions of the Study}

All research studies have limitations and the researcher should acknowledge the limitations in order to design a thorough and reliable study (Heppner \& Heppner, 2004; Yin, 
2003). One challenge met by the researcher was the amount of time needed to conduct a detailed investigation and compile the rich data necessary for an effective case study (Merriam, 1998). It was also important to concede the time restrictions of the participants and those constraints encountered by the researcher. In addition, participants may view the researcher as interfering and meddlesome. A second challenge was the researcher's personal bias encountered through personal experience with leadership and high-poverty students; keeping this in the forefront when conducting interviews with administrators and additional stakeholders was therefore intentional. For this reason, the researcher implemented various methods of data collection to ensure reliability and validity of the data and allow for triangulation (Creswell, 2007).

This research study also only considered a single case. Merriam (1998) stated a single case study can oversimplify or exaggerate a situation and might provide the reader with invalid conclusions regarding the actual context of the case study conducted. A single case limits the information to one site identified as high-poverty, high-achieving (Creswell, 2007; Fowler, 2004; Yin, 2003). However, a single case study allowed the researcher to proceed more in-depth into characteristics of the single site to develop a richer understanding of potential outcomes (Creswell, 2007; Merriam, 1998).

Finally, when conducting qualitative research, it is important to reflect upon how stakeholders are situated within the inquiry and how his or her personal experiences shape the study (Creswell, 2003). For this reason, when selecting a specific site for a qualitative case study, it was necessary for the researcher to utilize criterion-based selection (Merriam, 1998). As an administrator situated within a high-poverty school district, the researcher recognizes biases may exist that could adversely impact the analysis of the data collected and should strive to avoid researcher bias. The researcher accomplished this through a myriad of stakeholders and reflecting on these biases when analyzing the data. 


\section{Design Controls}

Angen (2000) believed trustworthiness is synonymous with the goodness of a piece of research. In order to ensure trustworthiness of the data, the researcher implemented multiple measures. As the interviews and focus groups information were transcribed, member-checking (Stake, 2000) was implemented and each participant was given the opportunity to examine his or her response so as to increase the reliability of the data collected (Creswell, 2007; Stake). Additionally, the researcher was the exclusive interviewer to ensure consistency throughout protocols with each interview and focus group conducted. As the researcher addressed and ensured dependability, stability over time could be expected (Guba \& Lincoln, 1989; Yin, 2003). Multiple types of data were gathered to support or contradict the interpretation of information gathered (Eisner, 1991). Another control incorporated into the inquiry was the use of multiple stakeholders allowing for a varying degree of experience with transformational leadership characteristics. These individuals, with varying experiences, may have provided a more in-depth picture of the impact on high-poverty, high-achieving schools.

Furthermore, the researcher continually questioned any underlying moral assumptions, political and ethical implications, and equity among all participants (Angen, 2000). Once the researcher recognized these issues, conformability could be concluded by the evidence gathered (Creswell, 2003).

\section{Definition of Key Terms}

The following terms were acknowledged as being important to the understanding of the research. Definitions were provided to give readers a clearer understanding of key concepts and to establish an important common language (Brufee, 1999), thus enabling readers with the ability to create knowledge and reach a deeper understanding of the study and its results: 
Achievement: A measure of student performance academically, based upon a standardized measure. For the purpose of this study, achievement refers to student performance on the Missouri Assessment Program (MAP) and End-of-Course Exam (EOC) in the areas of communication arts, mathematics, and science. The MAP assessments are administered in grades three through eight, whereas the EOC assessments are administered in grades nine through twelve.

Achievement Gap: A consistent difference in academic test scores between groups of students. The gaps most frequently referred to are those between white students and minority groups such as African-American, Hispanic students, as well as students of poverty. Traditionally, low-income and minority children have not performed as well as their peers on the tests (Anderson, Fowler, \& Medrich, 2007; Haycock, 2001).

Adequate Yearly Progress (AYP): The minimum level of improvement established by the federal government that public schools must achieve each year.

Contextual Environment: Location and environment where the research study is conducted and how the problem of practice is situated with in the environment.

Free/Reduced Lunch: Free/reduced lunch refers to a Department of Elementary and Secondary Education program providing free breakfast and/or lunch or breakfast and/or lunch at a reduced cost to students whose parent's/guardian's income falls below a designated amount according to household size (MODESE, 2011). All schools participating in the federally-assisted National School Lunch and School Breakfast Programs must make available free and reduced price lunches and breakfasts.

High-poverty: High-poverty will describe schools with a free/reduced lunch percentage of greater than $50 \%$ within the school setting. 
High-Performing Schools: High-performing schools will be a high school identified by the Missouri Department of Elementary and Secondary Education as demonstrating the highest sustained performance from the years 2009-2012 in communication arts as determined by MAP / End-of-Course Examinations (MSIP, 2004; MODESE, 2011)..

Missouri Assessment Program (MAP): In 1993, The Outstanding Schools Act called for the development of a new assessment system for Missouri's public schools (Northwest MAP Regional Center, 1999). The Missouri Assessment Program (MAP) is the professional assessment system implemented in Missouri public schools to address the requirements of that act. The MAP is primarily performance-based. The MAP assessments incorporate three types of test questions in order to evaluate student achievement (Missouri Department of Elementary and Secondary Education, 2011). The first type of question, selected response, is a question or incomplete statement that is followed by answer choices. The second type, constructed response, is an assessment unit with a question or problem that requires a written response. The third type of question, performance event, is like the constructed response with the exception that it requires a pictorial or graphic response. Both the constructed response and performance event questions are open-ended. The Department of Elementary and Secondary Education (DESE) requires the administration of the MAP in all schools in the areas of math and communication arts (MODESE, 2011). MAP assessment items are aligned with the Show-Me Content Standards and the Show-Me Process Standards.

Poverty: A student qualifying for free or reduced meals is identified as low socioeconomic status and/or a child of poverty. Socioeconomic status is determined by family income and results in low socioeconomic status.

School Choice: Families residing within attendance boundaries of failing schools have the option to send their children to schools meeting federal and state mandates (Four Pillars of NCLB, 2010). 
Socioeconomic Status (SES): Students that qualify for free or reduced meal prices are identified by SES for NCLB, MAP, and EOC for subgroup identification and tracking.

Supplemental Educational Services: Failing districts are required to expend additional funds on outside tutoring services to support student achievement (Four Pillars of NCLB, 2010).

Stakeholder: Is an individual with a given interest in the organization. Within this study stakeholders are identified as administrators, teachers, and parents.

Subgroups: Groups of students divided by socioeconomic level and performance levels (USDOE, 2005).

Title I: A federal program that provides funds to improve the academic achievement for educationally-disadvantaged students who score below the 50th percentile on standardized tests

Transformational Leaders: Identified by the following characteristics: charisma, motivation, intellectual stimulation, individualized consideration, and promoting a common vision and shared values. Additionally, transformational leadership promotes the moral issues of justice and equity (Avolio \& Bass, 1991; Burns, 1978; Firestone \& Heller, 1995; Leithwood, 1994).

\section{Summary}

With increased accountability due to NCLB, each school year, building administrators have to recognize the establishment of higher standards of student achievement on standardized tests (Farnsworth, 2010; Marzano, 2003; Four Pillars of NCLB, 2010). Furthermore, achievement results influence funding and sanctions (Farnsworth; Marzano; Four Pillars of NCLB). Multiple factors influence the success of our public schools across the nation and leadership plays a significant role (Elmore, 2002; Farnsworth; Marzano; Schmoker, 2001). Consequently, it is important to identify characteristics of what leaders of successful high-poverty schools implement to positively impact student achievement. This study, conducted through the 
transformational leadership lens, intends to identify and examine characteristics of effective leaders in high-poverty, high-achieving schools residing in districts.

Once districts and leaders have access to the characteristics of successful leadership implemented within high-achieving schools with instances of high-poverty, they can use the information to guide their own building or district. Utilizing the lens of transformational leadership allowed the researcher to narrow the focus based upon the characteristics of charisma, motivation, intellectual stimulation, and individualized consideration (Bass, 1985; Bolman \& Deal, 2008; Bush, 2003; Yukl, 2009).

Included in Chapter Two is a review of related literature relevant to the present. Presented in Chapter Three is the research design and methodology carried out for the study. Presented in Chapter Four is an analysis of data collected. Finally, in Chapter Five are the findings, conclusions, implications and areas of interest for further research. 


\section{CHAPTER 2}

\section{REVIEW OF RELATED LITERATURE}

\section{Introduction}

In 1983, during the Ronald Reagan administration, A Nation at Risk (1983) was issued (Farnsworth, 2010; Marzano, 2003), warning the United States if the educational system did not improve children would suffer the economic fallout. As a result, state departments of education across the nation and state legislators developed systems of accountability and assessment to measure student achievement (Casbarro, 2005; Cicchinelli, Gaddy, Lefkowits, \& Miller 2003; Hickok, 2004; Williams, 2003). This was followed with the United States government creating the No Child Left Behind Act of 2001(NCLB) (Cicchinelli et. al., 2003; Farnsworth, 2010; Hickok, 2004; Marzano, 2003), where by 2014 all public schools must ensure all students are proficient in both mathematics and communication arts (Cicchinelli et. al., 2003; Farnsworth, 2010; Hickok, 2004; Marzano, 2003). Accordingly, in order to meet the expectations of NCLB, school reform required both restructuring and acculturation forcing the role of the principal to change. Thus, when investigating school improvement initiatives it is necessary to explore leadership models implemented which result in positive reform efforts and results (Danielson, 2006).

Within this case study, relevant literature has been reviewed based on multiple constructs. First, school reform and the reform movement were reviewed focusing on schools located in low socioeconomic areas and the characteristics of high-performing schools. Additionally, various forms of leadership theory were cited and their impact on school improvement shared. Finally, poverty and the impact it has on the school reform movement were reviewed.

Throughout the review of relevant literature, the theoretical framework of leadership theory was narrowed to the conceptual framework of transformational leadership, which enabled 
the identification of key characteristics of leaders. Bass (1985) identified transformational leaders with the following characteristics: charisma, motivation, individualized consideration, and intellectual stimulation (p. 22). In addition, transformational leaders inspire their constituents meet the challenges of their universal needs and purpose (Bolman \& Deal, 2008). When a leader uses transformational leadership, the followers feel a trust, admiration, and loyalty. These qualities motivate stakeholders involved to do more than expected (Yukl, 2009).

Transformational leadership assumes the leader and staff share values and common vision as well as the expectation for high performance (Firestone \& Heller, 1995; Leithwood, 1994). Thus, followers perform beyond expected levels of performance as an outcome of the influence of the transformational leader (Bush, 2003). With successful transformational leadership, a school community can develop structures to foster participation in complex decisions and all participants can be engaged in the achievement of educational objectives (Bush, 2003; Leithwood \& Riehl, 2003). Therefore, within this inquiry, transformational leadership will provide a focused lens for the research of high-achieving, high-poverty schools.

\section{Reform}

Over centuries the multitude of school reform movements can be categorized by historical, political, and social reform (Gardner, 2007; Neuman, 2009). Beginning in the $19^{\text {th }}$ and $20^{\text {th }}$ centuries, the central political approach to childhood poverty was for citizens and lawmakers to protect children from the negative impact of poverty. The belief inspired President Lyndon B. Johnson to declare war on poverty (Neuman, 2009). Historically, Americans have relied on federal funds to tackle the issue of poverty and its impact on education (Neuman, 2009), resulting in poverty rates declining between the 1950 s to the 1970 s because of a thriving economy. However, as the economy slowed, poverty rates began to rise and continued to add to the number of children who lived in poverty (Betson \& Michael, 1997). Just as social inequality 
existed in neighborhoods, such disparity also found its way into the public school system (Cooper \& Crosnoe, 2007; Haycock, 2001; Leach \& Williams, 2007).

The idea of an achievement gap, as it was commonly known, traced its origins to the first achievement tests administered by the United States Army during the First World War (Gardner, 2007). The achievement gap studies focused on scores between White and African-American students based on National Achievement Tests. During the 1970s and 1980s progress was made toward eliminating the educational achievement gap; however, the difference in scores remained relatively unchanged (Anderson, Fowler \& Medrich, 2007; Farnsworth, 2010; Gamoran, 2007; Haberman, 1995; Marzano, 2003). Despite the NCLB shift in focus to how all subgroups perform, the current educational system has remained a primary focus as to the cause of the achievement gap (Gamoran, 2007; Marzano, 2003).

At it's inception, the public education system was not created to educate all students in exactly the same way with students being sorted and prepared for different paths beyond their education (Gardner, 2007; Neuman, 2009). American society portrayed a system where everyone received a free and adequate public education. Yet, some students were educated for skill attainment while others received advanced skills and were encouraged to achieve post-secondary degrees (Crooks, 1995; Leach \& Williams, 2007; Williams, 2003). However, since the achievement gap is based on socioeconomic status, race, or ethnicity suggests an unequal educational system (Lavin-Loucks, 2006). The landmark legislation, Brown v. Board of Education of Topeka, 347 U.S. 483 (1954), focused on equal educational opportunities, a corollary to the equal protection clause of the Fourteenth Amendment, finding that racially segregated schools were inherently unequal (Federal Education Policy and the States, 2009).

In the 1960s, the Lyndon Johnson administration developed policies addressing two important issues, civil rights and poverty, which resulted in the Elementary and Secondary 
Education Act of 1965 (ESEA). Title I of ESEA emphasized the needs of economicallydisadvantaged children (Federal Education Policy and the States, 2009) and was intended to address the political and social concerns of the quality of public educational systems of the United States (Kessler \& Schneiders, 2007). Furthermore, philosophical variations focusing on the role of education, inequities in educational access, resources or opportunities, and other such societal issues endorsed the need for further educational reform (Berube, 1994; Fullan, 1995; Keesler \& Schneiders, 2007).

The societal pressures between 1970 and 1980 drove the investigation of the United States educational system resulting in the publication of A Nation At Risk (1983). This publication was based on commissioned research papers and public hearings that revealed the United States had fallen behind Japan, West Germany, Eastern Europe, and Russia (USSR) in student achievement (Anderson, Fowler, \& Medrich, 2007; Farnsworth, 2010). This pressure of global competition remains with educators today (Farnsworth).

Further reform occurred in 2002 when President Bush signed NCLB into law. The Act set forth requirements forcing school systems to be accountable for all subgroups in the population, including students recognized as coming from low socioeconomic backgrounds (Federal Education Policy and the States, 2009). NCLB emphasized student achievement and focused on closing the achievement gap for all students. According to NCLB, by 2014, public schools must ensure that all students are proficient in math and communication arts (Cicchinelli, Gaddy, Lefkowits, \& Miller, 2003; Haycock, 2001; Hickok, 2004) with the flexibility to utilize funds provided by the federal government to meet their specific needs. Research-based instructional practices and programs were sought and promoted to improve student achievement and performance. Additionally, parents with students attending low-achieving schools were offered a choice of schools if their attending school did not meet federally mandated targets for 
achievement for two consecutive years (United States Department of Education [USDOE], 2011). Specifically, schools located within low socio-economic areas are required to meet the same federally-mandated requirements as schools located in more affluent districts. In addition, schools with high percentages of English Language Learners (ELL) or special needs populations are expected to perform as well as other schools with less diverse populations located in more affluent and economically prosperous areas (Casbarro, 2005).

Since the establishment of the $N C L B$, national attention has been the focus on improving the academic achievement of America's youth (USDOE, 2011). As NCLB was renewed and became known as the Reauthorization of Elementary and Secondary Education Act, not only must public schools ensure by 2014 every student is proficient at math and communication arts, but districts are required to promote the effectiveness of principals. The purpose is to ensure every building has a quality leader and increases in student achievement (USDOE, 20011).

In addition to an effective leader, $N C L B$ mandates every school should have highlyqualified teachers, meet adequate yearly progress, and report attendance and standardized test scores publically (Farnsworth 2010; Marzano, 2003; Pascopella, 2005). Title I schools have been specifically targeted due to national funding based upon the percentage of students qualifying for free or reduced lunch assistance (Pascopella, 2005). Stormont (2007) shared there were twentyseven million United States children who lived in poverty, which was associated with an increased chance for academic failure. Furthermore, schools located in low disadvantaged areas were held accountable to the same mandated requirements as schools located in more affluent areas (Casbarro, 2005; Stormont). Protheroe (2011) provided seven key elements for promoting success for failing schools and disadvantaged youth, to include: create high expectations, use research, get hooked on data, focus on student learning, think systematically and act systemically, manage change, and keep success in sight (p. 2). 
As the results of these reforms, expectations have changed at the national, state, and local levels with an increased emphasis on accountability. Educational leaders and government officials have implemented measures to ensure districts and schools are held accountable (Farnsworth, 2010; Marzano, 2003; Schiff, 2001). With the introduction of federal mandates, accountability initiatives have accentuated the need for effectively-trained principals who can lead low-performing, high-poverty schools to become high-performing schools. This is essential because, as Stiggins (2001) noted, building leaders and their leadership beliefs play a significant role in the school improvement process.

\section{Leadership and School Reform}

Bolman and Deal (2008) have highlighted that effective schools are led by strong leaders with a clear vision. Such successful leaders balance the public pressures of their position and constructively implement educational reform initiatives to promote student success and support classroom educators (Leithwood, 2003). This challenges educational leaders to have the knowledge, skills, and disposition to lead school districts ensuring all students have the best

opportunity to achieve success (Bolman \& Deal, 2008; Leithwood \& Riehl, 2003; Litchka, 2007; Stiggins, 2001).

Educators across the nation continually seek to implement leadership that will promote student achievement, resulting in successful school reform (Lambert, 2002; Litchka, 2007). While effective school leaders guide their organizations and motivate participants throughout the reform (Yukl, 2009), these same leaders embrace a skill set that will sustain the determination to champion successful results-based school reform efforts and continually pursue necessary improvement options (Farnsworth, 2010). Overwhelmingly, state and federal mandates continue to demand school administrators assist teachers to improve student achievement (Bass, 1985; Casbarro, 2005; Knipe \& Speck, 2002; Lewis, 2002). 
Furthermore, leaders who strive to reform low-performing schools should concentrate on motivating teachers, assessing and redefining skills, increasing instructional time for struggling students, establishing and sustaining orderly learning environments, and using a variety of data sources to continually monitor student progress (Bernhardt, 2004; Chenoweth, 2009; Duke, 2004). Bauck (1987) reported effective school administrators are more committed to professional development and management. Subsequently, administrators are encouraged to actively participate in developing meaningful and ongoing professional development. Strong professional development practices serve as a foundation for teaching, which is in the best interest of the children and to promotes successful reform (Knipe \& Speck, 2002). Bushaw (1997) shared that new learning among all participants in the school improvement process should be initiated by the building leader with a focus on collective learning. Salomonowicz and Levy (2009) contended a building leader working for reform should commit to targeted professional development.

Bauck (1987), Bushaw (1997), Duke (2004), Farnsworth, (2010), Knipe and Speck, (2002), and Salomonowicz and Levy, (2009) concurred; school reform is a challenging process. To aid leaders with the reform process, Thomas (2003) posited seven steps for a building leader to implement to overcome difficult circumstances. Leaders need to reiterate the foundational principles of their position. As challenges arise, leaders need to develop and maintain a fierce tenacity and be prepared to stand strong as change occurs. Leaders need to often re-evaluate particular positions and have the courage to make unpopular decisions if it will move the organization towards achieving the common vision. Creativity is necessary for leaders, as they should be willing to recreate systems already in place.

Leadership influences virtually every aspect of effective school reform (Marzano, 2003). Marzano presented three principles for effective school reform and detailed the critical role of building leaders. First, leadership for change is most effective when carried out by a small group 
of educators, including the principal, and functions as a strong unified force. The team must provide guidance while demonstrating respect for others not on the leadership team. Second, effective leadership entails specific behaviors which enhance interpersonal relationships. This change and structural realignment must include training in order to ensure success. Third, principals are now asked to assume a significantly more active role in supervising classroom instruction (Bolman \& Deal, 2008). As leadership roles change during the school reform process, the past cultural stability becomes disrupted and can create disequilibrium that is complicated and demanding. For this reason, participants in the reform process can often resist change (Beyer \& Trice, 1993). Consequently, it is important to understand what leadership style is the most effective when such an environmental change is necessary.

\section{Leadership Theory}

Bush (2003) argued that there is no agreed upon definition of leadership. Comparatively, Bolman and Deal (2008), Farnsworth (2010), and Yukl (2009) supported this lack of a unified definition by stating leadership is subjective and there is no one correct definition but only three dimensions: influence, collective effort, and shared vision (p. 7). Yukl also shared that leadership is an influence which facilitates performance of a collective task. A common vision and shared values provided an opportunity for participants to work towards the expected outcomes while building on one another's strengths (Katzenbach \& Smith, 1993; Lashway, 2002). Thus, successful leadership is a necessary component to the collective task of school reform (Lieberman, 1995; Marzano, McNulty, \& Waters, 2005; Reeves, 2001, 2006, 2007, 2009; Yukl).

Furthermore, school reform requires the role of school leaders to be diversified in order to affect change (Bernhardt, 2001; Kotter, 1994; Schmoker 1999). Diversity in roles promotes leaders to meet the multiple needs of participants (Marzano, McNulty, \& Waters, 2005; Snowden \& Gorton, 1998). Successful school leaders work to maintain the focus of all participants on the 
needs of the school in spite of federal and state requirements (Lashway, 2002). Katzenbach and Smith (1993) supported Lashway by emphasizing the importance of maintaining a common focus and shared that successful school leaders provide focus and facilitate ongoing team discussion for clarification and implementation. Discussions between participants and leadership regarding the reform process, encourages the development of a positive climate where learning is valued and central (Johnson, 1997). Johnson contended school improvement is a continuous journey which requires a leader who can utilize and implement multiple leadership theories and participants to recognize the need for reflection and discussion. Strong leadership provides the opportunity teachers to improved instructional practices and focus on student learning (Johnson, 1997; Lashway, 2002) and to promots the common vision and goals of the organization.

Instructional leadership must be explored for this reason.

\section{Instructional Leadership}

Instructional leadership was identified as one of the first real leadership models tailored to meet the specific needs of education (Hallinger, 2003). Researchers have provided multiple definitions of instructional leadership, yet the underlying components emphasize the role of the administrator as influencing teacher practice which positively impact student achievement (Blase \& Blase, 1998; Bush, 2003; Southworth, 2002). Through the school reform process, instructional leadership skills are necessary for administrators to effectively implement the change process and develop a building that functions as a learning community with participation from all stakeholders (Dufour \& Marzano, 2001). Andrews and Smith (1989) supported the researchers, Hallinger (2003) and DuFour and Marzano (2001) when they stated successful school reform happens when effective teachers perceive the principal as an instructional leader.

It is evident, instructional leaders lead from a combination of experience, expertise, and charisma (Guban, 1984; Hainger \& Murphy, 1986; Hallinger, 2003). Over the years, 
instructional leadership developed a broader perspective and became more inclusive of leadership practices (Hallinger). This renewed form of instructional leadership defined a mission, advanced positive learning climates, and improved instructional management practices (Hallinger). Thus enabling leaders to work with teachers to improve and strengthen both teaching and learning. Through this process a culture of learning and high expectations for teachers and students is developed (Hallinger; Mortimore, 1993).

Instructional leadership permits building administrators to recognize strengths and weaknesses and actively engage in classrooms to enhance learning (Andrews \& Smith, 1989). Hallinger (2003) contended strong instructional leaders are directive leaders with an emphasis on curriculum and instruction and clarity of focus on accountability. Instructional leadership places emphasizes prioritizing curriculum and instruction, setting goals, providing resources, establishing high expectations, monitoring student progress, articulating a clear vision, and fomenting collaborating and consulting with others (Bernhardt, 2004; Hallinger; Marzano, 2003; Smith \& Andrews, 1989, Williams, 2003). The components of instructional leadership have been shown to improve student achievement in low-performing schools (Andrews \& Smith; Carallo \& McDonald, 2002).

Additionally, the age of accountability and reform demands a strong educational leader is a facilitator of change (Fullan, 2010; Sergiovani, 2000). Although instructional leadership provides administrators with clarity of focus on curriculum and accountability, school reform encompasses a wider perspective of needs (Carallo \& McDonald, 2002). Many leaders do not possess the necessary skills to identify and develop internal participants (Lambert, 2003). Therefore, unsuccessful leaders are missing the critical components of commitment from participants necessary for high-achieving schools. For instructional leadership to be effective the philosophy should be shared by all (Lambert, 2003). Strong instructional leaders recognize the 
external accountability to motivate participants, but without the necessary skills and background knowledge the odds are against instructional leaders for developing a successful internal culture to promote necessary school reform (Elmore, 2002). Because the accountability of student achievement should be shared throughout the building, instructional leaders can no longer go it alone in the age of accountability and school reform (Lambert, 2002; Leithwood, 2004).

\section{Distributive Leadership}

In accordance with Lambert (2002) and Leithwood (2004), educators across the nation continually seek to build leadership capacity; therefore, distributive leadership is a widelyimplemented theory across educational settings. Scribner (2007) supported this theory of distributed leadership by stating educational leadership involves the practice of multiple individuals which occurs through complex networks, relationships, and interactions among an entire staff comprising a school. Del Favero (2003) shared that distributive leadership allows for a balance in interest as well as power providing a road map for implementing and achieving institutional goals. Harris (2005) and Leithwood characterized distributed leadership as a form of collective leadership where teachers and other participants develop expertise by working together and being provided opportunities to learn collaboratively, thus supporting the idea that learning is a social act rather than an individual activity.

Building administrators utilizing distributive leadership should be intentional with actions to establish mutual trust and respect due to the fact power is distributed, and allowances for individual expression should be considered (Andrews \& Crowther, 2002; Moller \& Pankake, 2006). Principals should be willing to relinquish power to establish a school culture which promotes shared leadership practices (Danielson, 2006). Furthermore, distributed leadership is a response to the increasing responsibilities of building principals and is a fundamental shift in organizational operations that redefines leadership as the responsibility of all participants in 
order to provide clear guidance and direction (Chirichello, 2004; Elmore, 2000; Harris, 2005). As a result, the implementation of distributive leadership strives to engage multiple individuals in the leadership process to promote collegiality, but also develop school effectiveness and improvement through the school reform process (Diamond, Halverson, \& Spillane, 2004; Harris, 2005).

However, there are negative consequences related to distributive leadership. When faculty assumes administrative roles, it can result in a narrow focus of faculty on immersion of one specific task. In addition, faculty often is not rewarded financially for institutional work (Del Favero, 2003). Although there are multiple shared roles, distributive leadership lacks clarity and distinction of the level of authority an individual assumes (Bush, 2003; Del Favero; Supovitz, 2000). Bush also believed further limitations to the practice of distributed leadership when positing that individuals who occupy leadership roles have their own values, beliefs, and goals. Unfortunately, often this framework can undermine the organizational values of the school. For this reason, effective school reform necessitates the need for the promotion of institutional goals rather than individual goals. Thus resulting in a school culture focused on meeting the needs of all students lead by a group of collectively-invested staff (Bass, 1985; Bush, 2003; Yukl, 2009). Social Justice Leadership

Since educational leaders of today are expected to take responsibility for the success of all students in meeting mandates set forth by federal and state legislation (Shields, 2004), they should challenge historical assumptions deeply embedded within educational traditions, institutions, practices, and beliefs (Goldfarb \& Grinberg, 2002; Swartz, 1997). Consequently, it is necessary for the researcher to explore the idea of social justice leadership theory within the confines of this study.

Social justice leaders, value diversity and cultural respect in addition to supporting a 
process within education built on respect, compassion, and recognition of diversity (Gewirtz 1998; Theoharis, 2007). Social justice theory is a social construct containing no guidelines or predictable definitions (Bogotch, 2002). Leaders implementing social justice theory understand the situations of marginalized groups cannot be separated from the overall practice of educational leadership (Bogotch; Gewirtz, 1998; Theoharis). Furthermore, Theoharis contended that one should work to transform schools to benefit the most marginalized students and their families as well as addressing the present issues of race and social class. Marginalized students do not receive the education they deserve unless purposeful steps have been taken by building leadership to change the current failing system on their behalf with the focus on justice and equity (Gewirtz, 1998; Marshall, 2004; Theorharis, 2007). Leaders choosing to implement social justice theory should focus on communication which is authentic and purposeful with the intent to develop a supportive network emphasizing a collaborative environment (Theorharis). These leaders should alter institutional arrangements to eliminate pull-out programs and promote heterogeneous groups with increased rigor and opportunity (Goldfarb \& Grinberg, 2002; Theoharis). Through this leadership theory, both faculty and staff develop professional freedom and a stake in the development of the school culture focused on closing the achievement gap, which reaches the marginalized students and families (Blackmore, 2002; Bogotch, 2000; Gewirtz, 2002).

However, federal regulations inhibit the practices of social justice theory at times, resulting in a lack of resources for all students (Theoharis, 2007). Additionally, social justice leaders should investigate other activist administrators to find collaborative partners to support the reform journey (Bogotch, 2000; Theoharis). Moreover, within the social justice theory, leadership is a deliberate intervention that requires a moral application of power (Bogotch, 2000). Educational leaders need to recognize the need for overcoming the silence regarding 
differences among students to provide a socially-just educational setting and academic excellence for all children (Sheilds, 2004; Swartz, 1997; Theoharis). These issues of federal regulations, the need to follow social justice mentors, and the courage it takes to deliberately overcome the marginalization of students (Theoharis) were limiting factors for the use of social justice leadership within this inquiry.

\section{Transformational Leadership}

When educational leaders succumb to the internal and external pressures and their respective schools are measured as inadequate, they are replaced (Leithwood \& Riehl, 2003; Lambert, 2002; Litchka, 2007; Marzano, McNulty, \& Waters, 2005) as noted in the regulations of NCLB. However, the examination of transformational leadership provided several important characteristics necessary for reforming schools labeled as inadequate (Bass, 1999).

Transformational leaders inspire constituents to rise to the occasion in order to meet the challenges of their universal needs and purpose such as school reform (Bass, 1999; Bolman \& Deal, 2008; Bush, 2003). Such followers feel a trust, admiration, and loyalty which motivates stakeholders involved to do more than expect when meeting the challenges and assumes the leader and staff share values and common vision as well as the expectation for high performance (Bass, 1985, 1999; Bush; Schein; Yukl). Similarly, Bass (1985) identified transformational leaders as individuals with four distinct factors; charisma, motivation, intellectual stimulation, and individualized consideration resulting in a productive, high-achieving school (Bass, 1999; Bush; Leithwood, 1994; Schein; Yukl).

Charisma. Schein (1992) stated charisma is how a leader conveys a message to participants and communicates the specific goals and values in a clear manner. Charismatic leaders exert influence over stakeholders and how they perceive realities and the way they act resulting in followers who feel their leader possesses remarkable qualities (Dufour \& Marzano, 
2011; Morgan 1997; Yukl, 2009). Such motivating leaders exhibit desirable qualities when communicating and promoting an exciting future, articulating a plan for obtainment, acting as role models, promoting and enforcing high expectations, and displaying confidence (Bass, 1999; Leithwood, 2004; Schein, 1992; Yukl; 2009).

Charisma can be identified within leaders who promote a vision which deviates from the status quo, yet still is accepted and supported by stakeholders (Yukl, 2009). Charisma is one of the main components of how a leader communicates major assumptions or beliefs in a clear manner as well as the expectation for high performance (Morgan 1997; Schein 1992). Similarly, Morgan supported Yukl and Schein as he explained charismatic leaders are able to exert significant influence on how participants interpret their realities. Leaders who are charismatic possess verbal skills or other characteristics which allow them to exercise personal power and are perceived by followers as individuals who possess wisdom or insight (Bush, 2003).

Qualities of a charismatic leader are evident within the context of crisis situations and, with failing schools being deemed as a crisis situation by stakeholders (Morgan, 1997; Schein, 1992; Yukl, 2009), it is logical to assume that a charismatic leadership style is needed. Explicitly, charisma is attributed to a leader who acts in an unconventional manner to achieve a specific vision which differs from conventional strategies and impresses followers with successful results (Bass, 1985; French \& Raven, 1995; Yukl, 2009).

Trust is an additional and necessary component of charisma and followers are impressed with a leader who risks substantial personal loss (Yukl, 2009). Leaders who are identified with this expertise show strength of expert power, which varies with the extent of knowledge or perception stakeholders attribute to the given area of expertise (French \& Raven, 1959).

Motivation. Bass (1985; 1999) asserted, as a result of transformational leadership, followers will perform beyond expectation resulting in a sustained vision for change. Firestone 
and Heller (1995) supported Bass by explaining the importance of sustaining a vision for change, encouragement, modification, and progress monitoring as additional components. With successful transformational leadership, a school community can develop structures to foster participation and motivation in school decisions and all participants can be engaged in the achievement of educational objectives (Bush, 2003; Leithwood, 2003). Building administrators who lead organizations through major change reforms must forge a vision and build a capacity for change by working collaboratively and motivating all stakeholders (Bass, 1999; Bush, 2003; Schiein, 1992; Yukl, 2009).

Transformational leaders develop appropriate institutional goals and lead participants to achieve the defined purpose of the organization (Bolman \& Deal, 2008; Bush, 2003; Yukl, 2009). Yukl further contended leaders intentionally motivate individuals to guide, structure, and facilitate activities within an organization to achieve goals. Goals exist at many levels within any organization and leaders must ensure personal and subunit goals are secondary to the official goals of the institution. Leaders assist constituents in achieving their goals and providing them with direction and support to ensure the individual goals support and sustain the overall goals of the organization (Bass, 1990; Bush; Yukl). Organizational goals result from the perspectives and needs of the most powerful individuals present within the organization (Bush). Transformational leadership respects the intellectual stimulation present within the culture of an organization, thus supporting individual considerations (Bass, 1985; Bush, 2003; Leithwood, 2004; Schein, 1992).

Individual Considerations. Transformational leaders understand the need for individualized consideration and intellectual stimulation for all stakeholders, thus supporting individual goals while inspiring and focusing constituents on the overall organizational goals and vision (Bass, 1985; Bush, 2003; Yukl, 2009). Bolman and Deal (2008) asserted human needs and goals must be met in order for an organization to succeed 
resulting in individual considerations present within the culture of an organization respected by transformational leaders. Concurrently, Bush recognized educational institutions as goal-oriented and consisting of members working toward the achievement of common goals.

Transformational leaders evoke individual participants to become better in order to move to a higher level of achievement and success while promoting organizational goals (Bass, 1985; Bolman \& Deal, 2008; Bush, 2003; Yukl, 2009). The transformational leader understands that all participants bring multiple perspectives, experiences, and bias to an organization (Bass, 1990). This understanding is critical when recognizing the importance of individual goals and considerations prominent within transformational leadership (Burns, 1978; Yukl). Grint (2005) asserted one should study the context in which a problem or situation exists in order to fully understand the rationale needed to solve the problem. Transformational leaders coordinate efforts of participants toward the achievement of common goals by creating an environment which provides direction and support in contrast to rewards and punishment found within transactional and charismatic leadership (Bass; Bolman \& Deal; Leithwood \& Riehl, 2003).

Intellectual Stimulation. Current educational mandates also demand that administrator preparation not only become a priority but that administrators are trained to assist teachers (Knipe \& Speck, 2002; Kelehear, 2003). The role of school leaders has evolved and diversified in order to effectively implement effective school reform and promote student achievement (Bernhardt, 2001; Kotter, 1994; Schmoker, 2011). Bauck (1987) described effective school leaders as more committed to professional development than management. These leaders are encouraged to take an active role in designing effective professional development activities for their faculty members.

Furthermore, Nanus (1992) explained that a leader must develop a mental picture of the possible future of the school. Avolio and Bass (1991) asserted this mental picture develops when 
a leader helps participants become more creative and innovative through guided conversations gathering the input of the stakeholders, illustrating intellectual stimulation. Effective principals should therefore develop a vision for the school by collaborating with all participants within the school community (Avolio \& Bass; Bass, 1985; Bush, 2003; Nanus). Bass (1990) shared that when people feel their input was valued they became more collaborative and supportive of the collective vision and organizational goals. If a building administrator forgoes developing the collaborative process of intellectual stimulation, Kotter (1985) argued a gap in understanding and commitment is developed when only positional power is exercised, thus creating an us versus them mentality. Lambert (2002) shared building leaders can no longer go it alone through times of reform. In order for successful reform efforts to be implemented, all participants must be working toward the same common goal; transformational leadership inspires all constituents to meet challenges of the school reform process (Bolman \& Deal, 2008).

Classroom instruction has been determined as the greatest school level factor impacting student achievement and transformational leadership has the second greatest impact on school reform efforts (Leithwood, 1994; Marzano, 2003; Marzano, McNulty, \& Waters, 2005). Research has shown successful leaders positively impact student achievement and other success factors through their implementation of transformational leadership. The transformational approach has the capacity to move a school community beyond surface level changes to deeper transformations that impact the daily structures of a school such as pedagogy, curriculum, and assessment and positively impact school reform (Lavery, 2011; Schmoker, 2011). Transformational leadership transforms attitudes, values, and beliefs from being self-seeking to being higher and more altruistic, qualities necessary for successful school reform (Sergiovanni \& Starratt, 1993), thus fitting as the conceptual framework for this inquiry with its focus on highperforming, high-poverty schools. 


\section{Poverty}

The achievement gap is an accepted educational term that refers to the inequality of academic performance among subgroups of students (Boyd-Zaharis \& Pate-Bain, 2008; Marzano, 2003). According to Gamoran (2007), this inequity is one of the most significant problems of the United States educational system. Haberman (1991) maintained all educators are helpers, models, guides, stimulators, and caring sources of encouragement, transforming themselves when necessary to an authoritative figure. While some school districts rank among the highest-achieving districts, other districts rank among the lowest-performing. Gamoran (2007) elaborated, the problem is predominantly evident for students who have economic hardships and children living in poverty. Today, one-fourth of American children live in poverty (Gibboney, 2008).Although the concept of poverty might be straightforward and recognizable; a person living in poverty does not have the means to acquire the necessities of living (Betson, 1997; Payne, 2003).

Every individual has an idea of what it means to live in poverty; however, the representation is not necessarily the same for everyone (Crooks, 1995; Gamoran, 2007; Payne, 2003). Students who live below the poverty level often hail from highly-mobile families, lack educational resources in the home, and fail to receive homework support and encouragement from less-educated family members (Byod-Zaharias \& Pate-Bain, 2008). Low socioeconomic status is not limited to one specific area of the nation, nor one race. Poverty targets all races and all age groups in every state of the nation (Crooks, 1995; Gamoran, 2007; Payne, 2003). Although the issue of poverty has been a dilemma in most societal arenas, traditionally schools have regrettably provided the least support and help to these children (Cavanagh, 2007; Haycock, 2001).

Poverty is cyclical and children often unwittingly grow to be what they live (Bowman, 
1994; Payne, 2003). In other words, poor children are very likely to become adults living in poverty (Behrlman, Lewit, \& Terman, 1997). Moreover, poverty is a recurring cycle that often begins with parents' lack of education. Arnold and Doctoroff (2003) contended poor educational attainment was a major cause of poverty and is a key component in educational failure. In addition, most children live with their parents or other family members and depend upon those adults for their economic well-being (Betson \& Michael, 1997). Therefore, to understand childhood poverty, one should examine the reasons that parents and caregivers lived in situational or generational poverty (Betson \& Michael, 1997; Payne, 1996). Generational poverty is defined as a family living in poverty for two generations or longer, whereas situational poverty is caused by circumstances such as a death or illness (Payne, 1996). Furthermore, Boyd-Zaharias and Pate-Bain (2008) contended family functioning within the cycle of poverty fair best when integrated with middle class neighborhoods.

Poverty also negatively affects the mental well-being of children. Children who experience even short-term periods of poverty suffered more frequently from emotional and behavioral problems (Arnold, D. \& Doctoroff, 2003; Brooks-Gunn \& Duncan, 2000). Likewise, children without access to life-sustaining resources were more likely to suffer from depression, experience high levels of stress, and face a greater risk of absenteeism (Payne, 2003; White, 1982).

Poverty and Low Performing Schools

Researchers suggest that persistent poverty is a significant indicator for later behavior problems, which likely manifest when a child enters school (Korenman, Miller \& Sjaastad, 1995). As evidenced by Brooks-Gunn and Duncan (1997), children raised in families with incomes falling below the poverty level were 1.3 times more likely to suffer from learning disabilities and developmental delays than their middle-and upper-class counterparts. Boyd- 
Zaharias and Pate-Bain (2008) contended it is not just school improvement that will make a difference. Children who lived in poverty often need additional resources from schools and teachers to overcome the daunting task of breaking the cycle of poverty (Payne, 2003). Schools that educate the multitude of children influenced by poverty were frequently the systems receiving the least amount of funding, resulting in their own economic disadvantage (Archibald, 2006; Arnold \& Doctoroff, 2003; Haycock, 2001). Consequently, as multiple school reform efforts fail, good teachers and administrators have been driven out of the profession (BoydZaharias \& Pate-Bain, 2008).

Likewise, Caldas and Bankston (1997) reported socioeconomic status as affirmed by participation in the school free and reduced price meals program negatively influenced achievement. Additional research confirmed economically-disadvantaged students averaged lower test scores regardless of content area (Arnold \& Doctoroff, 2003; Boloz \&Verrati, 1983; Cooper \& Crosnoe, 2007; Taylor, 2005). Gibboney (2008) stated policymakers should support legislation to reduce poverty instead of penalizing schools in poverty-stricken areas. Children of low socioeconomic status faced an increased risk of failing mandated standardized achievement tests due to reasons beyond their control. Such failure could result in devastating effects for these students, school system, family, and society at large (Cooper \& Crosnoe).

Additionally, Gibboney (2008) shared most children living in poverty start their formal educational career behind their middle class peers. Due to lack of school readiness and poor performance on achievement tests, economically-disadvantaged children often experience lowered levels of school success. The lack of success is often a result of students who encounter educators who are socially conditioned to expect poor people to be morally inferior, who remain in poverty by choice or attitude (Ametea \& West-Olatunji, 2007). Such educators often act as if these children are so influenced by their early experiences that they might be too difficult, or 
impossible, to educate (Wilkins, 2006). For many reformers who seek high achievement status, poverty is a continual source of frustration (Haberman, 1991). Therefore, such educators fail to provide needy students with the successful school experience necessary to eventually break the cycle of poverty. These same educators unintentionally contribute to the failure of poor students by imposing a cultural view of expected behaviors and experiences. These students were trained in the dominant view of society's expected view of appropriate behavior. To illustrate, Bowman (1994) asserted that to use mainstream behavior as the sole criterion for healthy development is to miscalculate the learning potential for a great number of students, thus resulting in the devaluation of families and students. Additionally, a study of longitudinal data exposed regular absenteeism rates were higher among low-income children (National Center for Children in Poverty (NCCP), 2007). Research revealed that missing class time had a more detrimental impact on low-income students than it did on more affluent children (Boloz \& Varrati, 1983; NCCP, 2007). Finally, Pogrow (2006) contended even though numerous reform movements have been implemented, schools remain highly ineffective in terms of their ability to reduce the achievement gap.

Amatea and West-Olatunji (2007) shared that the most obvious differences regarding school success are revealed when studying the conflicting rate of failures between social classes. Due to multiple obstacles, school failure is more likely an outcome for students who are more economically disadvantaged. Poverty has the most damaging effects on its youngest victims because they are more likely to be retained and many ultimately fail to complete high school (Thomas \& Stockton, 2003). Though reform movements have produced some gains, these gains level off and do not transfer to long term success (Pogrow, 2006). Educators and administrators need to directly confront the realities of poverty to reverse the damaging and harmful effects of the lack of school success. 
The identification of low-performing schools is dependent upon the criteria used to define low-performing and the definition of an achievement gap. Within an era of standards-based reform, low performing often refers to schools that do not meet standards set forth and monitored by federal and/or state educational agencies (Corrallo \& McDonald, 2001). Anderson, Fowler, and Medrich (2007) contended defining the achievement gap can be difficult. Historically, studies have focused on the differences in achievement between white and African Americans, while $N C L B$ has increased accountability to include all subgroups. Additionally, Corrallo and McDonald (2001) described common conditions that exist within low-performing schools, such as a correlation between community poverty and stress on the educational system. The stress is evidenced by low expectations for student achievement, high teacher absenteeism, and high rates of teacher attrition. Poverty levels in many Missouri schools meet or exceed the national description of $50 \%$ or more free and reduced lunch (Missouri Kids Count, 2010) using federal and state funding to address the teaching and learning of children in poverty (McCall 2004; USDESE, 2002). Other studies suggested that students coming from disadvantaged backgrounds lack opportunity for success (Schwartz, 1995) and a structure for learning due to the poverty in which they live (DeVol, 2004; Payne, 2005).

In a study of low-performing, high-poverty schools in Florida, researchers acknowledged the effects of poverty on schools (Acker-Hocevar \& Touchton, 2001). The authors shared the effects of poverty were clearly revealed in the low academic achievement in four areas: demographics patterns, language barriers and deficits, degree of parental support, and cultural and socioeconomic values.

Corrallo and McDonald (2001) further stated the characteristics of schools that succeed despite community poverty include a strongly-focused and cohesive instructional program, a strong planning process focused on improving student achievement, and a culture of 
collaboration among teaching staff and administration. In contrast, Boyd-Zaharias and Pate-Bain (2008) noted, if all efforts of a school focused solely on school reform, they will fail.

Furthermore, Gardner (2007) claimed funding all schools the same is an ineffective means of addressing the achievement gap.

The number of students on free and reduced lunch in the state of Missouri is on the rise (Missouri Kids Count, 2010) and the lowest-achieving schools serve communities with lower household income and with schools with fewer resources (Anderson, Fowler, \& Medrich, 2007; Archibald, 2006; Cooper \& Crosnoe, 2007). To reemphasize, children in poverty are more likely to have learning disabilities, low test scores, more special needs and are more likely to drop out of school during the middle and high school years (Missouri Kids Count, 2010). Therefore, schools in Missouri must seek out successful high-poverty schools and learn from their success.

Socioeconomic status impacts every aspect of a child's life from diapers to a diploma. It threatens a child's continued existence, ability to develop physically, and capacity to grow intellectually (Children's Defense Fund, 1994; 2007). Even with all the research and data detailed the detrimental effects of poverty on the most vulnerable victims, in 2006, a child was born into poverty every 35 minutes and nearly 13 million children lived in poverty every day (Children's Defense Fund, 2007). Policy makers, administrators, educators, and community members should also take action to assure that this generation of low-income families be the one to end the poverty cycle and permanently close the gap of academic achievement between affluent and economically-struggling students (Cooper \& Crosnoe, 2007).

Consequently, Brownson, Kahlert, Picucci, and Sobel (2004) identified key factors in high-poverty, high-performing schools. These factors include: common purpose, thoughtful school structures, and attention to individual students. Lashway (2002) continued with six practices evident in high-performing schools with low-socioeconomic students in Texas. These 
effective leaders practice high energy, hands-on leadership that promotes the vision and the focus moving towards quality instruction. Broad-based planning is also utilized to set clear instructional priorities and benchmarks for improvement. Focused and research-based professional development is driven by instructional needs. Accountability is shown through continual monitoring of student achievement. Flexible grouping is also allowed to focus on instruction based on student needs; if students continue to struggle, specific interventions are provided immediately (Bernhardt, 2004; Chenoweth, 2009; Dufour \& Marzano, 2001).

Farnsworth (2010) contended great individual school leaders need not have all of the talent necessary in order to achieve the intended goals, but they must only have the intangibles needed to sustain the resolve to champion results-based reform. As Sergiovanni and Starratt (1993) shared, principals who exercise a transformational approach to leadership often have the ability to move schools beyond surface level changes to deeper transformations which substantially influence school reform and alter the core business of a school. These transformations are achieved through charisma, motivation, individualized consideration, and intellectual stimulation (Bass, 1995; Bolman \& Deal, 2008; Yuk1, 2009). Building administrators working toward successful school reform should promote the pursuit of common goals and vision, empowerment, development and maintenance of a collaborative culture, promoting stakeholder professional development, and engaging people in collaborative problem solving strategies (Danielson, 2006; Dufour \& Marzano, 2011; Gardner, 2007; Haycock, 2001; Williams, 2003).

\section{Summary}

Principals who fail to meet the expectations of federal and state requirements face the possibility of sanctions and even loss of employment (Department of Elementary and Secondary Education, 2010). Districts and individuals must recognize and understand effective leadership 
involves a process where influence is intentionally exerted by an individual over others to guide, structure, and facilitate activities and relationships existent within an organization (Yukl, 2009). Thus, educational leaders across the nation are being forced to continually seek to implement a leadership model that will promote school improvement for all students (Lambert, 2002). The significance of this study will add to the existing body of research by identifying and examining important leadership characteristics that promote and sustain high achievement and guide district personnel to recognize key components of leadership, thus aiding in hiring and retaining high quality leadership.

Accountability within the world of public education will be a long standing component (Farnsworth, 2010; Marzano, 2003). Leaders must continually look to increase student achievement and at the same time support teachers as they reflect and look to improve their best practices to meet the needs of specific subgroups. Leadership is an important factor in school improvement and success (Leithwood, 1994; Marzano). Identifying styles of leadership and leadership characteristics established in a successful high-poverty school will afford important information in the area of school improvement.

The reauthorization of ESEA has forced districts to evaluate the effectiveness of principals. With this increased accountability, building leaders must pay particular attention to the establishment of higher standards of student achievement on standardized tests each school year and understand how achievement results are tied to funding and potential sanctions. While it is recognized that multiple factors influence the success of our public schools across the nation, leadership plays a significant role. Consequently, it is important to identify characteristics of what leaders of successful high-poverty schools have implemented to positively impact student achievement. This study, developed through the transformational leadership lens, intends to identify and examine characteristics of effective leaders in high-poverty, high-achieving schools 
residing in a district.

Once districts and leaders have access to the characteristics of successful leadership implemented within the successful schools with high-poverty, they can use the information to guide their own building or district. Viewing this study through the lens of transformational leadership allowed the researcher to narrow the focus based upon the characteristics of charisma, motivation, individualized considerations, and intellectual stimulation (Bass, 1985; Bolman \& Deal, 2008; Bush, 2003; Schein, 1992; Yukl, 2009).

Discussed in Chapter Three is a description of the research design and methodology. This discussion includes research questions, population, sample, methods of data collection, and data analysis. Presentation of the data findings and analysis of these findings are presented in Chapter Four. Findings, conclusions, implications for practice, and recommendations for future research are described in Chapter Five. 


\section{Chapter 3}

\section{RESEARCH DESIGN AND METHODOLOGY}

\section{Introduction}

Zorn and Noga (2004) conceded poverty negatively impacts school success, student achievement, and the social emotional functioning of our youth. Yet a critical issue for schoolaged children, and the schools in which they are educated, is the academic achievement of students from all socioeconomic backgrounds (Beston \& Michael, 1997; Gordon, 2004; Zorn \& Noga, 2004). Education is regarded by many as the great equalizer for income and social disparity in the United States. Federal and state mandates, outlined in NCLB and AYP, support this belief by the requirements set forth in accreditation expectations (Farnsworth, 2010; Marzano, 2003; Protheroe, 2011).

Principals whose students fail to meet the expectations of AYP face the possibility of sanctions and even loss of employment (DESE, 2011; Farnsworth, 2010; Marzano, 2003; Pascopella, 2005). Protheroe (2011) theorized that principal leadership tops the list of conditions enabling improvement in schools. Thus, educators across the nation continually pursue a leadership model that will promote school improvement (Farnsworth, 2010; Lambert, 2002; Marzano, 2003). Leaders should balance the public pressures of their position and constructively implement educational reform initiatives to promote student success and support classroom educators (Farnsworth, 2010; Leithwood, 2003). Complex educational environments add additional stressors for leaders as they respond to diversity, curriculum standards, program requirements, and physical and mental disabilities (Leithwood, 2003). This "problem of practice" (Creswell, 2007, p. 35) impacts the lives of principals across the nation as they continually strive for a leadership model that will promote and sustain school improvement (Beston \& Michael, 
1997; Farnsworth, 2010; Marzano, 2003; Protheroe, 2011; Reeves, 2007, 2009) in high-poverty schools.

Effective leaders meet these challenges by developing and promoting a shared vision, community, increased student achievement, building leadership capacity within others, supporting reflective practice, and confronting problems of practice (Bass, 1990; Bolman \& Deal, 2008; Bush, 2003; Lambert, 2002; Yukl, 2009). After an extensive review of the literature, the researcher discovered the use of transformational leadership to be the most effective in terms of necessary school reform (Bass, 1999; Bolman \& Deal; Bush; Leithwood, 1994; Schein, 1992; Yukl, 2009), thus becoming the conceptual lens upon which this inquiry was based.

AYP and NCLB mandated every school should have highly qualified teachers and administration in addition to reporting attendance and student achievement (Pascopella, 2005) with Title I schools being specifically targeted due to national funding (Pascopella). Consequently, these schools often are located in low socioeconomic areas and are expected to meet and maintain the same mandated requirements as schools with higher socioeconomic status located in more affluent areas (Casbarro, 2005). The focus of this research study was to add to the existing body of research identifying effective leaders and the leadership characteristics that promote and sustain high achievement in high-poverty high-achieving schools.

Within Chapter Three are the research questions, rationale for the use of a narrative case study, and limitations. The description of design controls, participant explanations of data collection and instrumentation, procedure of analysis of data, and summary are also shared.

\section{Research Questions}

Utilizing a qualitative approach, the following research questions will guide this case study: 
1. What transformational leadership traits of the principal are present in a highpoverty, high-achieving schools as perceived by teachers, parents, and the principal's supervisors?

2. How has the contextual environment of high-poverty, within a school community of the school, influenced the transformational leadership style of the principal?

3. How have the transformational leadership traits of the principal changed behaviors of the teachers and parents?

\section{Rationale for Narrative Case Study}

Research studies can be delineated into two categories, quantitative and qualitative research. Qualitative research accepts that multiple realities exist and are constructed in one of two ways, socially and individually (Heppner \& Heppner, 2004). Furthermore, qualitative research contends the knower interacts with the known and cannot be separated (Heppner \& Heppner). In summation, qualitative research grants the researcher to be more involved within the contextual situation of the study, creating the opportunity for the understanding of the contextual reality found within the research setting (Creswell, 2007; Heppner \& Heppner, 2004; Stake, 1995). Creswell's definition of qualitative research provided a foundation for this narrative case study:

Qualitative researchers try to develop a complex picture of the problem or issue under study. This involves reporting multiple perspectives, identifying the many factors involved in the situation, and generally sketching the larger picture that emerges. Researchers are bound not by tight cause-and-effect relationships among factors, but rather by identifying the complex interactions of factors in any situation (p. 39). Furthermore, Stake (1995) shared that a case study is a unique form of research which provides an opportunity to learn about a distinctive and complex situation. A case study will provide the 
researcher the ability to gather a holistic view and obtain meaningful characteristics of day-today events within the given setting and focuses on contemporary events (Yin, 2003).

A case study permitted this researcher to retain a holistic view and obtain meaningful characteristics of day-to-day, realistic events taking place within the research setting through interviews, focus groups, document and artifact analysis, and onsite observation (Creswell, 2007; Yin, 2003). Conversely, the researcher must concede that limitations of a case study exist and must be acknowledged (Creswell, 2007; Merriam, 1998; Yin, 2003).

\section{Limitations}

All studies have limitations. In order for a thorough research study to be conducted, the researcher should be attentive to the limitations (Creswell, 2007; Heppner \& Heppner, 2004; Yin, 2003). One limitation was the amount of time needed to conduct a thorough investigation and compile the rich data necessary for an effective case study (Merriam, 1998). It was also important to acknowledge the time constraints of the participants and researcher. The researcher also understood, as the research was conducted, that one may be seen as meddlesome and interfering. For this reason, the researcher implemented various methods of data collection to ensure reliability and validity of the data and create triangulation (Creswell).

Additionally, this research study was performed on a single case study. Other options such as a multiple case study were not explored due to time constraints and accessibility. A single case study has the potential to over simplify or exaggerate a situation, unless the researcher recognizes such a limitation (Merriam, 1998). The following section outlines the criteria utilized by the researcher to identify a research site, based upon the reviewed literature.

\section{Participants}

As Creswell (2007) postulated, qualitative researchers strive for understanding. Therefore, when selecting a specific site for a qualitative, single case study, it is necessary for the 
researcher to utilize criterion-based selection (Merriam, 1998). Criteria was identified prior to the selection process which limited the cases to those schools meeting the constraints and allowed for the researcher to gain knowledge and understanding (Creswell, 2007; Merriam, 1998). For this reason the selection of a specific school was purposeful and provided the researcher with a specific school meeting the criteria of a high-achieving school with a high incidence of poverty as identified by the Missouri Department of Elementary and Secondary Education (DESE; 2011).

Filtering was a necessary step in the identification process and guided the purposeful sampling (Yin, 2003). Filters were utilized by the researcher to narrow the subject range to stakeholders who meet the criterion identified by the researcher as most suitable for the study (Yin, 2003). The criterion identified by the researcher through the review of literature included: high instances of poverty within the student population, high student academic achievement, and consistent leadership (Chenowith 2007, 2009; Farnsworth, 2010; Haycock, 2001; Marzano, 2003; Reeves, 2001, 2004, 2007). Thus the school selected had to meet the entire criterion to be selected.

Initially, it was essential to identify schools in the state of Missouri with high instances of poverty. The socioeconomic level of students was identified through MSIP data reported annually by districts across the state, allowing for a consistent measure of poverty across all schools. Through MSIP data, high-poverty was identified as at least $50 \%$ of the student population qualifying for free or reduced meals. As the percent of students were narrowed by county, Jackson County ranged from $58.1 \%$ to $65.4 \%$ of students qualifying for free and reduced lunch (DESE, 2013) and consists of twelve school districts. Out of the twelve school districts seven of the school districts registered a free and reduced lunch rate greater than $50 \%$. Those 
seven school districts consist of 72 elementary schools with free and reduced lunch greater than $50 \%$ (DESE, 2013).

Once high-poverty schools were identified, it was necessary for the researcher to further filter the identified schools in order to identify schools that were considered high-performing schools. High-performing schools were identified by the Missouri Department of Elementary and Secondary Education as demonstrating the sustained academic growth and performance from the years 2011-2014 in communication arts as determined by MAP (MSIP, 2004; MODESE, 2011). The list of schools was now narrowed.

Finally, it was necessary to filter the remaining schools by the length of term of the administration. Many researchers (Leithwood, Louis, Anderson, \& Walstrom, 2004; Marzano et al., 2005) have identified building administration only second to the effectiveness of the classroom teacher as a necessary component to the success of all schools. And, as Fullan and Hargrave (1991) posited, it is necessary for at least three years of implementation to determine the true impact of leadership. Therefore, for the purpose of the study, only buildings with administration in place for at least three years were included. To select the stakeholders within the case study, Creswell (2007) emphasized the necessity for the purposeful sampling of a variety of participants in order to guarantee an accurate description of stakeholders within the organization. Such a purposeful selection allows for a multitude of perspectives to be explored in order to gain a clearer understanding of the organization. Therefore, in addition to the principal, , the principal's evaluator, the selection of four to six teaching staff was designed to represent those individuals who had been in the school for at least three years and also experienced testing students in grades three through five. Parents were also identified as important in providing additional insight valuable to the findings of the study; therefore, a group of four to six parents were selected by the building principal. The principal was asked to select the parents who were 
representative of the socioeconomic backgrounds which mirrored the population of the student body. The use of focus groups of teacher and parents enabled the participants to share first hand experiences and illustrations of the leadership traits present with in the research site (Creswell, 2007; Lincoln \& Guba, 1985).

\section{Data Collection and Instrumentation}

Data collections were comprised of interviews, focus groups, on-site observations, and document analysis. Ethical considerations must be part of any research that is conducted (Creswell, 2007; Merriam, 1998; Stake, 1995). The data were collected with the permission of the participants and followed guidelines set forth by and in accordance with the University of Missouri's Institutional Review Board (IRB) (see Appendix A). Prior to conducting any interviews or focus groups, the permission of the gatekeeper was pursued and acquired (see Appendix A). An ethical study also includes providing participants with an informed consent form (see Appendix B), which must first be approved by the IRB. Prior to contributing to the study, each participant was asked to read and sign the informed consent form with the understanding that his or her participation was voluntary and could be terminated at any time during the study (Creswell, 2007). Participants were permitted to ask questions concerning the study and the researcher answered the questions suitably before signatures were gathered.

The instrumentation consisted of three semi- structured one hour interviews, conducted with the building principal in one session, and a central office administrator during a second session. Additional data collection involved two semi-structured focus groups protocols completed in two sessions at the research site. The first focus session included four to six teachers. The second focus group was comprised of four to six parents who also represented a broad spectrum of the socioeconomic school community. The interview and focus group protocols allowed the participants the opportunity to provide explanations and firsthand 
perspectives regarding their perspectives of the leadership style of the principal (Creswell, 2007; Lincoln \& Guba, 1985).

The researcher administered each interview and focus group session using the established protocol forms. Once the interview or focus group session was completed and transcribed, member checking was completed by the researcher (Stake, 1995; Yin, 2003). Member checking added additional ethical considerations and protected the interviewees from potential misinterpretations of the data (Stake, 1995).

\section{Interview and Focus Group Protocols}

The two primary sources of data collection were interviews and focus groups. Both forms of data were central components in the explicit development of understanding regarding the experiences of the participants (Creswell, 2007; Merriam, 1998). Each process allowed the researcher to collect rich and descriptive data (Creswell, 2007), and enable clarifying questions to be asked (Heppner \& Heppner, 2004; Merriam). Such questions were derived from thorough analysis of the literature on school reform and also transformational leadership documents (Bass, 1985; Bolman \& Deal, 2008; Firestone \& Heller, 1995; Leithwood, 1994; Marzano, 2003; Schmoker, 1999). Prior to conducting each interview and focus group, participants received a letter of confirmation, interview questions (see Appendix C), and letters of informed consent (see Appendix B). Such process allowed time for participants to reflect of the questions which would be asked by the researcher and to reassure them of confidentiality.

Interviews The principal interviewed was selected through the filter of being in place for at least three years, placed within a school meeting subgroup growth toward AYP accountability mandates for their students of poverty over time. As Farnsworth (2010) and Marzano (2003) contended, the principal is second to only the teacher in successful schools. The second interview was conducted with a central office administrator who had firsthand working knowledge of the 
of the leadership style of the selected principal. All administrators were contacted directly by the researcher to arrange the interview date and time. Each semi-structured interview allowed for a structured questioning process while allowing the researcher to clarify and engage in conversation which allowed for a deeper insight as to the leadership style of the principal. Each interview was comprised of 10 to 20 open-ended questions, identified and developed through the review of literature, and lasted approximately 45 minutes to an hour (see Appendix C).

Focus Groups Teachers and parents were identified by purposeful selection in order to provide a variety of experiences. Each focus group consisted of four to six participants identified by the principal and researcher. The focus groups provided a social context which provided participants the opportunity to hear perspectives from others as it may have reminded them of additional information or elicited responses that would not have occurred in a traditional interview setting (Creswell, 2007; Emerson, 1995). Each session was comprised of semistructured questions that were asked by the researcher and lasted approximately one hour.

The focus group questions developed were semi-structured and allowed for open-ended responses from the participants (see Appendix C). Utilizing the semi-structured questions, yet allowing for the researcher to engage in conversation to gain further insight, provides the opportunity for rich data collection (Merriam, 1998). Each focus group session was taped using an audio recorder and lasted approximately one hour. Each session was transcribed by the researcher and made available for participant review. Creswell (2007), Merriam (2009), and Stake (1995) supported the validation process, of member checking, to ensure the reliability and accuracy of the information gathered. Additionally, confidentiality was ensured by the researcher by implementing the use of coding (Creswell, 2007; Merriam, 1998).

\section{On-Site Observations}


On-site observations were important to the study as they provided a first-hand account of how the school operates on a day-to-day basis. Handwritten field notes were taken during the course of the observations to provide insight and further clarification regarding the research questions. The observation process allowed the researcher to again a clear understanding of the daily operations of the research site and the interactions of the principal, teachers, and students. As a result, the field notes from the observations were utilized as a design control to balance the influence of researcher bias (see Appendix D). Furthermore, field notes allowed the researcher to record specific thoughts, impressions, and observations made through out each step of the research process (Emerson, 1995; Merriam, 2009) and enhanced the overall findings and helped to create an accurate portrayal of the research.

\section{Document Analysis}

The researcher relied on a variety of documents to supplement and connect the data collected throughout the research (Creswell, 2007; Mertens, 2005; Stake, 1995). The researcher reviewed numerous documents throughout the case study, both internal and external documents. The external documents reviewed by the researcher included the Missouri School Improvement Review of the case study school, Missouri Assessment Program (MAP) data results, as well as socioeconomic levels as defined by the school's free and reduced meal percentage (MODESE, 2001). In addition, internal documents, unique to the case study school, were reviewed. Such documents included weekly newsletters, staff meeting agendas, professional development agendas, and staff surveys.

Both external and internal documents are a part of the inductive process of building a thorough case study. Such documents allowed the researcher to build a strong case background and aided in the triangulation of the data (Yin, 2003). 


\section{Data Analysis}

Throughout the data analysis process, all relevant evidence must be valued and treated fairly in order to produce compelling conclusions (Yin, 2003). Furthermore, qualitative research can produce a vast amount of data, so it is important to have the data organized to allow for timely analysis (Creswell, 2007; Merriam, 1998; Stake, 1995). Merriam (1998) believed the data analysis process should ensue immediately after collection of the data. The researcher utilized multiple audio recording devices and field notes to document the interviews and focus group in order to aide with coding the data (Merriam, 1998).

The practice of coding included the identification of each item in the research and then organizing them into individual themes (Creswell, 2007; Emerson, 1995; Merriam, 1998). The codes used were determined by the literature review and the research questions. The coding process allows for the identification of emergent themes and must be completed in a logical manner and conducted by a single individual, in order to increase consistency throughout the data (Creswell, 2007; Merriam, 1998; Yin, 2003). Throughout this case study, validity was increased by the use of interviews, focus groups, historical document analysis, and observations (Yin, 2003).

Emerson (1995) supported this idea by outlining a clear process for ethnographic field notes and providing a system for each document, transcription, artifact, participant, and additional items to be numbered in a clear manner to ensure accuracy (see Appendix E). Once all transcriptions were completed, member checks were used to ensure the validity and reliability of the data collected. Member checks provide participants the opportunity to review transcripts for accuracy as was stated in the informed consent form (Merriam, 1998). This process was completed to ensure the data collected is correct and taken in the proper context as it was intended. Member checking also allows for clarification if necessary. The research questions 
sought by the researcher enabled the categories and patterns of the data to be identified and the researcher began the process of answering the research questions through the analysis and triangulation of the data. Triangulation refers to the use of various sources of data and of data collection methods to confirm the emergence of data (Creswell, 2007; Fowler, 2008). The implementation of triangulation increase the reliability and validity of the data collected during the course of the study (Creswell, 2007; Fowler, 2008; Merriam, 1998).

Subsequently, Stake (1995) suggested data were always being interpreted as qualitative research is a reflective process and a researcher should be committed to the reevaluation process and continually reinterpret the data. Consequently, the process of data analysis was ongoing throughout the research study and through the use of multiple sources of data a clearer picture was captured to identify the key elements of leadership necessary for increasing student achievement.

\section{Summary}

This qualitative single case study approach was selected to provide an in-depth descriptive process to gather information to add to the existing body of knowledge on leadership in high-achieving and high-poverty schools. Subsequently, in Chapter Four, data analysis and the research findings are presented and discussed. In Chapter Five are the discussion of findings the conclusions, implications for future research, and recommendations for future study. 


\section{CHAPTER FOUR}

\section{PRESENTATION AND ANALYSIS OF THE DATA}

Effective leadership is a key component in promoting student achievement and is second only to the effectiveness of the classroom teacher when it comes to impacting student success (Collins, 2001; Danielson, 2006; Marzano et al., 2003). High academic achievement by students in high-poverty, urban communities is the exception and not the rule. Furthermore, the issue of subgroups within districts demands attention, as districts focuses on student achievement (Anderson, Fowler, \& Medrich, 2007). While some economically disadvantaged schools in the state of Missouri have met targets set forth by the Department of Elementary and Secondary Education (2011), little research exists to identify these successful Missouri schools and the effective leadership styles promoting their success.

The purpose of this research study was to identify and examine the characteristics of effective leaders in high-poverty, high achieving schools within a single school district. The research also contributed to the existing body of knowledge that educators across the nation can use to increase student achievement set forth by federal and state mandates (USDOE, 2007). Transformational leadership provided the lens for the researcher to analyze the perspectives of multiple stakeholders present within the research site. In addition to discern the transformational leadership characteristics of the building principal in order to provide useful information for schools across the nation focusing on student success.

Within this chapter, a review of the study design, data collection methods, conceptual framework, research questions and analysis of the data will be presented. A detailed description of the research setting will be shared and the participating stakeholders will be introduced. 


\section{Study Design}

A narrative case study was selected as the framework for the investigation of a Missouri school with high incidents of poverty that has consistently demonstrated the ability to show continuous improvement or meet federal and state mandates for accountability. The qualitative framework allowed the researcher to outline a complex picture of the issues by gathering multiple perspectives in order to craft an accurate picture of the research setting (Creswell, 2007; Merriam, 1998). The setting was selected through a series of filters. The stakehoders (i.e., administrators, teachers, and parents) were purposefully selected to provide a variety of perspectives representative of the actual district and school populations (Creswell).

\section{Data Collection Methods}

Prior to collecting data, after approval from the University of Missouri Institutional Review Board from the (Appendix A), permission was obtained from the district gatekeeper (Appendix B). Data was collected through interviews, focus groups, on-site observations, and document analysis. Once the interviews and focus groups were completed, participants were asked to review the transcript of each session that was transcribed verbatim and provide feedback through the process of member-checking (Creswell, 2007; Merriam, 1998). The member checking process ensured the participants' viewpoints were articulated accurately (Mertens, 2005). Once all data was collected and member- checking completed, triangulation allowed for the identification of emergent themes (Creswell, 2007; Fowler, 2008).

\section{Research Questions}

Once a thorough review of current research was concluded, the following research questions emerged to guide the study: 
1. What transformational leadership traits of the principal are present in a highpoverty, high-achieving school as perceived by teachers, parents, and the principal's supervisors?

2. How does the contextual environment of high-poverty within a school community influence the transformational leadership style of the principal?

3. How do the transformational leadership traits of the principal change behaviors of the teachers and parents?

Interview, focus group, field observations, document and artifact analysis data were collected and analyzed through a process of defining common themes which emerged during the data collection process.

\section{Process of Data Analysis}

Data related to the study was gathered through observations and field notes obtained during on-site visits. The collection methods provided necessary contextual information important to the study. Interviews were conducted with two administrators individually. Two focus groups were conducted; one was comprised of teachers $(n=4)$ and the other parents $(n=4)$. An invitational letter was provided to each participant explaining the intended research topic and an informed consent outlining the rights of each participant. Data collected during the focus groups and interviews were collected using audiotapes and transcribed verbatim. Each transcription was provided to the participant asking for verification of accuracy for his or her words. Interviews and focus group data was analyzed once verification by participants was complete.

The data from the research study were examined and analyzed utilizing the following codes (see Appendix F): Additional codes included: Central Office administrator participant (CO1), administrator participant (AP1), teacher participant 1 (E1), teacher participant 2 (E2), teacher 
participant $3(\mathrm{E} 3)$, teacher participant $4(\mathrm{E} 4)$; parent participant $1(\mathrm{P} 1)$, parent participant $2(\mathrm{P} 2)$, parent participant 3 (P3), parent participant 4 (P4); interview 1 (I1), interview 2 (I2); focus group 1(FG1) focus group 2 (FG2); field observation 1 (FO1), field observation 2 (FO2). Motivation (MO), intellectual stimulation (IS), individualized consideration (IS), clear vision and shared values (V), were additional codes that were utilized during the data analysis process.

\section{Setting}

Blue Sky Elementary (pseudonym) an urban elementary school located in Missouri was the setting for this narrative case study. Blue Sky Elementary is one of eight elementary schools in the Lightning Ridge School District (pseudonym). Blue Sky Elementary is comprised of 345 students - 63.2\% Black, 6.7\% Hispanic, and 20.6\% White and an attendance rate of $87 \%$ and a free and reduced lunch rate of 77.5\% (MODESE, 2015). Within the supersub group identified by the DESE, $49.2 \%$ of the students achieve at the top two levels of the Missouri Assessment Program (MAP) qualifying them for making Adequate Yearly Progress (AYP) within that category. Additionally, the Black subgroup has made continuous growth for the past three years and the free and reduced subgroup has grown since 2012 toward obtaining AYP.

The Lightning Ridge School District serves over 6,200 students bordering a major metropolitan community in the Midwest and is currently provisionally accredited through DESE. The district is comprised of eight elementary schools, one middle school, one junior high school, one senior high school, one education building, and one alternative school. The ethnic diversity of the school district reflects that of the surrounding community: $78 \%$ Black, $10 \%$ White, $8 \%$ Hispanic, 2\% Asian, and 2\% Multiracial. Approximately 86\% of the students attending school in the Lightning Ridge School District qualify for free and/or reduced meals. Blue Sky Elementary School is located within a neighborhood setting surrounded by well-maintained, lower-middle class homes, surrounded by numerous mature trees within the southeast corner of the school 
district boundaries. The front exterior of the building was lined with rose bushes and a marquee sign located next to the parking lot entrance displayed upcoming events to parents and community members. In an effort to ensure the security and safety of students and staff, the entrance of the building is framed with security doors, an electronic scan pad, and camera. To enter the building one must show photo identification or scan a security card. The office is readily accessible to the left of the front entry and can be accessed through a single door. The front entry was covered with student artwork and plaques acknowledging the accomplishments of staff. The principal provided the researcher a tour of the building, allowing the opportunity for explanation of building layout and grade level locations. Found outside of each classroom, were weekly lesson plans stating the students learning objectives. Bulletin boards lined the hallways and were covered with writing samples created by the students at every grade level.

\section{Participants}

Interviews and focus groups were conducted by the researcher. Collectively one central office administrator, one building principal, four teachers, and four parents participated in the study. The parents who participated in the study, all had students at Blue Sky Elementary during the time the research was conducted. One special education teacher, two third grade teachers, and an instructional coach also participated in the study.

Central Office Administrator 1, Bob Jones (pseudonym,) was the Deputy Superintendent of Curriculum and Instruction. This was his first year in the Lightning Ridge School District. Bob was in his eighteenth year of education. Prior to assuming an administrative role his past experience was teaching art to kindergarten through college students. Bob came from the Phoenix area to Lightning Ridge in 2014. He had vast experience in curriculum and instruction throughout his educational career. 
Administrator Participant 1 Jim Smith (pseudonym) was the building principal at Blue Sky Elementary School for the past four years. Prior to his principalship at Blue Sky, he was an assistant principal a middle school within the Lightning Ridge School District. During that time he found that the middle school level was not what he preferred. His passion was the elementary level. Before entering the world of administration he was a teacher in a neighboring school district located within a highly populated metropolitan area. His teaching experience provided Jim the opportunity to build his knowledge of quality instruction and develop his ideals of what makes a school a community. Through his educational tenure, Jim has become firm in his beliefs. He expects his teachers to teach from their heart while focusing on what is best for their students. This is a standard in which he holds them accountable. Displayed in his office is a plaque which states, It is a rare person who can foster hearts and take care of business. Such a statement exemplifies Jim Smith.

The first teacher participant (Educator 1) was Jane Thomas (pseudonym), a veteran teacher at Blue Sky Elementary. Jane was in her tenth year at Blue Sky Elementary, but had been in education for 25 years. She began her teaching career in a neighboring school district. At the time of the study, Jane taught special education to first through sixth grade students in a resource room setting. Jane felt that Blue Sky Elementary was a cooperative team who worked hard to meet the needs of students and were focused on teaching and learning.

The second teacher participant (Educator 2) was Sue Adams (pseudonym). Sue had been a teacher at Blue Sky Elementary for seven years and recently assumed the role of instructional coach for her eighth year. As an instructional coach Sue worked with classroom teachers to support their needs in the classroom by providing instructional guidance, small group assistance, and finding other resources that might be necessary. In addition to working with teachers in 
classrooms, she was the professional development chair working to provide necessary professional development alongside the building administrator.

The third teacher participant (Educator 3) was Kim Mitchell (pseudonym). Kim was in her second year at Blue Sky Elementary and in her second year of teaching. Kim described herself as a competitive person by nature, so she fit well with the expectations placed upon teachers at Blue Sky. At the time of the study, Kim was working on focusing on her classroom instruction and meeting the needs of her students. Kim felt all the teachers at Blue Sky Elementary worked together to meet the needs of students.

The fourth teacher participant (Educator 4) was Pam Bryan (pseudonym), a nineteen-year veteran to education who had spent all nineteen years at Blue Sky Elementary School. Pam was a building leader through her participation on the professional development team. She received training in specific instructional strategies and provided training to the Blue Sky teaching staff in those areas of expertise. Pam shared that community of Blue Sky was like a family.

The first parent participant (Parent 1), Josie Grant (pseudonym), had one child currently at Blue Sky Elementary and one child at the middle school that had previously attended Blue Sky. Josie had been a parent in the Blue Sky Community for eight years and was excited to be a part of the focus group process. Josie was very active in the Parent Teacher Association and participated in almost all school-sponsored activities as well as activities at the middle school and district level. She was also a member of a district committee which developed the five-year strategic plan for the Lightning Ridge School District.

The second parent participant (Parent 2), Kat Bowman (pseudonym), had one child currently at Blue Sky Elementary and one child at the middle level who had previously attended Blue Sky. Kat had been a parent at Blue Sky Elementary for the past nine years. Kat was actively involved in the Blue Sky Community. She was an active member of the Blue Sky Parent Teacher 
Association and currently served as a board member. Not only did Kat attend almost all building activities sponsored at Blue Sky, but she also attended monthly School Board meetings.

The third parent participant (Parent 3), Ivy Ray (pseudonym), was new to the Blue Sky family. Ivy and her husband just recently moved to the Blue Sky attendance area. Prior to attending Blue Sky, her children attended a private school. Ivy had one child at Blue Sky, one child starting the early education program next year, and one student in high school. Ivy was a member of the Parent Teacher Association. She attended school functions and volunteered for school sponsored activities.

The fourth participant (Parent 4), Rita Kay (pseudonym), had been a parent at Blue Sky Elementary for the past seven years. Rita was an active member in the Parent Teacher Association and was willing to volunteer whenever it was needed. Her daughter also attended the after school program called Local Investment Network Commission (LINC) and participated in Girls Scouts. The communication at Blue Sky was one of the strengths according to Rita.

Themes

Two emergent themes were identified from the analysis of data and the implemented coding system. The first theme which emerged was: Achievement, which was supported by: (a) a community of learners, (b) data-driven decisions, (c) accountability, (d) differentiated instruction. The second theme identified was Clarity of Vision, which was supported by: (a) relationships, (c) clear expectations, and (d) motivation.

\section{Achievement}

Community. Supporting the theme of Achievement emerged the idea of community of learners. For any organization to be successful, participants' needs and goals should be obtained (Bolman \& Deal, 2008). It was apparent that through Jim Smith's time at Blue Sky the focus has been on building a community, learning, meeting the needs of participants, and building a 
partnership that focused on keeping children at the forefront of any school decision. He shared, "I came in focusing on building a community. We are in this together. We are a partnership. I wanted to partner with the PTA. I wanted to partner with parents. I wanted to hear what they were saying." This discussion between participants and leadership encouraged the development of a positive climate where learning was valued (Johnson, 1997). As the community began to evolve, a common thread developed among the staff and parents as they realized a family had emerged. Josie Grant shared, "I think as far as a community it feels like a family. That is what I have experienced here. What I am talking about is from the principal down to the teachers."

Parents emphasized the open expression of care, concern, and support. One basic ideal that fostered Jim Smith's action was the philosophy you have to treat others the way you want to be treated. Children, staff, and parents were considered stakeholders in the school. Their concerns and recommendations were highly valued by the administrator. Kat Bowman was asked what new parents needed to know about Blue Sky Elementary. She stated, "that their child will be listened to [and] feel safe and enjoy coming to school." Josie Grant supported this theme by adding, "With Mr. Smith you can go in and talk to him. He will make time for you." Finally, Mr. Smith encompassed this theme by the following statement: "A staff member gave me a plaque years ago which said, It is a rare person that can take care of hearts and take care of business. It has to be an open line of communication. If there is a problem you can talk to me about it and then we will come up with a solution." This construct, evident within the Blue Sky community, helped to develop a structure to foster participation in decision making and engage all participants (Bush, 2003; Leithwood \& Reichl, 2003). As a community evolved, the environment provides the building leader to constructively implement educational reform efforts to promote student achievement and support classroom educators (Leithwood, 2003). 
Data-Driven Decisions. The second theme which emerged was data-driven decisions.

After Mr. Smith established a school community, he began to focus on the importance of data.

Over the years progress had been made toward eliminating the achievement gap. However, scores remained relatively unchanged (Marzano, 2003; Anderson, Fowler \& Medreich, 2007). The implementation of utilizing data had been a powerful tool for the staff at Blue Sky Elementary when working toward moving students and monitoring growth. When asked what the school had done to address the influence of No Child Left Behind, Mr. Smith replied, "I believe we have addressed this by saying that no child will be left in below basic, if a child is in below basic what can we do to move that child up?" He continued by contending, "We have parent meetings and data meetings to discuss the progress of the students." When asked what he was doing to address his sub groups Mr. Smith articulated:

Well, analyzing data. Once the data comes in and your students are falling below where they need to be, we need to ask why. Once we figure out why, then what are we going to do with the information? How are we going to differentiate instruction inside the classroom so that these students are getting what they need?

Individualizing instruction for students sustains the determination of results based on school improvement efforts and continuous growth (Farnsworth, 2010). Teachers confirmed the focus on data. Sue Adams supported this idea by sharing:

Each room has a data wall. So teachers are responsible for having data conversations. We also have a data team which consists of the librarian, instructional coach, the principal, and our family resource specialist. We will pull grades from various grade levels and meet with them to discuss their data.

Leaders striving to reform low-performing schools should focus assessing skills and using various data sources to continually monitor student growth (Bernhardt, 2004; Chenowith, 2009; Duke, 2004). Mr. Smith reiterated that process and expectation through his publication of the Rocket News which was circulated to teachers each week. As the researcher reviewed numerous 
artifacts, the message emphasized the expectation of data analysis by teachers and students. Pam Bryan expressed:

We have a lot of data talks. Our school is data driven. We have data walls and data folders. From those two things we have data conferences with our students where we try to communicate with them where they are based on their performance in the classroom and what their goals are.

The data driven process transcends beyond the classroom, as parents are also included in the process. A key element for promoting success is embracing data (Marzano, 2003;

Farnsworth, 2010). Blue Sky parents illustrated such claims. From the classroom, data was sent home to parents. Parents received reports from progress monitoring tests or benchmarking tests. Kat Bowman shared:

The principal does about three assemblies a year and he lets the parent body know how they are doing or how the students did with their state testing. Progress reports are sent home with students and STAR reading and STAR math.

Finally, to sum up the importance of data at Blue Sky Elementary Bob Jones stated:

A good example is when we have school board meetings. We have all of the schools come. It is a brag night. They come and do a presentation. Last year he actually had the students come and present where they were with MAP preparation. They explained what their MSIP score would be.

From the principal, to the teachers, to the parents, to the students, everyone was informed and focused on student data. Mr. Smith summed up the importance of data by stating, "You can't run a school without data. If you miss the data then you miss a whole piece of school." The utilization of data allows teachers to focus on student learning systematically.

Accountability. To coincide with the evolution of a data-driven focus, accountability was a natural transition. Educational leaders and governmental officials have implemented measures to ensure that districts and schools are held accountable (Farnsworth, 2010; Marzano, 2003). In order for data to have meaning it should be utilized. Moreover, to ensure utilization and accountability, successful leaders should work to maintain the focus of all participants on the 
needs of the students (Protheroe, 2011). Kim Mitchell supported this theme by emphasizing, "there are a lot of expectations of you as a teacher coming in to this school. You are not going to have the opportunity to slack off and get away with it." Teachers are expected to set goals with students based upon data and discuss a student's progression with them. Kim Mitchell continued, “there is no opt-out, no excuse, there is no reason why you can’t do this." When asked to describe the leadership processes and structures of the administrator, Pam Bryan added:

He has a check list of what he expects to see in the classroom related to vocabulary, small group, or our anchor charts. He will address that. He constantly asks students what they are learning and what they are doing with that learning.

Expectations have been made clear. Sue Adams shared:

He is a believer in strong instructional practice and definitely the strategies. He is asking to see one or two strategies per lesson for the various subjects so you have students on their feet not just sitting there with a sit and get type lesson. He wants the classroom to be an interactive environment and not just students sitting there board with instruction. Engagement needs to be high.

Providing opportunities for teachers to improve instructional practices allows a building leader to promote a common vision and goals of the organization (Hallinger, 2003).

Observations and feedback are an important component to accountability at Blue Sky. Mr. Smith visited classrooms regularly, utilizing the 360 Feedback program. Teachers were immediately sent feedback after a classroom observation had been conducted. If a teacher was not doing well or if there was an issue, it was dealt with immediately. Mr. Smith stated:

They are honored when they do a great job. If it is not going well, I have private conversations. I do not do to a person what I would not want done to me. I don't want to be embarrassed in front of my colleagues.

Sue Adams supported this philosophy by responding:

He likes to iron out issues when they arise. He doesn't want people to hold on to things. He would rather know right away so he can address it so it does not create a problem down the road. Teachers are provided opportunities to improve when they might be struggling. 
Jane Thomas expressed, "He gives teachers a chance to improve and resources are given to them

to improve." When Mr. Smith was asked how his expectations have changed he responded:

I have seen too many teachers fail students many, many ways with their attitudes, their beliefs, not really wanting to teach but just hang out. I have become firm in my beliefs. I have always expected great teaching to take place. If you are not teaching here in this building you are not going to be here long.

Through a clear process of accountability, a culture of high expectations and learning emerges (Hallinger, 2003; Mortimer, 1993).

Student expectations are made clear from the very beginning of school. The first week of school the building administrator went to each classroom and reviewed the behavioral and academic expectations of Blue Sky Elementary. When it came to new students, Sue Adams expressed:

We want you to have a positive experience here. We definitely have a strong focus on instruction. We let students know when they come in. Mr. Smith after the first week of school, he interviews every family that comes through. He sits down with the parent and student and lets them know what we expect as far as academics and behavior. He goes over all of the issues they may have had at the past school explaining we are different here. We need you to do what we do here.

If students were not able to be successful, a parent meeting was immediately scheduled and goals were set to help the student improve either behaviorally or academically. Goals were set and data conferences once again would resume. The focus was on improving and learning. Jane Thomas shared, "With my students we work a lot on, what is the reason we come to school? To learn. They know that is the only answer and we do not discuss it any further." Sue added:

Everyone is held accountable, not matter if you are a para, in the kitchen, or a teacher. Everybody is held accountable. It was easier to not be as good as they could be. He will give you any support that you need so it can't be I didn't have this or I didn't have that. If you need a resource you will get it. He wants to give you every reason to be successful.

Differentiated Instruction. With the belief that all children will be successful and should reach their full potential, it is necessary to focus on each child as an individual. However, the 
educational system was not designed to educate all students in the same manner (Gardner, 2002;

Neuman, 2009). As teachers analyze Missouri Assessment Data, benchmark data, or progress

monitoring day, they are constantly analyzing each individual child's ability and setting

reasonable goals for expected growth. Therefore, Differentiated Instruction was a subtheme

which evolved from the research data. Pam Bryan stated:

We use our vision to help us with differentiated instruction. We know we can't reach students in the same way, students learn in different ways. So we do a lot of small group instruction...I may be reverting back to phonics with some of my students because they have not mastered that or working with one of my students that are beyond grade level.

Students are encouraged to focus on strengths and build upon areas of weakness. Priority is placed on valuing the diversity and recognizing this to support the educational process (Gewirtz, 1978; Theoharis, 2007). Kat Bowman explained:

From day one of being here one teacher, we love her to death, saw he was different and she pushed him to stay different. He is very smart. She didn't keep him on the level of Kindergarten. She pushed both of my children to the next level.

In order to meet the variety of needs found within classrooms, professional development is essential. The Blue Sky teachers received training in the Dan Mulligan Strategies. Sue Adams was the professional development representative who coordinated and planned building level learning activities for teachers. Sue Adams shared:

We have certain days, but one of our major focuses is the Dan Mulligan Strategies that we use, which we call the Lightning Ridge strategies. We are incorporating those strategies into the classroom. It will give students various ways to approach a problem in a fun but interesting way and they catch on to it.

Pam Bryan continued, "We expect our staff to use them on a daily basis. And a lot of these strategies are based on differentiated instruction. How students learn in different ways." Jane Thomas articulated, "I always have to find that ground where I am addressing everybody's needs." 
Once teachers are provided the tools to help meet the needs of all students, it is their responsibility to make professional decisions based upon the needs of their students. Kim Mitchell explained:

I feel like it is teacher discretion if you use it. If I think it will work then I use it. If not then I will search for something else. A lot of what we have been doing with Dan Mulligan really caters to similar students and it progresses with each lesson. It all depends on what strategy you end up using.

This philosophy provided the opportunity for Blue Sky staff, to meet the needs of students classified with in the subgroups of the building population. Jim Smith explained:

...once you figure out why, then what are we going to do with the information we receive? How are we going to differentiate instruction inside the classroom so that these students are getting what they need? That is why I like the Collaborative Grant which focuses on the subgroups and how to move every student out of below basic. It is difficult to move everybody out of below basic but that is what we are doing with our dub groups. Especially when we only have one special education teacher in the building that has a huge population, I am constantly talking about how we are going to differentiate instruction.

\section{Clarity of Vision}

Relationships. Within the theme of Clarity of Vision emerged the subtheme of the relationships. Payne (2003) postulated that no significant learning occurs without a significant relationship. The researcher heard during discussion with parents that it was not just the open door of the building administrator, but the open door of the classroom for all stakeholders. Bob Jones illustrated this philosophy by stating:

He is a professional so they also trust that he knows what is best for their students. He welcomes them to come to school any time they want. He is one that does not require an appointment. We have a lot of schools that say you can come but you have to give me a day's advance notice. He is pretty much an open policy and they can come out and put a chair in the back. He is always inviting parents in. there are no secrets it is transparent.

Conversations between all participants will support the development of a culture that revolves around student learning (Johnson, 1997). Josie Smith supported this statement by adding, "It is a very open door school. With Mr. Smith you can go in and talk to him. He will 
make time for you. I have never had a problem with the teachers. There is a very open door policy here. I have never been denied up here.” Within high poverty, urban school settings parent involvement can be a challenge, thus the more barriers that are removed from allowing and promoting parental involvement, the better.

Teachers also believed that Mr. Smith was there to support them and expressed their admiration and trust. Sue Adams shared:

Well, even though he has high expectations one thing he lets everyone know at the beginning of the year is that he has an open door policy. Any time that you have a concern you are welcome to come through the door, set a time with the secretary, or if he is available he will see you at any point.

Finally, Kim Mitchell expounded:

I feel he is very supportive. If you come to him with anything I feel he supports you whether it is with families or with any issues you are having. I feel like he is a true advocate for the teachers that are here at this school.

Trust and admiration are imperative when developing relationships in order to meet the challenges educators encounter (Bass, 1895; 1999; Bush, 2003; Schein, 1992; Yukl, 2009). Mr. Smith said confirmed by asserting, "It is an open line of communication. My door is always open. If there is a problem you can talk to me about it and then we will come up with a solution." He continued by stating:

In order to build a school you have to build a community. It has to be a family. If one hurts we all hurt. If one suffers we all suffer... it is building a family, but also taking care of business. They are valued. They are respected. They are honored when they do a great job.

Students also feel the support of the administrator. This was evidenced by Jane

Thomas when she indicated, "He has a pretty personable relationship with a lot of students.

They are free to go up to him and talk to him." Sue Adams added:

He is big on data conferences with students. With the students he is assigned for his data groups meet with him they openly share and discuss. If they are not making the gains they need to make he helps them to set goals and encourages 
them. Passing them in the hall students are constantly coming up to him telling him about their scores.

Kim Mitchell continued, "He acknowledges them and the successes they are having in their classroom. I know it is big for my kids." Knowing that during every interaction the conversation will be turned back to academics and how you will reach your long term goals. One student entered the office. This student was there to share her success with Mr. Smith on the recent progress monitoring test. Mr. Smith stated, "You have to start by knowing where they want to go and their career path. When a student wants to be a doctor, I say then a doctor needs to continue to read, to write in order to research things." He emphasized, "If a student is sent to me. I will always turn the conversation back to academics. I am not about suspending kids. If they have missed 20 days of school that is 20 days of missed learning."

Clear Expectations. The notion of clarity of vision promotes the school's vision to be clear, consistently shared and emphasized with both parents and staff. How a leader conveys a message to participants communicating goals and expectations is a quality necessary for progress and sustained growth (Schein, 1993). When asked what the vision of Blue Sky Elementary was Kat Bowman shared, "We expect every child to succeed and be prepared for secondary education. Every child is getting a good education." The communication and importance of the vision is communicated to parents throughout the school year. Josie Grant recalled, "We received an introduction letter was sent from the principal at the beginning of the school year. I remember receiving a mailer where he talks about his expectations. The teachers provide a mailer as well. It is a very consistent message." Kat Bowman added, "The vision is communicated through test scores. The principal does three assemblies a year and he lets the parent body know how they are doing or how the students did with their state testing." 
Mr. Smith's expectations were also clearly articulated with in the weekly Rocket News circulated to teachers each week. Teachers were expected to post lesson plans outside of their classroom for the week. Objectives must be posted with in classrooms. Student work samples were to be displayed in classrooms. When Mr. Smith walked into a classroom, students would be questioned as to what they were learning and why the subject matter was important. Jane Thomas explained, "He looks for evidence in the classroom with what the children are doing, what is on your board.” Kim Mitchell added, "Mr. Smith came into my room multiple times this year. He spoke with my children asking them what they were doing. So the expectation is very high and I think every staff knows that." Also found within the Rocket News was the expectation that at least one to two Dan Mulligan strategies must be implemented per lesson. Kim Mitchell supported this when she stated:

He has made it clear that he wants one to two strategies in every lesson. He wants students to know what they are supposed to be doing. He will ask students what they are doing and why it is important. So it is important as a teacher to make sure you are telling the kids the objectives and they know what they are doing in your classroom.

Teachers were also expected to have ongoing conversations with students regarding their data and progress with in the classroom. The expectation was that every student be aware of their current scaled score and grade equivalent. Teachers were then expected to set goals with students and progress monitors their growth toward obtaining their goal. With this data, teachers were expected to implement differentiated and small group instruction on a daily basis. When Jim Smith was asked what his expectations for his teachers were, he emphatically stated, “Teach!” Later he articulated:

It has to come from here (pointing to his heart). Is it you who really want to do what is best for children? I feel $95 \%$ of teachers here have teaching at heart. They want to teach. They want to be here. They want to work with children. They come prepared to teach. You see that when you come into the classroom. I have never been embarrassed taking someone to a classroom. 
Motivation. A third subtheme identified by the researcher was motivation. Once relationships were developed, expectations made clear, it was time to motivate stakeholders to achieve. It is necessary to understand that all participants bring multiple perspectives, experiences, and biases to the school community (Bass, 1990). A building administrator has the daunting responsibility of managing and motivating all stakeholders to perform to the best of their ability and supporting the overall vision. Jim Smith has worked to create a culture centered around student success, along with an environment which supports healthy competition and determination to succeed. Kim Mitchell confessed:

I am a very competitive person by nature so just always trying to meet his expectations is something that motivates me. I look at myself and I expect myself to be the best. Where he is putting the standard at, I want to try and always reach it or exceed it at some point.

Pam Bryan added:

He lets us know when we are doing a good job. He likes to share good news. When something good happens at school he does not take credit. He gives credit to others. He rewards with little things like lunches and jeans days...He is very good about letting us know when we are doing well.

Jim Smith shared the importance of recognizing his staff. He explained:

It is acknowledging the good things that people are doing constantly. In our Rocket News there are always kudos given to several teachers that are doing a great job. People want to be recognized for the work that they do. They may not act like it but trust me they do. It is building a community. It is building a family, but it is also taking care of business. They are valued. They are respected. They are honored when they do a great job. If it is not going well, I have a private conversation. I do not do to a person I would not want done to me. I don't want to be embarrassed in front of my colleagues. That is the respect piece that I see missing sometimes in schools.

As one enters Blue Sky Elementary he or she may notice a wall full of plaques displaying the

highest classroom scores for the district. Numerous teachers have earned this prestigious honor.

Bob Jones explained:

He sets the high goals and the competitive attitude he has just kind of permeates through. When they do that well they feel the best as a family and school environment and school community. They feel supported by Mr. Smith. They feel 
welcomed by Mr. Smith. They feel he puts them on a pedestal and brags to other schools about them. It is a very positive atmosphere that he creates for his teachers and they know that.

When expectations are high, motivations is also a key component, when focusing on moving students in order to realize their goals. When asked what he does to address the achievement gap Mr. Smith stated:

I don't just focus on Blue Sky. I focus on the surrounding schools in the area. I focus on elementary schools in Adams (pseudonym). I focus on elementary schools in Backwater (pseudonym). I focus on elementary schools in Grant (pseudonym). You go to DESE and put in Blue Sky as well as the surrounding areas and it will let you know exactly where you are according to MSIP 5... I share that data with the teachers and then I share that with students. They strive to do even better so they can continue to compete in society.

Ivy Ray supported Mr. Smith's process when she shared:

I believe he is treating the students with respect and makes them accountable, why they have to follow rules, do your homework. He has given them a path to get what they want to do in life. Whatever that may be, for you to get to this point you have to do well here, here, and here. I think they really understand that.

In order for successful reform efforts to be implemented, all participants must be working toward the same common goals and be motivated to meet the challenges (Bolman \& Deal, 2008).

\section{Summary}

The objective of Chapter Four was to provide a detailed account of the design of the study, data collection, conceptual underpinnings, research questions, outline of data analysis, general results, and specific findings. The setting and participants of the research were outlined by the researcher to define the context in which the study was conducted. By reviewing the data through the lens of Transformational Leadership, the researcher was able to ascertain themes related to the leadership characteristics of the building principal in a high-poverty, highachieving school. Outlined in Chapter Five are detailed discussion of the findings, limitations of the study, as well as implications for leadership practices and recommendations for future study. 


\section{Chapter Five}

\section{SUMMARY, RECOMMENDATIONS, AND CONCLUSIONS}

The purpose of this narrative case study was to identify and examine the characteristics of effective leaders in high-poverty, high-achieving schools in a single school district located within an urban setting. Transformational leadership provided the conceptual framework for the research. A thorough examination of the data allowed the researcher to ascertain transformational leadership practices and structures that led to the success of students comprising the population of the case study school. The data collected throughout the study were triangulated through comparison of interviews and focus group sessions, as well as documents collected. Member checking was instituted to allow for the authentication of the interviews and focus group sessions. This case study examined a "problem of practice" (Creswell, 2007) present in schools across the nation: what do effective school leaders do to promote high academic achievement?

Two emergent themes were identified from the analysis of data and the implemented coding system. The first theme which emerged was Achievement, which was supported by: (a) a community of learners, (b) data-driven decisions, (c) accountability, and (d) differentiated instruction. The second theme identified was Clarity of Vision, which was supported by: (a) relationships, (c) clear expectations, and (d) motivation.

A summary of findings related to the research study along with conclusions based on the date analysis will be conveyed in Chapter Five. In addition, the implications of practice and recommendations for future study will be advised. The qualitative outline of this narrative case study allowed the researcher to tell a story through the first hand experiences of the participants (Creswell, 2007; Merriam, 1998). Through the interview and focus group process along with onsite observations, accounts of the experiences and beliefs of all participants were gathered by the 
researcher (Creswell; Stake, 2012). Conversely, the researcher captured the prevalent insights regarding the leadership characteristics she experienced which, in her mind, contributed to the success of students.

\section{Summary of Findings}

The overarching question associated with this qualitative case study was: What transformational leadership traits are present in high-poverty, high- achieving schools as perceived by faculty and staff, students, and administrators? Transformational leadership represented the lens through which this study was defined. For the purpose of this study, transformational leadership was identified by the following characteristics: motivation, intellectual stimulation, individualized consideration, and promoting a common vision and shared values. Additionally, transformational leadership promotes the moral issues of justice and equity (Avolio \& Bass, 1991; Burns, 1978; Firestone \& Heller, 1995; Leithwood, 1994). Bass (1999) , Bolman and Deal (2008), and Bush (2003) contended that transformational leaders inspire constituents to rise to the occasion in order to meet the challenges of their universal needs and purpose.

Two themes emerged as data was reviewed related to the perception of stakeholders regarding transformational leadership characteristics: Achievement and Clarity of Vision. Based on the conceptual framework presented within the context of this study, the researcher sought to provide answers for the following questions:

1. What transformational leadership traits of the principal are present in a highpoverty, high-achieving school as perceived by teachers, parents, and the principal's supervisors?

2. How does the contextual environment of high-poverty within a school community influence the transformational leadership style of the principal? 
3. How do the transformational leadership traits of the principal change behaviors of the teachers and parents?

Through the summary of the data analysis process presented in Chapter Four, consensus among teachers, parents, and administration emerged the idea of accountability and clarity of vision. Within the analysis of data the many stories shared by teachers, parents, and administrators were an authentication of their insights concerning the leadership qualities of the building principal and the impact on student success.

The review of relevant literature clarified the importance for the researcher to develop a complex picture of the problem or issue under study (Creswell, 2007). It was also necessary in order that the participants included in the sample population had spent extensive time within the context under study (Creswell; Stake, 2000). The transformational leadership lens, which directed the study, was composed of four principles (Bass, 1999; Bush, 2003; Schein, 1992; Yukl, 2009). Through the analysis of data each of the four principles were identified and supported by the triangulations of data.

The first principle of charisma materialized through the subtheme of accountability and clear expectations supporting the main emergent themes of achievement and clarity of vision. Accountability was evident through observations, interviews, and focus groups. Sue Adams shared:

He is a believer in strong instructional practices. He is asking to see one or two strategies per lesson for the various subjects so you have student on their feet not just sitting there with a sit and get type lesson. He wanted the classroom to be an interactive environment and not just students sitting there bored with instruction. Engagement needs to be high.

Motivation was the second principle of transformational leadership which emerged through the themes of achievement and clarity of vision, as well as the subthemes of clear motivation. It was necessary for the building principal to understand 
that all stakeholders bring multiple perspectives, experiences, and biases to the school community (Bass, 1990). The building principal has the daunting task of managing and motivating all stakeholders to perform to the best of their ability (Bass, 1999; Bush, 2003; Bolman \& Deal, 2008; Yukl, 2009). Pam Bryan shared:

He lets us know when we are doing a good job. He likes to share good news. When something good happens at school he does not take credit. He gives credit to others. He rewards with little things... He is very good about letting us know when we are doing well.

Individual consideration is the third principle of transformational leadership that emerged through the subthemes of community, data-driven decisions, and differentiated instruction supporting the overarching themes of achievement and clarity of vision. For any organization to be successful, participants' needs and goals must be met (Bolman \& Deal, 2008). Jim Smith arrived at Blue Sky Elementary focusing on building a community, learning, meeting the needs of participants, and building a partnership that focused on keeping children at the forefront of any decision that was made. Once the community developed, Mr. Smith began to focus on the importance of data and the importance of moving students and monitoring growth based upon the needs of individuals. Mr. Smith articulated:

Once data comes in and your students are falling below where they need to be, we need to ask why. Once we figure out why, then what are we going to do with the information? How are we going to differentiate instruction inside the classroom so that these students are getting what they need?

Finally, the fourth principle which emerged was intellectual stimulation. Such principle emerged through the theme of achievement and the supporting subthemes of differentiated instruction and accountability. To ensure success, one must have accountability and successful leaders work to maintain the focus of all participants on the needs of the students (Protheroe, 2001). With the belief that all students will be successful and reach their full potential, it is necessary to focus on each child as an 
individual; one must thus understand that the educational system was not meant to educate all students in the same exact way (Gardner, 2002; Neuman, 2009). Teachers must therefore be prepared to meet the needs of students. Pam Bryan shared:

We use our vision to help us with differentiated instruction. We know we can't reach students in the same way, students learn in different ways. So we do a lot of small group instruction.

Kim Mitchell added, "He gives you feedback whether it is through 360 feedback or if there is an issue it will be addressed."

Student expectations are made clear from the very beginning of school. During the first week the building principal went to each classroom and discussed academic and behavioral expectations. If a student was not successful, a parent meeting was scheduled and goals were developed to help the student improve either behaviorally or academically. Josie Smith specified:

His expectations from the staff down to the children, the expectations are visible. For example you show up on time, the way the staff dress, and how the students are to dress. Some people might thank that doesn't mean anything but is does. It gives you a sense of pride.

She also continued with, "They put the scores up and discuss how every child is going to be at grade level or above, implementing the tutoring, enforcing homework." Such motivating leaders exhibit desirable qualities when communicating and promoting the expectations while at the same time promoting and enforcing high expectations (Bass, 1999; Leithwood, 2004; Schein, 1992; Yukl, 2009).

What transformational leadership traits of the principal are present in a high-poverty, highachieving school as perceived by teachers, parents, and the principal's supervisors?

Through the review of relevant literature, the examination of transformational leadership theory provided the several important characteristics necessary for school reform (Bass, 1999). 
Such transformational leaders inspire constituents to rise to the occasion in order to meet the challenges of their universal needs and purpose such as school reform (Bass; Bolman \& Deal, 2008; Bush, 2003).

The review of literature provided the researcher the opportunity to explore various leadership theories such as instructional leadership, distributive leadership, social justice leadership, and transformational leadership. Components from each leadership theory were present at one time or another through the observations, interviews, and focus groups. Specifically, the principles of transformational leadership most closely represent the leadership style and characteristics present at Blue Sky Elementary and reflective of Mr. Jim Smith.

The first principle of transformational leadership presented to the researcher was charisma. Charisma is one of the main components of how a leader communicates major assumptions and beliefs in a clear manner as well as the expectation for high performance (Morgan, 1997; Schein, 1992). Trust is an additional component of charisma and followers are impressed with a leader who risks substantial personal loss (Yukl, 2009). The themes of accountability and Clarity of Vision fit well within this principle as well as the subthemes of accountability, clear expectations, and relationships. The teachers believe that $\mathrm{Mr}$. Smith is there to support them and expressed their admiration and trust. Sue Adams explained, "Even though he has high expectations, one thing he let everyone know at the beginning of the year [is that] he has an open door policy.” Kim Mitchell expounded:

I feel very supported. If you come to him with anything, I feel he supports you whether it is with families or with any issues you are having. I feel like he is a true advocate for the teachers that are here at his school.

Trust and admiration are imperative when developing relationships in order to meet the challenges educators face (Bass, 1985; Bass, 1999; Bush, 2003; Schein, 1992; Yukl, 2009). Mr. 
Smith explained, "In order to build a school you have to build a community...It has to be a family."

Within a school community or family, how a leader conveys a message to participants communicating goals and expectations is a quality necessary for progress and sustained growth (Schein, 1993). When asked about the vision of Blue Sky Elementary, Kat Bowman responded, "We expect every child to succeed and be prepared for secondary education. Every child is getting a good education." The communication and the importance of the vision is communicated to parents throughout the school year. Josie Grant recalled, "We received an introduction letter from the principal at the beginning of the year." Kat Bowman added, "The vision is communicated through test scores. The principal does three assemblies per year and he let the parents know how they are doing." Both participants agreed it was a very consistent message.

Mr. Smith clearly articulated his expectation in the Rocket News circulated to teachers each week. Teachers were expected to post lesson plans outside of their classrooms, and students were questioned as to what they were learning and why the subject matter was important. Jane Thomas explained, "He looks for evidence in the classroom with what the children are doing." Kim Mitchell continued, "He has made it clear that he wants one to two strategies in every lesson. He wants students to know what they are supposed to be doing." When Mr. Smith was asked what he expects from teachers, he emphatically stated, "Teach!” Later, he expressed that teaching has to come from the heart.

Parents also emphasized the open expression of care, concern, and support. One basic ideal that fostered Jim Smith's actions was the philosophy you have to treat others the way you want to be treated. Children and staff were listened to and had a voice. Kat Bowman and Josie Smith explained that children at Blue Sky were listened to, felt safe, and enjoyed coming to 
school. Mr. Smith encompassed his beliefs by sharing a quote from a plaque given to him by a staff member: It is a rare person that can take care of hearts and take care of business.

The second principal evident throughout the observations, interviews, and focus groups was motivation. Motivation itself was a subtheme which emerged from the overarching theme of Clarity of Vision. Building administrators who lead organizations through major change reforms must forge a vision and build a capacity for change by working collaboratively and motivating all stakeholders (Bass, 1999; Bush, 2003; Schein, 1992; Yukl, 2009). Leaders must also assist participants in achieving their goals and providing them with direction and support to endure the individual goals necessary to supporting and sustaining the overall goals of the organization (Bass; Bush; Yukl).

Through observation, interviews, and focus groups, it was evident to the researcher that Jim Smith had worked to develop a culture not only centered on student success but also a climate which fostered a healthy competition and determination to succeed. Jim Smith shared, "It is acknowledging the good things that people are doing constantly." He continued with, "People want to be recognized for the work that they do. They may not act like it but trust me they do." Bob Jones supported this trait by sharing:

He sets high goals and the competitive attitude he has just kind of permeates through. When they do that well they feel the best as a family and school environment and school community. They feel supported by Mr. Smith. They feel welcomed by Mr. Smith. They feel he puts them on a pedestal and brags to other schools about them. It is very positive atmosphere that he creates for his teachers and they know that.

The third principle identified from the data collected was individual considerations. Leaders practicing transformational leadership understand and support individual goals while inspiring and focusing participants on the overall goal of the school (Bass, 1999; Bush, 2003; Yukl, 2009). Additionally, a transformational leader understands that all participants bring multiple perspectives, experiences, and bias to the school (Bass, 1990). 
Such principle is evident within the overarching themes of achievement, specifically within the subthemes of data-driven decisions, accountability, and differentiated instruction. Jim Smith worked to coordinate efforts of all participants toward the common vision that all students would meet their full potential.

Understanding that data is a powerful tool for the staff a Blue Sky Elementary when working toward moving students and monitoring their growth is important. Mr. Smith explained that analyzing data allowed teachers to figure out what needs were not being met within their classrooms. Once that information was gathered, the opportunity to differentiate instruction was provided. Sue Adams confirmed the focus on data by stating, "Each room has a data wall. So teachers are responsible for having data conversations."

In order to meet the needs of diverse learners, teachers were provided opportunities for professional development which focused on meeting the needs of a group of diverse learners. Kim Mitchell explained that from the professional development it was up to the teacher to implement the Dan Mulligan instructional strategies to meet the needs of their students. What occurred in the classroom was based on teacher discretion as well as the needs of the students and how the teacher felt he or she was able to best meet their needs as learners.

Finally, the fourth principle evident from the data was intellectual stimulation. Bauck (1987) labeled effective school leaders as more committed to professional development than management. This principle materialized within the overarching theme of achievement and the subtheme of differentiated instruction and individual considerations. As teachers analyzed state assessment data, benchmark data and progress monitoring data, they were constantly looking at each individual child. 
For this reason, differentiated instruction had been the focus for professional development. Sue Adams explained the major focus of professional development had been differentiated instruction and strategies that would meet the needs of students. Jane Thomas shared, "I always have to find that ground where I am addressing everybody's needs.” Mr. Smith also utilized observations to provide intellectual stimulation for his teachers. As he observed classrooms each week, if he consistently saw missing components necessary for effective instruction, that component would be addressed through professional development. Also the information would be reiterated through weekly staff newsletters.

How does the contextual environment of high-poverty within a school community influence the transformational leadership style of the principal?

Transformational leaders understand that all participants bring multiple perspectives, experiences, and biases to an organization (Bass, 1999; Bolman \& Deal, 2008; Bush, 2003; Yukl, 2009). Transformational leaders must understand situational context in order to fully understand how to solve the problem (Grint, 2005). When asked to describe the school community, Mr. Smith shared, "It is a community of learners. The children are exceptional. The parents and community are very supportive." Sue Adams shared:

Our parents are very serious about their children's education. We have parents that need you to be on top of everything so that is something important to know. Communication is big here. Parents want to have information communicated to them they look forward to our weekly newsletters, phone calls. They know teachers are always going to do that. Getting constant communication is number one.

Kat Bowman described the community at Blue Sky Elementary by sharing:

I think it as far as a community it feels like a family style. That is what I have experienced here. And what I am talking about is that from the principal down to the teachers. I have always had a great working relationship with the teachers. They have allowed me to email them and text them...It has that small feel that 
everybody seems to know everybody. If you don't know you will know and you will know if you get involved in the activities.

With the understanding that parents wanted to be involved, Mr. Smith worked to develop a community focused on the achievement of students. The discussion between participants allowed for the development of a positive climate where learning was valued (Johnson, 1997). Parents emphasized the open expression of care, concern, and support. Parents and teachers were able to communicate individual concerns and needs. Josie Smith stated, "With Mr. Smith you can go up to him and talk to him. He will make time for you." This ideal allowed for Mr. Smith to illustrate a common message of high expectations, individual considerations, and motivation.

By understanding that parents are committed to the success of their students and believe in the community at Blue Sky Elementary, Mr. Smith conveyed a message that all participants worked together to build an exciting future, a clear plan for achievement, and confidence that it would happen (Bass, 1999; Leithwood, 2004; Schein, 1992; Yukl, 2009). Not only did teachers and administration analyze student data and plan for growth, but this information was also communicated to parents. Individual student information was sent home multiple times throughout the year. If there was a concern, parent meetings were held to include administration, parents, and teachers. This process worked to motivate participants to collaborate for the success of students. Charisma, motivation, individual considerations, and intellectual stimulation are all transformational leadership characteristics prevalent as a result of the contextual environment. How do the transformational leadership traits of the principal change behaviors of the teachers and parents?

Transformational leaders motivate participants to exhibit desirable qualities in order to promote organization goals, promote and enforce high expectations, and display confidence (Bass, 1999; Morgan, 1997; Schein, 1992). Mr. Smith shared, "I came in focusing on building a community. We are in this together. We are a partnership.” Through this transition behaviors 
changed. Data became a major focus of the school community. The administration, teachers, and parents focused on student data and growth. Individual needs were a primary focus through professional development for teachers and differentiated instruction for students. Pam Bryan stated, "We have a lot of data talks. Our school is data-driven." There was a clear focus that supported the charismatic principle of transformational leadership.

Accountability and motivation also stood out as a change that had occurred throughout Mr. Smith's four years. Sue Adams illustrated changes that had occurred by sharing:

Everyone is held accountable, no matter if you are a para, in the kitchen, or a teacher. Everybody is held accountable. . It was easier to not be as good as they could be. He wants to get rid of any excuses so he will give you any support that you need. So it can't be I didn't have this or I didn't have that. If you need the resources you will get it. He wants to give you every reason to be successful.

Jane Thomas also agreed that the expectations had changed from the old administration to Mr. Smith, as there was a marked difference in how well the students performed on standardized tests. That is very clearly Mr. Smith's focus. Thus it is now the focus of the entire school community. If an individual did not hold the same expectation or belief, he gave that individual a chance to improve as well as their sources needed to improve. It is common knowledge that teacher attrition in the first several years is quite high relative to other professions; one might question if the motivations of many of these teachers were not as aligned to the teaching and learning of students as they perhaps should have been. It is clear that accountability and motivation are traits that influence and change behaviors of parents and teachers. When Mr. Smith was asked how his expectations have changed he responded:

I have seen too many teachers fail students many, many ways with their attitudes, their beliefs. Not really wanting to teach but just hang out. I have become firm in my beliefs. I have always expected great teaching to take place. If you are not teaching here in this building, you will not be here long. 


\section{Conclusions Based on Findings}

This qualitative research approach allowed the researcher to develop a complex picture of a natural setting. In order to examine the leadership qualities present in high-poverty, high achieving schools, such qualitative research methods allowed the researcher to experience indepth description of a specific setting (Creswell, 2007; Mertens, 2007). Found within the research setting were multiple perceptions of participants involved in the study which supported the idea that qualitative research is rooted in the belief that meaning is socially constructed by individuals through interactions (Creswell; Merriam, 2004; Yin, 2003). For this reason an on-site single case study was selected.

Such case study allowed the researcher to learn about a distinct and complex situation. As a result, multiple forms of data were collected and utilized to conduct analysis of the data. The researcher provided the following conclusions related to the findings of the study of transformational leadership characteristics present in high-poverty, high-achieving schools as perceived by faculty, parents, and administration.

\section{Achievement}

Achievement represents the first principle ascertained from the data analysis. Four additional subthemes emerged as essential components of achievement: community, data-driven decisions, accountability, and differentiated instruction. Thus, the first emerging conclusion from the data presented as it relates to transformational leaders within a public school setting is that a transformational leader cultivates a community which focuses on utilizing data to individualize instruction through differentiation and holding one another accountable in order to ensure the clear focus and common goal of academic success of all students.

Through the process of observations, artifact and document analysis, interviews, and focus groups, the researcher discovered that the principal of a high-poverty, high-achieving 
school must clearly understand the process of positively impacting student achievement through a community of data-driven learners. Such learners include parents, students, staff, and administration. This conclusion is supported by Bauck (1987), Bernhardt (2004), Chenoweth (2009), and Duke (2004) as they postulated that leaders within low-performing schools must focus on assessing and redefining skills, commit to meaningful and ongoing professional development, and utilize a variety of data sources to continually monitor student growth. The coordinated effort of participants towards the achievement of common goals by creating an environment which provides clear direction and support is an indispensable characteristic of the transformational leader (Bass, 1999; Bolman \& Deal, 2008; Leithwood \& Riech, 2003). The transformational leadership of the principal permeated the opinions of the participants and, according to the data collected, had direct association to the achievement and progress of the students. If teachers stray from the expectation, look away from utilizing data to inform instruction, or trudge along with the status quo, they are addressed. Sue Adams shared:

Our overall vision is to educate all students to their greatest potential, meeting them where they are but we want to push them to the limit. As far as we can get them and they can meet their greatest potential.

Dr. Bob Jones, the direct supervisor of Mr. Smith, contended:

He is very involved. It is part of his style. He gets students involved. A good example is we have board meetings we have all the schools come to, it is a brag night. They come and do a presentation. Last year he actually had his student come and present where they were with MAP preparation, they explained what their MSIP score would be. So not only is it focused on how student achievement is measured it is focused all the way down to the students. The students know if they are or not being successful based on achievement measured by the state. So he has gone through and it has permeated the whole building. Everybody knows how to calculate MSIP scores, find out status points, and progress points.

Finally Pam Bryan confirmed such characteristics by elaborating:

Our school is data-driven. We have data walls and data folders. From those two things we have data conferences with our students where we try to communicate with them where they are at based on their performance in the classroom where their goals are. We discuss with our students what their goals will be to move 
forward and what they need to do in order for that to happen. We use our vision to help us with our differentiated instruction. We know that we can't reach students in the same way, students learn in different ways. So we have a lot of small group instruction or where the students are working in groups of two or three working on skill that they need.

It is evident through the review of literature and the analysis of data collected that the data-driven community focusing on meeting the needs of all students and enabling to reach their utmost potential transcends from the principal, to the teachers, to the parents, to the students. Such a transformational leader empowers followers and makes them less dependent on the leader. One delegates authorities, which allows followers to develop skills and build self-confidence resulting in a culture of empowerment (Yukl, 2008). Understanding key principles evident within successful schools such as Blue Sky Elementary can assist struggling schools in meeting the needs of students and directly impacting student success. The contributing subthemes are depicted in Figure 1.

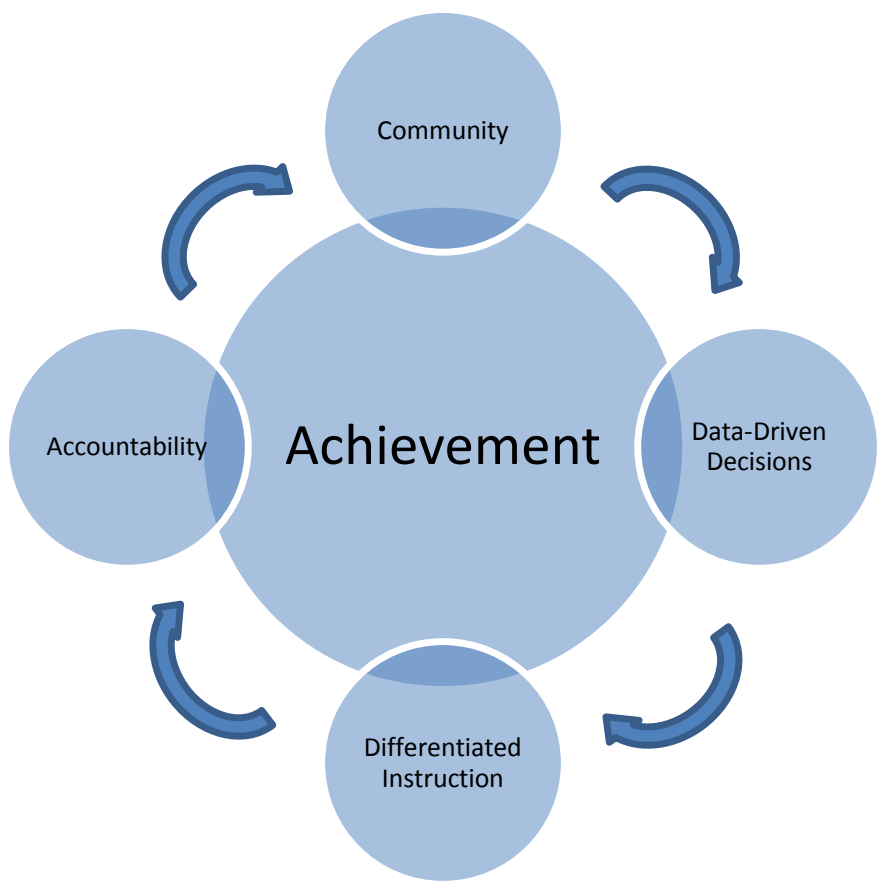

Figure 1: Contributing subtheme resulting in a positive impact on Achievement.

The diagram presented in Figure 1 represents the four subthemes which together and build upon one another to support and surround the focus and overarching theme of Achievement. Such a 
process works to support administrators focusing on meeting state and federal mandates for student achievement. Overwhelmingly, state and federal mandates continue to demand school administrators assist teachers to improve student achievement (Bass, 1985; Casbarro, 2005; Knipe \& Speck, 2002; Lewis, 2002). As educators seek to implement leadership that will promote student achievement, resulting in successful school reform, these same leaders embrace a skill set that will sustain the test over time and continually promote improvement (Farnsworth, 2010; Yukl, 2008). The characteristics illustrated by Mr. Smith at Blue Sky Elementary have resulted in identifying key components necessary for developing a community focused on successful student growth and achievement.

\section{Clarity of Vision}

Clarity of Vision for all participants emerged as the second overarching theme identified through the data analysis process. Three subthemes presented as necessary components of the theme of Clarity of Vision: relationships, clear expectations, and motivation. According the Mr. Smith, all three subthemes are necessary when working toward promoting and sustaining student achievement. Relationships must be fostered and trustworthy in order for expectations to be clearly communicated and allow for the motivation of all participants to succeed.

Teachers and parents believed that when any situation occured Mr. Smith would be there to support them. They trusted that he would be open and honest when it came to his expectations and that his door was always open when a concern may arise. Kim Mitchell shared, "I feel he supports you whether it is with families or with any issue you are having. I feel he is a true advocate for the teachers that are here in his school." Parents also recognized the importance of developing a relationship. Josie Grant explained, "It is a very open door. With Mr. Smith you can go in and talk to him. He will make time for you." This was evident through multiple interviews and focus group sessions. As the researcher reviewed weekly newsletters the invitation was 
continually extended to visit with Mr. Smith regarding support one may need. Mr. Smith's main focus when dealing with participants and relationships within his school community boiled down to the adage of treating others as one would like to be treated. He continued by stating, "In order to have a school you have to have a community. It has to be a family. If one hurts we all hurt. If on suffers we all suffer."

As relationships materialized, so did the expectations. When asked what his expectations for teachers were, Mr. Smith stated, "Teach.” Later he added it is truly teaching from the heart. It is wanting to be present teaching students every single day. It is an expectation of every participant that they understand the data. Data is collected from the state assessment program, district benchmarking data, and progress monitoring data. The researcher found within the weekly newsletters reminders for teachers to analyze their district benchmarking data and progress monitoring data for their class. Then, once that was completed, they were expected to have data conferences with students surrounding the student's individual data. At any time Mr. Smith expected any student to be able to discuss their progress and relate it back to their individual data. Kim Mitchell explained, "It is our structure here. You can’t have effective teaching and learning if you don't have structures. We set goals and watch their progression. They want to know how they are doing." When teachers were asked what processes and structures were put in place by Mr. Smith it was clear that he expected the students to be the center of the classroom. Teachers were expected to share the data with the students. Lesson plans were posted outside of classrooms each week for visitors to assess at any given time. Objectives were to be posted in the classroom and when Mr. Smith visited classrooms each week, it was an expectation that students be able to explain what they were learning and why it was important to learn it. Pam Bryan cemented this subtheme by stating, "I think it really comes down to the 
expectations. When you have high expectations not unrealistic, you show that you believe in your staff and your students."

Motivation is the final subtheme presented within the overarching theme of Clarity of Vision. Mr. Smith's active involvement throughout Blue Sky was critical when discussing motivation. The first motivating factor was the data. First, the data was reviewed and shared by Mr. Smith. Data was shared with teachers, students, and parents. . Teachers and students discussed the data and set goals, which were then communicated with parents. Progress monitoring the goals that had been set was a continuous process. Students were motivated by competition and by success to continually reflect on and obtain their goals. When students reached a goal that had been set rewards ensued. Students achieving proficient or advanced on the Missouri Assessment Program received t-shirts. These t-shirts were worn every Friday instead of the regular school uniform. Student often frequented Mr. Smith's office to share good news when goals were met. The researcher observed such an event when one of two observations was conducted. Sue Adams shared, "He is big on data conferences with students...passing them in the hallway they are constantly coming up to him telling him about their scores. He is constantly encouraging them."

When it comes to motivating staff Mr. Jones shared an important statement when describing Mr. Smith. He stated, "He brags on his teachers...he writes them notes about how well they are doing as well as any kinds of issues." During one of the researcher's observations, Mr. Smith stopped at a wall present in the front entry. The wall was lined with plaques with teacher pictures and names. Each place displayed the teacher or teachers who had received the highest scores in the district when compared to other buildings. Teachers could also find their names listed in the weekly newsletter giving them extra accolades when outstanding things had 
occurred. The pride was evident when Mr. Smith talked about his school. He excitedly shared, "I have never been embarrassed taking someone to a classroom."

Clarity of Vision has allowed Sky Blue Elementary to commit to relationships that are centered on open communication, trust, and support. With strong relationships in place clear and exposed expectations are shared and reinforced through motivation. When all three components fuse Clarity of Vision is evident. Figure 2 illustrated the fusion of relationships, clear expectations, and motivation the three subthemes essential for true Clarity of Vision indispensable for successful school reform.

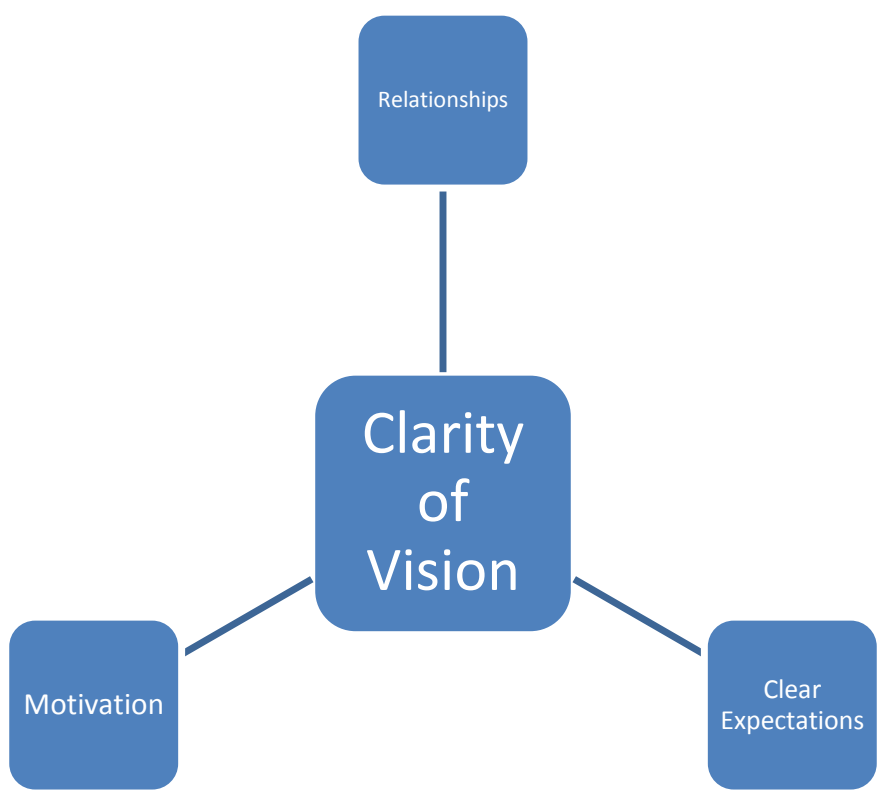

Figure 2: Clarity of Vision fusion of relationships, clear expectations, and motivation.

The fusion of all three subthemes of relationships, clear expectations, and motivation work to support clarity of vision a necessary component to successful school reform. Mr. Jones said it best when he shared, "There are no secrets; it is transparent."

The conclusions derived from the findings of this research study, identified the transformational leadership characteristics presented in and high-poverty, high-achieving school. The overarching themes and subthemes presented ultimately work together to support the overall 
clear vision of Blue Sky Elementary that no child will be left behind and all students will reach their full potential.

\section{Limitations}

All research studies have limitations and the researcher should acknowledge the limitations in order to design a thorough and reliable study (Heppner \& Heppner, 2004; Yin, 2003). One challenge met by the researcher was the amount of time needed to conduct a detailed investigation and compile the rich data necessary for an effective case study (Merriam, 1998). It was also important to concede the time restrictions of the participants and those constraints encountered by the researcher. As participants were contacted to request their participation in the study, the participants were individuals every involved within the school community. If individuals who were less active within the school community had agreed to take part in the study, the findings may have been different. In addition, participants may view the researcher as interfering and meddlesome. To ensure the accuracy of interviews and focus groups participants, the researcher received permission from the Institutional Review Board from the University of Missouri, Columbia (see Appendix A). Prior to conducting interviews and focus groups the participants completed and agreed to an informed consent (see Appendix B). Member checking was also executed following the transcriptions of interviews and focus groups to ensure accuracy and reliability.

A second challenge was the researcher's personal bias encountered through personal experience with leadership and high-poverty students; keeping this in the forefront when conducting interviews with administrators and additional stakeholders was therefore intentional. For this reason, the researcher implemented various methods of data collection to ensure reliability and validity of the data and allow for triangulation (Creswell, 2007). 
This research study also only considered a single case. Merriam (1998) stated a single case study can oversimplify or exaggerate a situation and might provide the reader with invalid conclusions regarding the actual context of the case study conducted. A single case limits the information to one site identified as high-poverty, high-achieving (Creswell, 2007; Fowler, 2004; Yin, 2003). However, a single case study allowed the researcher to proceed more in-depth into characteristics of the single site to develop a richer understanding of potential outcomes (Creswell, 2007; Merriam, 1998).

Finally, when conducting qualitative research, it is important to reflect upon how stakeholders are situated within the inquiry and how his or her personal experiences shape the study (Creswell, 2003). For this reason, when selecting a specific site for a qualitative case study, it was necessary for the researcher to utilize criterion-based selection (Merriam, 1998). As an administrator situated within a high-poverty school district, the researcher recognized biases may exist that could adversely impact the analysis of the data collected and should strive to avoid researcher bias. The researcher accomplished this through a myriad of participants and reflecting on these biases when analyzing the data.

\section{Implications for Practice}

The implications related to this research study are applicable for public school leaders who are facing the daunting task of school reform. Fullan (2001) and Marzano (2003) contended the building principal is second only to the classroom teacher when it comes to positively impacting student achievement as the principal has a direct impact on student achievement. The themes and subtheme which emerged from the research ought to be considered by any school leader and are relevant to successful school reform and directly impact student achievement.

Transformational leadership as defined by Bass (1985), Bolman and Deal (2008), Bush (2003), and Firestone and Heller (1995) as a leader who exhibits charisma, motivation, 
individual considerations, and intellectual stimulation for participants. Transformational leadership emphasizes the importance of the leader and key participants sharing a common vision and overall goals (Firestone \& Heller, 1995).

The characteristics of a transformational leader work to support the overall vision of Blue Sky Elementary and are present within the leadership according to the participants of the study. Therefore, the first implication is for school districts implementing leadership training programs to include transformational leadership along with subthemes presented in the data. Such programs should focus on how to hold conferences with parents so they feel as though they are a part of the educational process. At times conversations can be difficult when discussing strengths and weaknesses of students. As information is shared with parents, openly and honestly a transparent learning community can develop such as it did at Blue Sky Elementary.

A second implication for practice is for current building principals to implement the identified themes recognized from the research study: Achievement, with the subthemes of: community, data-driven decisions, differentiated instruction, and accountability; and Clarity of Vision, with the subthemes of: relationships, clear expectations, and motivation. The identified themes and subthemes could be implemented in any contextual situation. The impact such themes would have on any school are evident trough the research.

Finally, a third implication would be for leadership programs to introduce participants and prospective principals to transformational leadership theory with an emphasis on school reform. Future building leaders should have the opportunity to explore traits which have a lasting impact on school reform and student success. Situated within the focus of school reform, differentiated instruction should also be an emphasis within educational leadership programs to better prepare principals as instructional leaders. It is important for future principals to recognize 
the need for change and respond accordingly verses reacting to change mandates (Farnsworth, 2010; Leithwood, 1999; Marzano, 2003).

\section{Recommendations for Future Study}

Results associated with this study should enhance the current body of knowledge centered on high-achieving, high-poverty schools. Leadership theory has been identified as a critical component of effective school reform (Collins, 2001; Marzano et. al. 2005).

Comparatively, however, research regarding effective school leadership as it is related to highachieving, high-poverty schools is lacking (Leithwood, 1999). Additionally, NCLB mandates that all students should have reached the targets of proficient or advanced by 2014, unless qualifying for a federal waiver (USDOE, 2007). Thus the identification of schools who met such mandates is necessary as well as schools who have successfully worked to close the achievement gap among subgroups. From this research three suggestions for future study are recommended in this section.

The first recommendation for future research would be to conduct a multi-case study analysis of multiple high-achieving, high-poverty schools located within an urban setting with similar community populations. The implementation of a multi-case study would allow the researcher to discover numerous locations and methods to collect open-ended, evolving data one could use to develop relevant themes and subthemes for analysis and implementation (Creswell, 2007). Within a multi-case study, focusing on one issue or concern will allow multiple perspectives to be shared thus, resulting in a thick description of the context and research inquiry (Creswell; Mertens, 2005). Additionally, Yin (2003) suggested that the use of a multi-case study can reinforce the external legitimacy of the findings.

As NCLB has been reauthorized and criteria redefined, further research could be conducted to analyze the progress of individual subgroups comprising the super subgroup as 
defined by MSIP, within districts with high instances of poverty. Districts must focus on the issue of subgroups present within districts demands attention (Anderson, Fowler, \& Medrich, 2007; Haycock, 2001); Marzano, 2003). Just a social inequity exist in neighborhoods, such disparity also exists in in the public school setting (Cooper \& Crosnoe, 2007; Haycock, 2001; Leach \& Williams, 2007). Even with the emphasis on closing the gap within subgroups, the reality is such efforts have done little to close the achievement gap (Farnsworth, 2010: Marzano). For this reason a second recommendation for future research would be to study the specific subgroups present within high-poverty, high-achieving schools. This research would allow failing schools to implement measures that are proven effective at promoting student success and closing the achievement gap.

Leadership is an important factor in the school improvement process second to only the classroom teacher (Leithwood, 1994; Marzano, 2003). Leaders must continually look to increase student achievement and at the same time support teachers. For this reason the third recommendation for further research would be to study a cohort of building principals of highachieving, high-poverty schools implementing transformational leadership theory as related to the scholarly training they have received. Leadership roles have changes as a result of the reform process (Beyer \& Trice, 1993). Elmore (2002) stated that many school leaders lack the knowledge, skills, and training to implement the necessary initiatives to attain the mandated NCLB requirements. For this reason principal predatory programs must take notice in order to support the educational system by preparing leaders ready to make a significant impact in the world educations.

Finally, as Building leaders work to maintain their ability to provide strong instructional leadership it is necessary to consider professional development (DuFour and Marzano, 2001; Hallinger, 2003). Leaders must provide on-going meaningful professional development in order 
to support and sustain student success. For this reason a fourth recommendation for future study would be to study professional development provided to teachers in high-poverty, high-achieving schools. Thus enabling leaders to work with teachers to improve and strengthen both teaching and learning. Through this process a culture of learning and high expectations for teachers and students is developed (Hallinger; Mortimore, 1993).

\section{Concluding Overview}

This qualitative research study examined the leadership characteristics of a principal of a high-achieving, high-poverty school. The analysis of data resulted in identifying two overarching themes: Achievement and Clarity of Vision. As the researcher conducted interviews, focus groups, reviewed documents, and observations, the two themes permeated the data analysis resulting in a positive impact on student success at Blue Sky Elementary. Additionally, the data showed that transformational leadership characteristics are evident and have a significant impact on school reform.

The data also illuminated the opportunity and need for follow up research focusing on a multi-case study focusing on the transformational leadership styles in multiple settings of highachieving, high-poverty schools, research based on specific subgroups where transformational leadership is present in high-achieving, high-poverty schools, and to study a cohort of principals and their leadership practices as related to their leadership training.

In conclusion, when addressing the overarching question of what transformational leadership traits of a principal are present in a high-achieving, high-poverty school as perceived by teachers, parents, the principal's supervisor, and building principal, the research identified that charisma, motivation, intellectual stimulation, and individual considerations were present and directly impacted student achievement and overall student success. The participants at Blue 
Sky Elementary recognized that community, data-driven decisions, differentiated instruction, and accountability support student achievement. Additionally, relationships, clear expectations, and motivation sustain clarity of their vision that all students will meet their full potential and ensure that no child will be left behind. 


\section{References}

Amatea, E. \& West-Olatunju, C. (2007). Emerging leadership roles for school counselors in high-poverty schools. Professional School Counseling, 11(2), 81-89.

Anderson, S., Fowler, D., \& Medrich, E. (2007). Which achievement gap?. Phi Delta Kappan, $88(7), 547-550$.

Andrews, D., \& Crowther, F. (2002). Parallel leadership: A clue to the contents of the "blackbox" of school reform. The International Journal of Educational Management, 16(4/5), 152-160.

Archibald, S. (2006). Narrowing in on educational resources that do affect student achievement. Peabody Journal of Education, 81(4), 23-42.

Arnold, D., \& Doctoroff, G. (2003). The early education of socioeconomically disadvantaged children. Annual Review of Psychology, 54, 517-545.

Avolio, B. J., \& Bass, B. M. (1991). The full range of leadership development: Basic and advanced manuals. Binghamton, NY: Bass, Avolio, \& Associates.

Bernhardt, V. (2004). Data analysis for continuous school improvement (2nd Ed.). Larchmont, NY: Eye on Education.

Bass, B. (1985). Leadership and performance beyond expectations. New York: Free Press.

Bass, B. (1990). From transactional to transformational leadership: Learning to share the vision. Organizational Dynamics, 3(18), 19-31.

Betson D. \& Michael, R. (1997). Why are so many children poor? The future of children. Children and Poverty, 7(2), 25-39.

Beruber, M.R., (1994). American school reform: progressive, equity, and excellence movements, 1883-1993, Westport, CT: Praeger.

Beyer, B.L. \& Trice, H.M. (1993), The cultures of work organizations. Englewood, Cliffs, NJ: 
Prentice Hall.

Blackmore, J. (2002). Leadership for socially just schooling: More substance and less style in high risk, low trust times? Journal of School Leadership, 12, 198-222.

Bogotch, I. (2002). Educational leadership and social justice: Theory into practice. Journal of School Leadership, 12(2), 138-156.

Bolman, L. G., \& Deal, T. E. (2008). Reframing organizations: Artistry, choice, and leadership (4th Ed.). San Francisco: Jossey-Bass.

Bowman, B. (1994). The challenge of diversity. Phi Delta Kappan, 76(3), 18-24.

Boyd-Zaharias, J., \& Pate-Bain, H. (2008). Class matters-In and out of school. Phi Delta Kappan, 90(1), 40-44.

Brady, R.C. (2003). Can failing schools be fixed?. Washington D.C.: The Thomas B. Fordham Institute.

Brooks-Gunn, J. \& Duncan, G.J. (2000). Family poverty, welfare reform, and child devlopment, Child Development, 71(1); 188-196.

Brownson, A., Kahlert, R., Picucci, A., \& Sobel, A. (2004). Middle school concept helps highpoverty schools become high-performing schools. Middle School Journal, 36(1), 4-11.

Burns, J.M. (1978). Leadership. New York, NY: Harper \& Row.

Bush, T. (2003). Theories of educational leadership and management (3rd Ed.). Thousand Oaks, CA: Sage.

Caldas, S. J., \& Bankston, C. (1997). Effect of school population socioeconomic status on individual academic achievement. The Journal of Educational Research, 98(5), 269-277.

Casbarro, J. (2005). The politics of high-stakes testing. Education Digest, 70(6), 20-24.

Collins, J. (2001). Good to great: Why some companies make the leap... and others don't. New York, NY: Harper Business. 
Creswell, J. W. (2007). Qualitative inquiry and research design: Choosing among five approaches. Thousand Oaks, CA: Sage.

Chenoweth, K. (2009). It can be done, it's being done, and here's how. Phi Delta Kappan, 91(1), 38-43.

Children's Defense Fund. 1994. Wasting america's future: The children's defense fund report on the costs of child poverty. Boston: Beacon Press.

Children's Defense Fund (2007). America's cradle to prison pipeline: A children's defense fund report. Washington, D.C.

Chirichello, M. (2004). Co-principals: Leading and learning together. Instructional Leader, $17(1), 1-12$.

Cicchinelli, L., Gaddy, B., Lefkowits, L., \& Miller, K. (2003). No child left behind: Realizing the vision [Policy Brief]. Aurora, CO: Mid-continent Research for Education and Learning.

Cooper, C. E., \& Crosnoe, R. (2007). The engagement in schooling of economically disadvantaged parents and children. Youth \& Society, 38(3), 372-391.

Corallo, C., \& McDonald, D. H. (2002). What works with low-performing schools: A review of research literature on low-performing schools. Charleston, WV: Appalachian Educational Laboratory.

Creswell, J. W. (2007). Qualitative inquiry and research design: Choosing among five approaches (2nd Ed.). Thousand Oaks, CA: Sage.

Cuban, L. (1984). Transforming the frog into a prince: Effective schools research, policy, and practice at the district level. Harvard Education Review, 54(2), 129-151.

Danielson, C. (2006). Leadership that strengthens professional practice. Alexandria, VA: Association for Supervision and Curriculum Development.

Del Favero, M. (2003). Faculty- Administrator relationships as integral to high-performing 
governance systems. American Behavioral Scientist, 46 (7), 902-922.

Devol, D. (2004). Using the hidden rules of class to create sustainable communities. Highland, TX: aha! Press Inc.

DuFour, R. \& Eaker, R. (1998). Professional learning communities at work: Best practices for enhancing student achievement. Alexandria, VA: Association for Supervision and Curriculum Development.

Dufour, R., \& Marzano, R. J. (2011). Leaders of learning: How district, school, and classroom leaders improve student achievement. Bloomington, IN: Solution Tree Press.

Duke, D., \& Salmonowicz, M. (2010). Key decisions of a first-year 'turnaround' principal. Educational Management Administration and Leadership, 38(1), 33-58.

Duke, D. (2004). The turnaround principal: High-stakes leadership. Principal, 84(1), 12-23.

Elementary and Secondary Education Act (1965). P. L. 89-10, United States at Large, 79: 27-58.

Elmore, R.F. (2002). Building capacity to enhance learning: A conversation with Richard Elmore. Principal Leadership, 2(6), 39-43.

Emerson, R., Fretz, R., \& Shaw, L. (1995). Writing ethnographic fieldnotes. Chicago: University of Chicago Press.

Farnsworth, K. (2010). Grassroots school reform. New York: Palgrave Macmillan.

Fowler, F.C. (2004). Policy studies for educational leaders: an introduction (2nd Ed.). Upper Saddle River, NJ: Pearson.

Firestone, W.A. \& Heller, M.F. (1995). Who's in charge here? Sources of leadership for change in eight schools. The Elementary School Journal, 96(1), 65-86.

Four pillars of NCLB (2010). Retrieved 3/27/10.

http://www.ed.gov/print/nclb/overview/intro/4pillars.html

French, J \& Raven, B. (1959). The bases of social power. Leadership as an Influence Process, 
Ann Arbor, MI: University of Michigan, 86-91.

Fullan, M. (2010). The awesome power of the principal. Principal, 89(4), 10-12.

Fullan, M., \& Hargreaves, A. (1991). What's worth fighting for? Working together for your school. Andover, MA: The Regional Laboratory for Educational Improvement of the Northeast and Islands.

Furman, G. C., \& Gruenewald, D. A. (2004). Expanding the landscape of social justice: A critical ecological analysis. Educational Administration Quarterly, 40(1), 49-78.

Gamoran, A. (2007). Standards-based reform and the poverty gap: Lessons for No Child Left Behind. Washington, DC: Brookings Institution Press.

Gardner, D. (2007). Confronting the achievement gap. Phi Delta Kappan 88 (7), 542-546.

Gewirtz, S. (1998). Conceptualizing social justice in education: Mapping the territory. Journal of Education Policy, 13(4), 469-484.

Gibboney, R. (2008). Why an undemocratic capitalism has brought public education to its knees: the public schools are being punished for the achievement gap, which they did not create and cannot close. Phi Delta Kappan, 90(1), 21.

Goldfarb, K. P., \& Grinberg, J. (2002). Leadership for social justice: Authentic participation in the case of a community center in Caracas, Venezuela. Journal of School Leadership, 12, $157-173$

Gordon, E. W. (2004). Closing the gap: High achievement for students of color. American Educational Research Association, 2(3), 4.

Gorton, P. \& Snowden, R. (1998). School leadership and administration: Important concepts, case studies and simulations (5th Ed.). New York: McGraw-Hill.

Grint, K. (2005). Problems, problems, problems: The social construction of 'leadership': Human Relations, 58(11), 1467-1494. 
Gulick, L. \& Urwick, L. (1937). Papers on the science of administration. Institute of Public Administration. New York, NY: Columbia University.

Haberman, M. (1995). Selecting star teachers for children and youth in urban poverty. Phi Delta Kappan, 76(10), 777-781.

Hallinger, P. (2003). Leading educational change: Reflections on the practice of instructional and transformational leadership. Cambridge Journal of Education, 33(3), 329-351.

Hallinger, P. \& Murphy, J. (1986), The social context of effective schools. American Journal of Education, 94(3), 328-355.

Heppner, P. P., \& Heppner, M. J. (2004). Writing and publishing your thesis, dissertation \& research: A guide for student in the helping professions. Belmont, CA: Brooks/ColeThompson Learning.

Harris, A. (2003). Teacher leadership as distributed leadership: Heresy, fantasy or possibility. School Leadership and Management, 23 (3), 313-324

Haycock, K. (2001). Closing the achievement gap. Educational Leadership, 58(6), 6-11.

Hickok, E. W. (2004). Statement by Eugene Hickok acting deputy secretary of education on flexibility in no child left behind. U. S. Department of Education [USDOE].

Katzenbach, J. R., \& Smith, D. K. (1993). The discipline of teams. Harvard Business Review, 71(2), 111-120.

Kelehear, Z. (2003). Mentoring the organization: Helping principals bring schools to higher levels of effectiveness. National Association of Secondary School Principals Bulletin, 87(637), 35-47.

Kessler, V.A. \& Schneiders, B.L. (2007). School reform 2007: Transforming education into a scientific enterprise. Annual Review of Sociology, 33, 197-217. 
Knipe, C. \& Speck, M. (2002). Improving competence in the classroom. Principal Leadership, $3(2), 57-59$.

Kotter, J. P. (1996) Leading change. Boston: Harvard Business School Press.

Korenman, S., Miller, J.E., \& Sjaastad, J.E. (1995). Long-term poverty and child development in the US: results from the NLSY. Child and Youth Service Review, 17, 127-155.

Lambert, L. (2002) A framework for shared leadership. Association for Supervision and Curriculum Development, 37-40.

Lambert, L. (2006) Lasting leadership: a story of high leadership capacity schools. The Educational Forum, 70(3), 238-254.

Lashway, L. (2002). Accountability: a positive force for change. Principal Leadership, 5(2), 1620.

Lavin-Loucks, D. (2006). Research brief: The academic achievement gap. A project of the J. McDonald Williams Institute and the Foundation for Community Empowerment.

Leach, M.T., \& Williams, S.A. (2007). The impact of the academic achievement gap on the African-American family: a social inequity perspective. Journal of Human Social Environment, 15(2-3), 39-59.

Leithwood, K. (1994). Leadership for school restructuring. Educational Administration Quarterly, 30(4), 498-518.

Leithwood, K., Louis, K., Anderson, S., \& Wahlstrom, K. (2004). How leadership influences student learning: A commissioned report. New York: Wallace Foundation.

Levy, M. K. \& Salmonowicz, M. J. (2009). Turning around maple shade middle school: A principal's initial reform efforts. Journal of Cases in Educational Leadership, 12(1), 2637.

Lewis, A.C. (2002). A horse called NCLB. Phi Delta Kappan, 84(3), 179-180. 
Lieberman, J. M. \& Wilkins, E. A. (2006). The professional development pathways model: From policy to practice. Kappa Delta Pi Record, 42(3), 124-128.

Lincoln, Y.S., \& Guba, E.G. (1985). Naturalistic inquiry. Beverly Hills, CA: Sage.

Litchka, P. R. (2007), No leader left behind: planning to prepare effective educational leaders in this era of accountability, Educational Planning, 16(2), 44-52.

McCall Jr. \& Morgan W. (2004). Leadership development through experience. Academy of Management Executive, 18(3), 127-130.

Marshall, C. (2004a). Social justice challenges to educational administration: Introduction to a special issue. Educational Administration Quarterly, 40, 5-15.

Marzano, R. J. (2003). What works in schools: Translating research into action. Alexandria, VA: Association for Supervision and Curriculum Development.

Marzano, R., McNulty, B. A., \& Waters, T. (2005). School leadership that works: From research to results. Alexandria VA and Aurora, CO: Association for Supervision and Curriculum Development and Mid-continent Research for Education and Learning.

Mortimore, P. (1993). Schools effectiveness and the management of effective learning and teaching. Schools Effectiveness and School Improvement, 4(4), 290-310.

Merriam, S. B. (1998). Qualitative research and case study applications in education. San Francisco, CA: Jossey-Bass Publishers.

Mertens, D. M. (2005). Research and evaluation in education and psychology; Integrating diversity with quantitative, qualitative and mixed methods $\left(2^{\text {nd }}\right.$ ed.). Thousand Oaks, CA: Sage Publications.

Missouri Department of Elementary and Secondary Education (2011). Missouri Assessment Program: Guide to Interpreting Results. Retrieved 4/30/2011. http://www.dese.mo.gov./divimprove/assess/2011 
Missouri Kids Count Data Book Online. (2010). Retrieved 9/22/201.

http://oseda.missouri.edu/kidscount/databook/kidscount_databook_full_2010.pdf

Missouri School Improvement Program [MSIP]. (2004). Integrated standards and indicators manual. Missouri Department of Elementary and Secondary Education.

Moller, G. \& Pankake, A. (2006). Lead with me: A principal's guide to teacher leadership. Larchmont, NY: Eye on Education.

Morgan, G. (1997). Images of organizations. Thousand Oaks, CA: Sage Publications.

Murphy, J. (1998). Preparation for the school principalship: The United States'story. School Leadership \& Management, 18(3), 359-372.

Myers, V.L., Scribner, J.P., Sawyer, R.K., \& Watson, S.T. (2007). Teacher teams and distributed leadership: a study of group discourse in collaboration. Educational Administration Quarterly, 43(1), 67.

Nanus, B. (1992). Visionary leadership: Creating a compelling sense of direction for your organization. San Francisco: Jossey-Bass.

National Commission on Excellence in Education (1983). A nation at risk: The imperative for educational reform. A report to the nation and the Secretary of Education, United States Department of Education. Washington, DC.

NCCP | Who are America's poor children? (2011) NCCP | Home. Retrieved September 3, 2011, from http://www.nccp.org/publications/pub_1001.html

Neuman, S. B. (2009a). Changing the odds for children at risk: Seven essential principles of educational programs that break the cycle of poverty. Westport, CT: Praeger.

Ogbu, J. (1992). Understanding cultural diversity and learning. Educational Researcher, 21(8), $5-14$.

Pascopella, A.(2005). Inside the law: Analyzing, debating and explaining no child left behind. 


\section{District Administration, 41(2), 25.}

Payne, R. (2003). A framework for understanding poverty ( $3^{\text {rd }}$ Ed.). Highlands, TX: aha! Process. Payne, R. (2009). Poverty does not restrict a student's ability to learn. Phi Delta Kappan, 90(5), 371-372.

Pearl, A. (1991). Systemic and institutional factors in Chicano school failure. In R. R. Valencia (Ed.), Chicano school failure and success: Research and policy agendas for the 1990s (pp. 273-320). London: Falmer.

Pogrow, S., (2006). Restructuring high-poverty elementary schools for success: A description of the hi-perform school design. Phi Delta Kappan, 88(3), 223-229.

Picucci, A., Brownson, A., Kahlert, R., \& Sobel, A. (2002). Driven to succeed: High-performing, high-poverty, turnaround middle schools. Volume I: Cross-case analysis of high-performing, high-poverty, turnaround middle schools. Washington, DC: U.S. Department of Education.

Protheroe, N. (2011). Implementing and sustaining school improvement. Principal's Research Review, 6(2), 1-8.

Reeves, D. B. (2001). Accountability in action: A blueprint for learning organizations. Boston: Advance Learning Press.

Reeves, D.B. (2004). Accountability for learning: How teachers and school leaders can take charge. Alexandria, VA: Association for Supervision and Curriculum Development.

Reeves, D. B. (2006). The learning leader: How to focus school improvement for better results. Alexandria, VA: Association for Supervision and Curriculum Development.

Reeves, D. B. (2007). The principal and proficiency: The essential leadership role in improving student achievement. Leadership Compass. (4)3.

Reeves, D. B. (2009). Leading change in your school: How to conquer myths, build commitment, 
and get results. Alexandria, VA: Association for Supervision and Curriculum Development.

Schmoker, M. (1999). The key to continuous school improvement. Alexandria, VA: Association for Supervision and Curriculum Development.

Schmoker, M. (2011). Focus: elevating the essentials to radically improve student learning. Alexandria, VA: Association for Supervision and Curriculum Development.

Schmoker, M. J. (2006). Results now: How can we achieve unprecedented improvements in teaching and learning. Alexandria, VA: Association for Supervision and Curriculum Development.

Schiff, T. (2001). Priorities and barriers in high school leadership: A survey of principals. Reston, VA: National Association of Secondary School Principals.

Schein, E.H. (1 992). Organizational culture and leadership (2nd Ed.). San Francisco: JosseyBass, Inc.

Sergiovanni, T. J. (2000). Standards and the lifeworld of leadership. The School Administrator, $57(8), 6-12$.

Shields, C. M. (2004). Dialogic leadership for social justice: Overcoming pathologies of silence. Educational Administration Quarterly, 40(1), 109-132.

Southworth, G. (2002). Instructional leadership in schools: Reflections and empirical evidence. School Leadership and Management, 22(1), 73-92.

Spillane, J. P., Halverson, R., \& Diamond, J.B. (2001). Investigating school leadership practice: A distributed perspective. Educational Researcher, 30 (3), 23-28.

Stake, R. (1995). The art of case study research. Thousand Oaks: SAGE Publications.

Stiggins, R. (2001). The principal's leadership role in assessment. National Association of Secondary School Principals Bulletin, 13-26. 
Stormont, M. (2007). Fostering Resilience in Young Children Vulnerable for Failure: Strategies for K-3. Pearson/Merrill/Prentice Hall: Columbus, $\mathrm{OH}$

Supovitz, J.A. (2000). Manage less, lead more. Principal Leadership, 1 (3), 14-19

Swartz, D. (1997). Culture and power: The sociology of Pierre Bourdieu. Chicago, IL: University of Chicago.

Taylor, J. A. (2005). Poverty and student achievement. Multicultural Education, 12(4), 53-55.

Tanenhaus, K. (2008). Brown verses the Board of Education, 347 U.S. 483 (1954), Encyclopedia of the Supreme Court of the United States.

Theoharis, G. (2007). Social justice educational leaders and resistance: Toward a theory of social justice leadership. Educational Administration Quarterly, 43(2), 221- 251.

Thomas, G. (2003). In times of turmoil great leaders emerge. Leadership, 32(5), 8-10.

U.S. Department of Education [USDOE]. (2005, March). No Child Left Behind: Expanding the promise. Retrieved April 28, 2011, from http://www.ed.gov

U.S. Department of Education [USDOE]. (2007). Public Law 107-11-Jan. 8, 2002: The No Child Left Behind Act. Retrieved March 10, 2010, from http://www.ed.gov/policy/elsec/leg/esea02/107-110.pdf

U.S. Department of Education [USDOE] (2010). A blue print for reform: The reauthorization of the elementary and secondary education act.

White, K. R. (1982). The relationship between socioeconomic status and academic achievement. Psychological Bulletin, 91(3), 461-481.

Wilkins, A. (2006). Yes we can: Telling truths and dispelling myths about race and education in America, Washington, D.C.: The Education Trust.

Williams, L. (2003) Closing the achievement gap: A vision for changing beliefs and practices, Alexandria, Va: Association for Supervision and Curriculum Development. 
Yin, R. K. (2003). Case study research: Design and methods (3rd Ed.). Thousand Oaks, CA:

Sage Publications, Inc.

Yukl, G., (2006). Leadership in organizations (6th Ed.). Singapore: Pearson Education.

Zorn, D., \& Noga, J., (2004). Family poverty and its implications for school success. Cincinnati: University of Cincinnati Evaluation Services Center. 


\section{APPENDIX A}

IV Campus Insfitutional Review Board

ET University of Missoun-Columbia
$465 \mathrm{McRemoids} \mathrm{Hal}$

Cohurbis. MO $65211-1150$

PHONE: (573) 852-9585

FAX: (573) 8940663

December 5,2014

Ptincipal Invesgator: Geant, Cynthis S

Department Educational Leadership and Policy Ansilysis

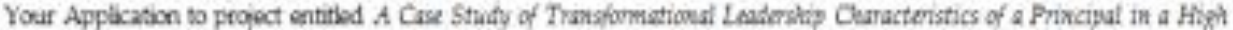
Poverty Hiph Achieving School. was revinved and approved by the MU Campus hstitubonal Reviev Bourd according to terms and conditions described below:

\begin{tabular}{|c|c|}
\hline IRB Project Number & 1213778 \\
\hline Iutial Aoplicabon Asproval Date & Decanber 5,2014 \\
\hline IRB Expiration Date & December 5, 2015 \\
\hline Level of Reviene & Expoditod \\
\hline Profect Sunds & Actre-Open to Enrolieners \\
\hline Exoedited Catercries & $\begin{array}{l}15 \text { CFR \& } 1.10 \text { a }(f)(6) \\
\text { to } 4 \text { K thinuairen }\end{array}$ \\
\hline Risk Lend & Minimal Riek \\
\hline Irpect Coroent & Written Coroent \\
\hline
\end{tabular}

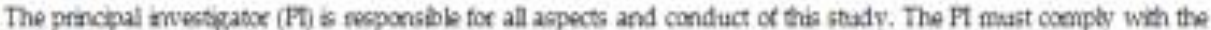
following canditions of the approral:

L. No subjects mav be involved in any study procedure prox to the IRB approval date or after the expiration dane

2. All uranbchated probiens, serions adverse events, and devistions mast be reported to the IRB within 5 divs.

3. Al modifrations matst be IRB appeoved prior to insplementation tribse they ane intended to seduce risi.

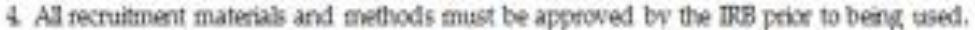

5. The Contrnuing Reriev Report mast be submitted to the IRB for review and approval at least 30 davs prot to the prosect experation date.

6. Maintain all research reoods for a period of seven years from the project completion date.

7. Ublize the IRE stampod conaent documents and othes approved sesoanch documents bcatod within the document storage section of ellRB

If you have any questiona, plese cantact the Campus IRB at 573,552-9585 or umcresearchcibemissouriedu.

Thank you,

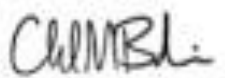

Charks Borduin. FhD

Campua IFB Chair 


\section{APPENDIX B}

Gatekeeper and Informed Consent Forms

1. District Gatekeeper Permission for Principal, Teacher, Central Office Administration, Parent, and Student Participation Letter

2. Letter of Informed Consent- Principal Participant

3. Informed Consent from Principal Participant

4. Letter of Informed Consent-Central Office Administrator Participant

5. Informed Consent from Central Office Administrator Participant

6. Letter of Informed Consent-Teacher Participant

7. Informed Consent from Teacher Participant

8. Letter of Informed Consent-Parent Participant

9. Informed Consent from Parent Participant

10. Letter of Informed Consent-Student Participant

11. Informed Consent from Student Participant 


\section{DISTRICT GATEKEEPER PERMISSION FOR TEACHER, PARENT, AND ADMINISTRATOR PARTICIPATION LETTER \\ $<$ Name of District>}

Dear <insert name>,

With your permission I would like invite members of your staff to participate in a doctoral research study entitled: A Case Study of Transformational Leadership Characteristics of a Principal in a High Poverty High Achieving School. The case study will focus on the transformational leadership practices of building administration and the leadership practices implemented within the school that have been significant in realizing high student achievement. All individual and program information will be confidential and therefore your name, the name of individual members, and the name of the school will not be included in the research study.

I am seeking your permission as the Gatekeeper of the <Name of School District> to work with the principal <Name of School> for the purpose of inviting a variety of teachers, parents, and building and district administration, to participate in this study. The selected staff members, parents, and administrators from your district will be asked to participate in either an individual interview or small focus group interview session. Each interview or focus group will last approximately one hour. Furthermore, I would also like to request your permission to spend up to two days of on-site observation to record anecdotal notes. I have included a copy of the teacher, parent, and administrator informed consent forms, for your review.

Participation in the study is voluntary and participants have the right to withdraw at any time without penalty. Participants also have the right to decline to answer any of the questions presented during the interview and focus group processes. Participants' identity, answers and building's identity will remain confidential and not included in this study or future studies. For your convenience and analysis, I have included a copy of the interview protocol, questions and informed consent forms.

You may contact me at any time with questions or comments regarding the proposed research study. I can be contacted by phone at (816) 719-7410 or through email at grantc@aol.com. My dissertation advisor, Dr. Barbara Martin is also available to answer questions regarding the study and she can be reached at 660-543-8823 or bmartin@ucmo.edu .

If you choose to allow me to contact you regarding the participation and selection of staff concerning participation in this study, please complete and sign the attached permission form. Signing the attached form indicates that you understand and agree to the terms presented for allowing participation in the study. You should retain a copy of this letter and your written consent for your records.

Thanking you in advance for your consideration.

Sincerely,

Cynthia S. Grant 
Doctoral Candidate

University of Missouri-Columbia 


\section{ADMINISTRATIVE PERMISSION FOR TEACHERS, PARENTS, AND ADMINISTRATORS PARTICIPATION}

$\mathrm{I}$, , grant permission for the program

director and staff to be contacted to participate in the study entitled: A Case Study of Transformational Leadership Characteristics of a Principal in a High Poverty High Achieving School conducted by Cynthia S. Grant, a doctoral candidate at the University of MissouriColumbia. I understand the following:

- All participation is voluntary, and maybe withdrawn at any time before the conclusion of the study without penalty.

- I have been provided an opportunity to ask questions regarding the study and those questions have been answered to my satisfaction.

- The responses that are provided by participants will be used both in this dissertation and in future research publications.

- The interviews will take approximately one hour.

- Necessary related documents which would provide the researcher with a more comprehensive view of the program will be provided.

- The researcher will be conducting informal observations within the case study setting for up to two days.

I have read the above mentioned statements, and any questions I have posed have been answered to my satisfaction. I grant permission for the staff members in my district to be contacted and invited to participate in this case study.

Signed:

Date:

Title:

Organization:

Please return the following document to Cynthia S. Grant,

8149 NE $97^{\text {th }}$ St., Kansas City MO 64157 


\section{LETTER OF INFORMED CONSENT PRINCIPAL PARTICIPANT}

Dear <Name of Principal $>$, Principal,

My name is Cynthia S. Grant and I am a doctoral candidate at the University of MissouriColumbia. I am in the process of preparing for my doctoral research study titled: A Case Study of Transformational Leadership Characteristics of a Principal in a High Poverty High Achieving School. You have been invited to participate in this study because you have been a principal in a high performing, high poverty school. The information gathered should be beneficial to PK-12 educational leaders responsible for student success.

Researcher: Cynthia S. Grant. University of Missouri, Doctoral Candidate, email csg7cf@mail.missouri.edu or call (816) 719-7410.

Dissertation Supervisor: Dr. Barbara N. Martin, University of Central Missouri, Dr. Martin can be reached at 660-543-8823 or by email at bmartin@ucmo.edu.

Institutional Review Board: University of Missouri Campus Institutional Review Board, 483 McReynolds, University of Missouri, Columbia, MO 65211. If you have questions regarding your right as a research participant please contact the Campus IRB at 573-882-9585.

Purpose: The purpose of this study is to add to the body of knowledge regarding leadership characteristics present in highly effective schools located in high poverty areas, as well as provide insight into the professional practices of principals in order to build and sustain leadership capacity for high poverty schools. The researcher will examine perceptions of teachers, parents, and administrators.

The following questions guide this qualitative study:

4. What transformational leadership traits of the principal are present in a highpoverty, high achieving suburban/urban high schools as perceived by teachers, parents, and the principal's supervisors, and other building administrators?

5. How has the contextual environment of high poverty within the high school community of the school influenced the transformational leadership style of the principal?

6. How has the transformational leadership style of the principal changed behaviors of the teachers, parents, and other building administration?

Procedures: If you choose to participate in this study, the researcher will conduct a 45 to 60 minute interview at your school. In a location appropriate for such interaction. An audio recording device will be used to record the interview and the questions presented will be semistructured in nature in order to provide the participant with the opportunity to provide openended questions. Participants have the option of answering any or all of the questions asked. If through the course of the interview process, new significant findings develop the participant may be asked to take part in an additional interview session or via email. All interviews will be 
transcribed verbatim for use by the researcher. Upon completion of interview transcriptions, participants will be provided an opportunity to review the transcripts for accuracy.

Consent: In order to participate in this study, please sign the consent form indicating you understand and agree to participate in the study. Please retain a copy of this letter and your written consent for your records.

Sincerely,

Cynthia S. Grant

Doctoral Candidate

University of Missouri-Columbia 


\section{INFORMED CONSENT FROM PRINCIPAL PARTICIPANT}

I, , agree to participate in a research study entitled A Case Study of Transformational Leadership Characteristics of a Principal in a High Poverty High Achieving School conducted by Cynthia S. Grant, a doctoral candidate at the University of MissouriColumbia.

By signing this consent form and participating within the interview process, you understand that the following safeguards are in place to ensure protection:

1. Your participation is voluntary, and maybe withdrawn at any time before the conclusion of the study without penalty or loss of benefit.

2. You have been provided an opportunity to ask questions regarding the study and those questions have been answered to my satisfaction.

3. Your responses provided during the interview will be used both in this dissertation and in future research publications.

4. You will be asked to provide the following resources as a part of your participation in the research study; MAP results, daily schedules, staff meeting agendas, Comprehensive School Improvement Plans, staff and student handbooks, and teacher professional development plans.

5. You understand this is a minimal risk study. The only foreseeable risks would be if information was compromised and given to the wrong participants. The researcher will avoid such risks by keeping the information confidential and kept in a locked location.

6. The documents will be stored electronically and password protected. The only persons with access will be the researcher and advisor.

7. Your identity and the off-campus center will be confidential in the reporting of results. Your name or your corresponding institution will not be listed in the dissertation or any future publications of this study.

8. Your consent to participate or refusal to participate will not affect employment in any way.

Please keep a copy of the consent letter and a signed copy of the consent form for your records. If you have any questions, please contact the researcher.

I have read the material above, and any questions that I have posed have been answered to my satisfaction. I voluntarily agree to participate in this study.

Signed: Date:

Title/Position:

School/District:

\section{Contact Information:}

Phone

(circle one) WORK HOME

CELL

Best time for contact:

E-mail: 
Please return the following document to Cynthia S. Grant, 8149 NE $97^{\text {th }}$ St., Kansas City MO 64157 


\section{LETTER OF INFORMED CONSENT CENTRAL OFFICE ADMINISTRATOR PARTICIPANT}

Dear <Name of Participant $>$,

My name is Cynthia S. Grant and I am a doctoral candidate at the University of MissouriColumbia. I am in the process of preparing for my doctoral research study titled: A Case Study of Transformational Leadership Characteristics of a Principal in a High Poverty High Achieving School. You have been invited to participate in this study because you are a supervisor of a principal in a high performing, high poverty school. The information gathered should be beneficial to PK-12 educational leaders responsible for student success.

Researcher: Cynthia S. Grant. University of Missouri, Doctoral Candidate, email csg7cf@mail.missouri.edu or call (816) 719-7410.

Dissertation Supervisor: Dr. Barbara N. Martin, University of Central Missouri, Dr. Martin can be reached at $660-543-8823$ or by email at bmartin@ ucmo.edu.

Institutional Review Board: University of Missouri Campus Institutional Review Board, 483 McReynolds, University of Missouri, Columbia, MO 65211. If you have questions regarding your right as a research participant please contact the Campus IRB at 573-882-9585.

Purpose: The purpose of this study is to add to the body of knowledge regarding leadership characteristics present in highly effective schools located in high poverty areas, as well as provide insight into the professional practices of principals in order to build and sustain leadership capacity for high poverty schools. The researcher will examine perceptions of teachers, parents, and administrators.

The following questions guide this qualitative study:

1. What transformational leadership traits of the principal are present in a high-poverty, high achieving suburban/urban high schools as perceived by teachers, parents, the principal's supervisors, and other building administrators?

2. How has the contextual environment of high poverty within the high school community of the school influenced the transformational leadership style of the principal?

3. How has the transformational leadership style of the principal changed behaviors of the teachers, parents, and other building administration?

Procedures: If you choose to participate in this study, the researcher will conduct a 45 to 60 minute interview at your school. In a location appropriate for such interaction. An audio recording device will be used to record the interview and the questions presented will be semistructured in nature in order to provide the participant with the opportunity to provide openended questions. Participants have the option of answering any or all of the questions asked. If through the course of the interview process, new significant findings develop the participant may be asked to take part in an additional interview session or via email. All interviews will be 
transcribed verbatim for use by the researcher. Upon completion of interview transcriptions, participants will be provided an opportunity to review the transcripts for accuracy.

Consent: In order to participate in this study, please sign the consent form indicating you understand and agree to participate in the study. Please retain a copy of this letter and your written consent for your records.

Sincerely,

Cynthia S. Grant

Doctoral Candidate

University of Missouri-Columbia 


\section{INFORMED CONSENT FROM CENTRAL OFFICE ADMINISTRATOR PARTICIPANT}

$\mathrm{I}$, , agree to participate in a research study entitled $A$ Case Study of Transformational Leadership Characteristics of a Principal in a High Poverty High Achieving School conducted by Cynthia S. Grant, a doctoral candidate at the University of MissouriColumbia.

By signing this consent form and participating within the interview process, you understand that the following safeguards are in place to ensure protection:

1. Your participation is voluntary, and maybe withdrawn at any time before the conclusion of the study without penalty or loss of benefit.

2. You have been provided an opportunity to ask questions regarding the study and those questions have been answered to my satisfaction.

3. Your responses provided during the interview will be used both in this dissertation and in future research publications.

4. You understand this is a minimal risk study. The only foreseeable risks would be if information was compromised and given to the wrong participants. The researcher will avoid such risks by keeping the information confidential and kept in a locked location.

5. The documents will be stored electronically and password protected. The only persons with access will be the researcher and advisor.

6. Your identity and the off-campus center will be confidential in the reporting of results. Your name or your corresponding institution will not be listed in the dissertation or any future publications of this study.

7. Your consent to participate or refusal to participate will not affect employment in any way.

Please keep a copy of the consent letter and a signed copy of the consent form for your records. If you have any questions, please contact the researcher.

I have read the material above, and any questions that I have posed have been answered to my satisfaction. I voluntarily agree to participate in this study.

Signed: Date:

Title/Position:

School/District:

\section{Contact Information:}

Phone

(circle one) WORK HOME CELL

Best time for contact:

E-mail:

Please return the following document to Cynthia S. Grant, 8149 NE $97^{\text {th }}$ St., Kansas City MO 64157 


\section{LETTER OF INFORMED CONSENT TEACHER PARTICIPANT}

Dear <Name of Participant $>$,

My name is Cynthia S. Grant and I am a doctoral candidate at the University of MissouriColumbia. I am in the process of preparing for my doctoral research study titled: A Case Study of Transformational Leadership Characteristics of a Principal in a High Poverty High Achieving School. You have been invited to participate in this study because you have been a principal in a high performing, high poverty school. The information gathered should be beneficial to PK-12 educational leaders responsible for student success.

Researcher: Cynthia S. Grant. University of Missouri, Doctoral Candidate, email csg7cf@mail.missouri.edu or call (816) 719-7410.

Dissertation Supervisor: Dr. Barbara N. Martin, University of Central Missouri, Dr. Martin can be reached at 660-543-8823 or by email at bmartin@ucmo.edu.

Institutional Review Board: University of Missouri Campus Institutional Review Board, 483 McReynolds, University of Missouri, Columbia, MO 65211. If you have questions regarding your right as a research participant please contact the Campus IRB at 573-882-9585.

Purpose: The purpose of this study is to add to the body of knowledge regarding leadership characteristics present in highly effective schools located in high poverty areas, as well as provide insight into the professional practices of principals in order to build and sustain leadership capacity for high poverty schools. The researcher will examine perceptions of teachers, parents, and administrators.

The following questions guide this qualitative study:

1. What transformational leadership traits of the principal are present in a high-poverty, high achieving suburban/urban high schools as perceived by teachers, parents, the principal's supervisors, and other building administrators?

2. How has the contextual environment of high poverty within the high school community of the school influenced the transformational leadership style of the principal?

3. How has the transformational leadership style of the principal changed behaviors of the teachers, parents, and other building administration?

Procedures: If you choose to participate in this study, the researcher will conduct a 45 to 60 minute interview at your school. In a location appropriate for such interaction. An audio recording device will be used to record the interview and the questions presented will be semistructured in nature in order to provide the participant with the opportunity to provide openended questions. Participants have the option of answering any or all of the questions asked. If through the course of the interview process, new significant findings develop the participant may 
be asked to take part in an additional interview session or via email. All interviews will be transcribed verbatim for use by the researcher. Upon completion of interview transcriptions, participants will be provided an opportunity to review the transcripts for accuracy.

Consent: In order to participate in this study, please sign the consent form indicating you understand and agree to participate in the study. Please retain a copy of this letter and your written consent for your records.

Sincerely,

Cynthia S. Grant

Doctoral Candidate

University of Missouri-Columbia 


\section{INFORMED CONSENT FROM TEACHER PARTICIPANT}

$\mathrm{I}$, , agree to participate in a research study entitled A Case Study of Transformational Leadership Characteristics of a Principal in a High Poverty High Achieving School conducted by Cynthia S. Grant, a doctoral candidate at the University of MissouriColumbia.

By signing this consent form and participating within the interview process, you understand that the following safeguards are in place to ensure protection:

1. Your participation is voluntary, and maybe withdrawn at any time before the conclusion of the study without penalty or loss of benefit.

2. You will be participating in one, one hour focus group interview session. The opportunity to review your responses once your focus group interview has been transcribed will be provided.

3. You have been provided an opportunity to ask questions regarding the study and those questions have been answered to my satisfaction.

4. Your responses provided during the focus group interview will be used both in this dissertation and in future research publications.

5. You understand this is a minimal risk study. The only foreseeable risks would be if information was compromised and given to the wrong participants. The researcher will avoid such risks by keeping the information confidential and kept in a locked location.

6. The documents will be stored electronically and password protected. The only persons with access will be the researcher and advisor.

7. Your identity and the off-campus center will be confidential in the reporting of results. Your name or your corresponding institution will not be listed in the dissertation or any future publications of this study.

8. We cannot guarantee absolute confidentiality, someone participating in the focus group might repeat something you say outside of the group, or might identify you as a group participant.

9. Your consent to participate or refusal to participate will not affect employment in any way.

Please keep a copy of the consent letter and a signed copy of the consent form for your records. If you have any questions, please contact the researcher.

I have read the material above, and any questions that I have posed have been answered to my satisfaction. I voluntarily agree to participate in this study.

Signed: Date:

Title/Position:

School/District:

\section{Contact Information:}

Phone (circle one)

WORK

HOME

CELL

Best time for contact:

E-mail:

Please return the following document to Cynthia S. Grant, 8149 NE $97^{\text {th }}$ St., Kansas City MO 64157 


\section{LETTER OF INFORMED CONSENT PARENT PARTICIPANT}

Dear <Name of Participant $>$,

My name is Cynthia S. Grant and I am a doctoral candidate at the University of MissouriColumbia. I am in the process of preparing for my doctoral research study titled: A Case Study of Transformational Leadership Characteristics of a Principal in a High Poverty High Achieving School. You have been invited to participate in this study because you are a parent of a student who attends a high performing, high poverty school. The information gathered should be beneficial to PK-12 educational leaders responsible for student success.

Researcher: Cynthia S. Grant. University of Missouri, Doctoral Candidate, email csg7cf@mail.missouri.edu or call (816) 719-7410.

Dissertation Supervisor: Dr. Barbara N. Martin, University of Central Missouri, Dr. Martin can be reached at 660-543-8823 or by email at bmartin@ucmo.edu.

Institutional Review Board: University of Missouri Campus Institutional Review Board, 483 McReynolds, University of Missouri, Columbia, MO 65211. If you have questions regarding your right as a research participant please contact the Campus IRB at 573-882-9585.

Purpose: The purpose of this study is to add to the body of knowledge regarding leadership characteristics present in highly effective schools located in high poverty areas, as well as provide insight into the professional practices of principals in order to build and sustain leadership capacity for high poverty schools. The researcher will examine perceptions of teachers, parents, and administrators.

The following questions guide this qualitative study:

1. What transformational leadership traits of the principal are present in a high-poverty, high achieving suburban/urban high schools as perceived by teachers, parents, the principal's supervisors, and other building administrators?

2. How has the contextual environment of high poverty within the high school community of the school influenced the transformational leadership style of the principal?

3. How has the transformational leadership style of the principal changed behaviors of the teachers, parents, and other building administration?

Procedures: If you choose to participate in this study, the researcher will conduct a 45 to 60 minute focus group interview at your school. In a location appropriate for such interaction. An audio recording device will be used to record the interview and the questions presented will be semi-structured in nature in order to provide the participant with the opportunity to provide openended questions. Participants have the option of answering any or all of the questions asked. If through the course of the interview process, new significant findings develop the participant may be asked to take part in an additional interview session or via email. All interviews will be transcribed verbatim for use by the researcher. Upon completion of interview transcriptions, participants will be provided an opportunity to review the transcripts for accuracy. 
Consent: In order to participate in this study, please sign the consent form indicating you understand and agree to participate in the study. Please retain a copy of this letter and your written consent for your records.

Sincerely,

Cynthia S. Grant

Doctoral Candidate

University of Missouri-Columbia 


\section{INFORMED CONSENT FROM PARENT PARTICIPANT}

I, , agree to participate in a research study entitled $A$ Case Study of Transformational Leadership Characteristics of a Principal in a High Poverty High Achieving School conducted by Cynthia S. Grant, a doctoral candidate at the University of MissouriColumbia.

By signing this consent form and participating within the interview process, you understand that the following safeguards are in place to ensure protection:

1. Your participation in the focus group interview is voluntary, and maybe withdrawn at any time before the conclusion of the study without penalty or loss of benefit.

2. You will be participating in one, one hour focus group interview session. The opportunity to review your responses once your focus group interview has been transcribed will be provided.

3. You have been provided an opportunity to ask questions regarding the study and those questions have been answered to my satisfaction.

4. Your responses provided during the focus group interview will be used both in this dissertation and in future research publications.

5. You understand this is a minimal risk study. The only foreseeable risks would be if information was compromised and given to the wrong participants. The researcher will avoid such risks by keeping the information confidential and kept in a locked location.

6. The documents will be stored electronically and password protected. The only persons with access will be the researcher and advisor.

7. Your identity and the off-campus center will be confidential in the reporting of results. Your name or your corresponding institution will not be listed in the dissertation or any future publications of this study.

8. We cannot guarantee absolute confidentiality, someone participating in the focus group might repeat something you say outside of the group, or might identify you as a group participant.

9. Your consent to participate or refusal to participate will not affect your relationship to the school and/or your child's academic standing.

Please keep a copy of the consent letter and a signed copy of the consent form for your records. If you have any questions, please contact the researcher.

I have read the material above, and any questions that I have posed have been answered to my satisfaction. I voluntarily agree to participate in this study.

Signed: Date:

Title/Position:

School/District:

\section{Contact Information:}

Phone

(circle one) WORK HOME CELL

Best time for contact:

E-mail: 
Please return the following document to Cynthia S. Grant, 8149 NE $97^{\text {th }}$ St., Kansas City MO 64157 
Interview Protocols

\section{APPENDIX C}

1. Principal Interview Protocol

2. Central Office Administrator Protocol

Focus Group Protocols

1. Parent Focus Group Protocols

2. Teacher Focus Group Protocols 


\section{Principal Participant Interview Protocol}

Date:

Start Time:

Introduction:

Hi, my name is Cynthia S. Grant and I am a doctoral student from the University of Missouri, Columbia. Thank you for agreeing to talk with me about your experiences as a principal of a building with high instances of poverty and high achievement. I will be conducting the interview. I will ask some questions to guide the discussion this is meant to be a semi- structured interview with possible follow-up questions.

In order to ensure accuracy and my full attention on you, I will be audio taping the interview. Once the interview has been transcribed, you will have an opportunity to review the transcript. The tape will only be used for the purpose of note taking and transcription and will be destroyed following the completion of the study.

Remember, you should feel free to answer honestly. If at any time, a question is unclear, please ask clarifying questions. You may refuse to answer any questions or to stop the interview at any time.

This interview should last approximately one hour and there will be no formal break. Please let me know if you need a break at any time. Do you have any questions before we get started?

\begin{tabular}{|l|l|}
\hline Questions & Research Question (s) \\
\hline
\end{tabular}

Opening Questions: 5 min.

1. Is this your first principalship experience? If not, please describe past experiences.

Principal participant background

2. How long have you been a principal at this school?

Introductory Questions: 10-15 min.

3. How would you describe your school and the community it represents?

Question Probes: what are the demographics of the school and community?

4. How would you describe the community's perception of your $\quad$ Q2 school?

5. Describe the relationship between administration, staff, and parents.

\section{Q2}

Q2

Q2, Q3 
Transition Questions: 5-10 min.

6. What has your school done to address the influence of No Child $\quad$ Q1, Q3 Left Behind?

7. What have you done to address the achievement gap? Question Probe: what have you done to address your subgroups?

8. What are the overall trends you see related to student achievement?

Q1, Q3

Q1, Q2

Q2

Question Probe: What are the strengths? What are the concerns?

9. How do you involve staff in this process?

Key Questions: 35-40 min.

10. How were professional development needs determined?

11. What professional development activities have been provided to your staff regarding reducing the achievement gap and students of poverty?

12. How did you create the overall vision for your school?

Q1, Q3

13. How did you involve staff in the development of the school's vision?

14. How do you encourage the staff, students, and community to follow the vision?

15. How would you describe your leadership style?

16. What are your expectations for teachers?

17. How have your expectations changed during your principalship?

18. Describe the specific leadership structures and processes you have implemented and have resulted in high student achievement.

19. How have your teachers changed?

20. What has the parent response been to the implemented changes?

Ending Question: 5-10 min.

21. Is there anything that I haven't asked that would help me understand your leadership style? 


\section{Central Office Participant Interview Protocol}

Date:

Start Time:

Introduction:

$\mathrm{Hi}$, my name is Cynthia S. Grant and I am a doctoral student from the University of Missouri, Columbia. Thank you for agreeing to talk with me about your experiences as a principal of a building with high instances of poverty and high achievement. I will be conducting the interview. I will ask some questions to guide the discussion this is meant to be a semi- structured interview with possible follow-up questions.

In order to ensure accuracy and my full attention on you, I will be audio taping the interview. Once the interview has been transcribed, you will have an opportunity to review the transcript. The tape will only be used for the purpose of note taking and transcription and will be destroyed following the completion of the study.

Remember, you should feel free to answer honestly. If at any time, a question is unclear, please ask clarifying questions. You may refuse to answer any questions or to stop the interview at any time.

This interview should last approximately one hour and there will be no formal break. Please let me know if you need a break at any time. Do you have any questions before we get started?

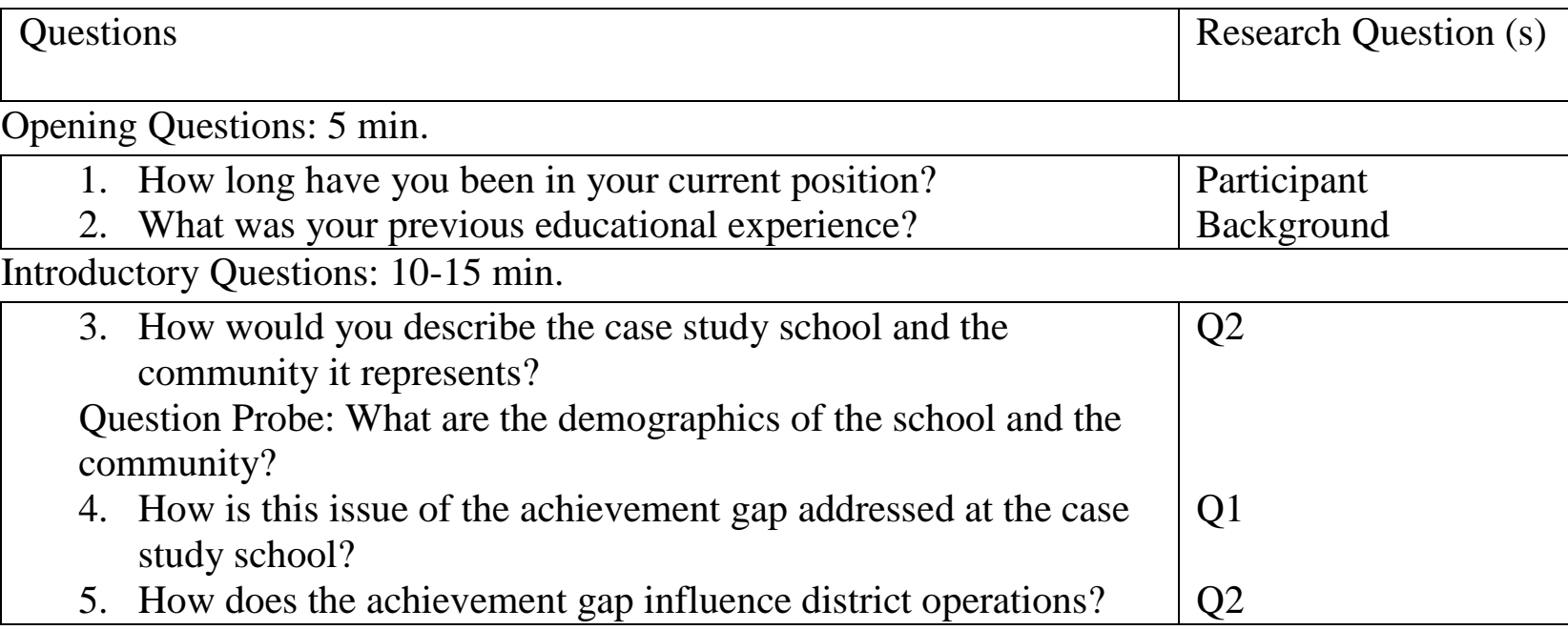

Key Questions: $35-40 \mathrm{~min}$.

6. How is professional development regarding the achievement gap determined?

7. Describe the leadership style of the administrator?

8. How did the leadership style of the administrator influence student achievement?

Q1

Q1

Q1, Q3 
9. How did the leadership of the administrator influence teacher behaviors?

Questions Probes: Motivation, goal setting, individualization, accountability, intellectual stimulation.

10. What process and structures changed as a result of the administrator's leadership style?

Question Probes: Motivation, goal setting, individualization, accountability, intellectual stimulation.

11. Please explain what processes and structures have led to the ongoing success of student achievement.

Question Probes: Student date, rigor, goal setting, high expectations

12. How did parents respond to changes?

13. How did the administrator's leadership style influence visions of the case study school?

How does the administrator's leadership style influence the longevity of the vision?

Q1

Q1

Ending Question: 5-10 min.

15. Is there anything else you would wish to tell me that I have not asked? 


\section{Parent Focus Group Protocol}

Date:

Start Time:

Introduction:

Hi, my name is Cynthia S. Grant and I am a doctoral student from the University of Missouri, Columbia. Thank you for agreeing to talk with me about your experiences as a principal of a building with high instances of poverty and high achievement. I will be conducting the interview. I will ask some questions to guide the discussion this is meant to be a semi- structured interview with possible follow-up questions.

In order to ensure accuracy and my full attention on you, I will be audio taping the interview. Once the interview has been transcribed, you will have an opportunity to review the transcript. The tape will only be used for the purpose of note taking and transcription and will be destroyed following the completion of the study.

Remember, you should feel free to answer honestly. If at any time, a question is unclear, please ask clarifying questions. You may refuse to answer any questions or to stop the interview at any time.

This interview should last approximately one hour and there will be no formal break. Please let me know if you need a break at any time. Do you have any questions before we get started?

Questions

Research Question (s)

Opening Questions: 5 min.

1. How long has your child attended this school?

Introductory Questions: 5-10 min.

2. How would you describe the school community?

Query Probes: demographics, vision, achievement

3. What school activities and programs do you participate in?

4. What do new parents and students need to know about your schools?

Key Questions: 35-40 min.

5. What is the vision of your school?

6. How was the vision created and shared with you?

Q3

7. How would you describe the leadership style of the principal?

Q1

Q1

Question Probes: Student achievement, relationships, motivation, work with parents

8. What leadership qualities of the administrator led to the success

Q2

Q2

Q2 


\begin{tabular}{|c|c|}
\hline $\begin{array}{l}\text { of the students and school community? } \\
\text { 9. How is parent involvement encouraged? } \\
\text { Question Probe: communication, school events, concerns addressed } \\
\text { 10. What changes have occurred over time to promote success? }\end{array}$ & $\begin{array}{l}\text { Q1, Q2, Q3 } \\
\text { Q1, Q3 }\end{array}$ \\
\hline
\end{tabular}

Ending Question: 5 min

11. Is there anything else you would wish to tell me that I have not asked? 


\section{Teacher Focus Group Protocol}

Date: Start Time:

Introduction:

$\mathrm{Hi}$, my name is Cynthia S. Grant and I am a doctoral student from the University of Missouri, Columbia. Thank you for agreeing to talk with me about your experiences as a principal of a building with high instances of poverty and high achievement. I will be conducting the interview. I will ask some questions to guide the discussion this is meant to be a semi- structured interview with possible follow-up questions.

In order to ensure accuracy and my full attention on you, I will be audio taping the interview. Once the interview has been transcribed, you will have an opportunity to review the transcript. The tape will only be used for the purpose of note taking and transcription and will be destroyed following the completion of the study.

Remember, you should feel free to answer honestly. If at any time, a question is unclear, please ask clarifying questions. You may refuse to answer any questions or to stop the interview at any time.

This interview should last approximately one hour and there will be no formal break. Please let me know if you need a break at any time. Do you have any questions before we get started?

Questions

Research Question (s)

Opening Questions: 5 min.

1. How long have you taught at the case study school?

2. How long have you been in education?

Introductory Questions: 5-10 min.

3. How would you describe your school community?

4. What do new staff members need to know about the case study $\quad$ Q2 school?

5. What do new students need to know about the case study school?

Transition Questions: 5-10 min.

6. What is the vision of your school?

Q1, Q2

7. How was the vision developed?

Q1, Q2, Q3

8. How do you address the achievement gap?

Q1

9. How does the vision of the case study school influence how you address the achievement gap?

10. How are your professional development needs met regarding the achievement gap?

Q1, Q3

Q1, Q2, Q3

Key Questions: 35-45 min.

11. How would you describe the leadership style of the

Q1, Q2 


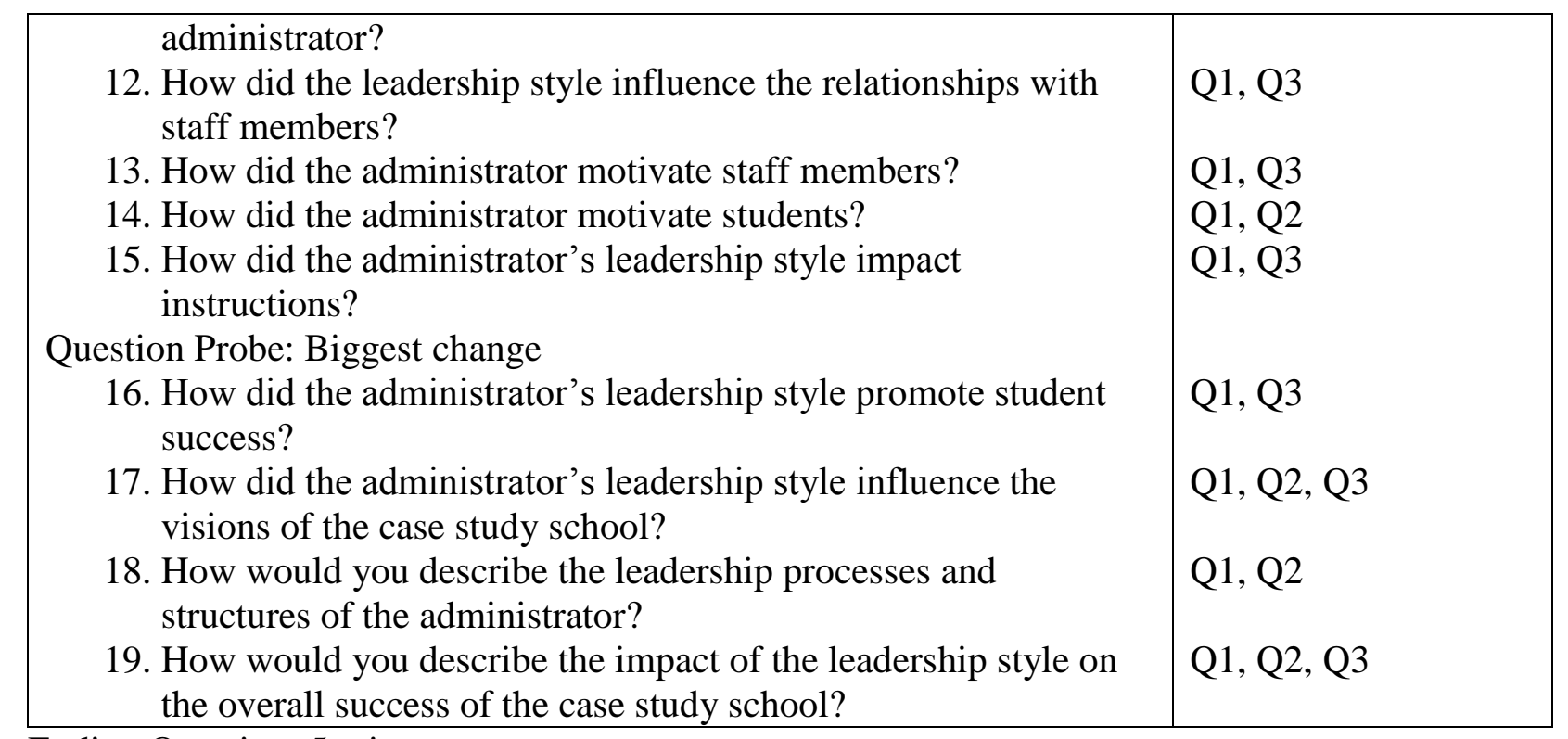

Ending Question: 5 min.

20. Is there anything else you would wish to tell me that I have not asked? 


\section{Appendix D}

\section{On-Site Observation Form}

Date:

Participants:

Beginning Time: Ending Time:

Location:

Observations: 


\section{Data Codes}

1. Central Office Participant - CO1

2. Administrator Participant - AP1

3. Teacher Participant $1-\mathrm{E} 1$

4. Teacher Participant 2 - E2

5. Teacher Participant $3-\mathrm{E} 3$

6. Teacher Participant $4-$ E4

7. Parent Participant $1-\mathrm{P} 1$

8. Parent Participant 2- P2

9. Parent Participant $3-\mathrm{P} 3$

10. Parent Participant $4-\mathrm{P} 4$

11. Interview $1-$ (I1)

12. Interview $2-$ (I2)

13. Focus Group $1-(\mathrm{FG} 1)$

14. Focus Group 2 - (FG2)

15. Field Observation $1-(\mathrm{FO} 1)$

16. Field Observation $2-(\mathrm{FO} 2)$

17. Motivation (MO)

18. Intellectual Stimulation (IS)

19. Individual Consideration (IC)

20. Charisma $(\mathrm{CH})$ 
Appendix F

Review of Documents Form

Date:

Name of Document:

Type of Document:

Received From:

Coding Number:

Notes: 
VITA

Cynthia S. Van Iten-Grant was born in Mexico, Missouri as the first child of Alfred and Dottye Van Iten. Cynthia graduated from Truman High School in Independence, Missouri in 1992. She attended Rockhurst College (renamed Rockhurst University) - Kansas City, Missouri, and earned an undergraduate degree of a Bachelor of Science degree in Elementary Education. In May of 2000, she went on to earn her Master of Arts in teaching from Webster University- Saint Louis, Missouri. Continuing her educational career, in 2006 she earned an Educational Specialist degree from William Woods University - Fulton, Missouri, followed by a Doctorate in Educational Leadership and Policy Analysis from the University of Missouri - Columbia in 2015.

Cynthia's professional career illustrates her commitment to education. Her career began as a fourth grade teacher at Glendale Elementary school in the Independence School District and she remained at home there for six years. In 2004 she assumed the position of Mentor Teacher for the University of Missouri, Columbia within the Teaching Fellows program in the Independence School District and spent two years supporting first year teachers as they worked toward earning their Master Degrees. Two years later she was offered a position with the Independence School District as the principal of Randall Elementary school which she fulfilled for six years. Upon the completion of her sixth year as a building principal in 2012, she was offered the position as the Director of Human Resources with the Independence School District, and currently still holds this position.

Cynthia lives in Kansas City, Missouri, with her husband Tye, and children, Madyson and Dylan. She and her husband love spending time with their children watching them compete in different sporting activities. Upon the completion of her doctoral degree, she looks forward to spending additional time with her family as they prepare to send their son Matthew off to 
Northwest Missouri State University in the fall and as her daughter Madyson begins her freshman year of high school. 